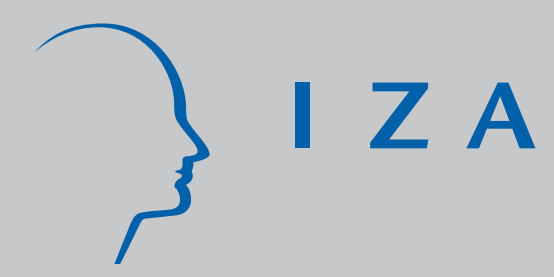

IZA DP No. 2460

The Economics of Prozac: Do Employees Really Gain from Strong Employment Protection?

Etienne Wasmer

November 2006 


\title{
The Economics of Prozac: Do Employees Really Gain from Strong Employment Protection?
}

\author{
Etienne Wasmer \\ Institut d'Etudes Politiques de Paris, OFCE, \\ CEPR and IZA Bonn
}

\section{Discussion Paper No. 2460 \\ November 2006}

\author{
IZA \\ P.O. Box 7240 \\ 53072 Bonn \\ Germany \\ Phone: +49-228-3894-0 \\ Fax: +49-228-3894-180 \\ E-mail: iza@iza.org
}

\begin{abstract}
Any opinions expressed here are those of the author(s) and not those of the institute. Research disseminated by IZA may include views on policy, but the institute itself takes no institutional policy positions.
\end{abstract}

The Institute for the Study of Labor (IZA) in Bonn is a local and virtual international research center and a place of communication between science, politics and business. IZA is an independent nonprofit company supported by Deutsche Post World Net. The center is associated with the University of Bonn and offers a stimulating research environment through its research networks, research support, and visitors and doctoral programs. IZA engages in (i) original and internationally competitive research in all fields of labor economics, (ii) development of policy concepts, and (iii) dissemination of research results and concepts to the interested public.

IZA Discussion Papers often represent preliminary work and are circulated to encourage discussion. Citation of such a paper should account for its provisional character. A revised version may be available directly from the author. 


\section{ABSTRACT}

\section{The Economics of Prozac: Do Employees Really Gain from Strong Employment Protection?*}

Unlike many other contracts, employment contracts are subject to various external administrative procedures governing separations, ranging from compulsory severance payments and advance notice periods (usually seniority based), to collective layoff procedures (usually depending on the firm's size), and other forms of protections against arbitrary dismissal. These external constraints may raise the wellbeing of workers if everything remains constant, but may fail to do so once other economic channels are accounted for. Here, we explore the effect of such legislation on the firm's attitude towards insiders (i.e. protected workers), notably worker monitoring, working environment, and ultimately what we could term harassment. We show that during downturns, harassing workers in order to induce a quit is a substitute for greater dismissal freedom, and that intense monitoring and depreciated working conditions will occur. Thus, a more protected workforce may loose more than it gains from non-pecuniary pressures exerted by the firm. We test these mechanisms using data from a panel of Canadian individuals (the National Public Health Survey) including details on work-related stress and the consumption of various medications, including anti-depressants. By exploiting cross-province differences in employment protection legislation (EPL), we cannot reject the theoretical hypothesis: we even find positive links between individual employment protection and some dimensions of stress, and weaker but positive links between employment protection, depression and the consumption of various psychotropic drugs. Tenure and firm size information from another dataset is then used to generate further variance in EPL by imputation. This confirms the previous results, as well as falsification exercises: family stress for instance is not correlated with regional EPL, while financial stress is negatively correlated with EPL.

JEL Classification: $\quad$ J41, J53, J81

Keywords: $\quad$ stress at work, employment protection, personnel economics

Corresponding author:

Etienne Wasmer

OFCE

69 Quay d'Orsay

75340 Paris Cedex 07

France

E-mail: wasmer.etienne@gmail.com

\footnotetext{
* This research was financed by internal funds (PAFARC) at UQAM and a grant from SSRHC. I would like to thank Mario Bedard, Denis Gonthier and Isabelle Pronovost from CIQSS for their very useful suggestions on geographical codes to match NPHS with the Census data, colleagues at UQAM, participants in various seminars and conferences, notably the European Symposium in Labour Economics (Ammersee 2005), the Fed of Cleveland, Journées du CIRPÉE, OFCE, MIT Macro seminar, SOEGW conference in Rimini, CIAR's meeting in Montreal and Wilfried Laurier Univ. I would also like to thank Daron Acemoglu, David Altig, Stéphane Auray, Roland Benabou, Giuseppe Bertola, Olivier Blanchard, Matthieu Chemin, Damon Clark, Azim Essaji, Armin Falk, Jean-Paul Fitoussi, Xavier Gabaix, Winfried Koeniger, John Helliwell, Maia Guell, Pierre Lefebvre, Nicolas Lepage-Saucier, Lars Ljungqvist, Nicolas Marceau, Espen Moen, Jose Rodriguez Mora, Ed Nosal, Louis Phaneuf, Michael Piore, Chris Pissarides, Gilles Saint-Paul, Peter Rupert, Mark Schweitzer and Philippe Weil, and in particular Alain Guay, Francis Kramarz, Phil Merrigan and Julian Messina.
} 
Is employment protection legislation (EPL) an efficient device for raising the well-being of workers? It has long been known that the answer to this question is mixed: all else being constant, employment protection increases job duration and might therefore be beneficial to currently employed workers. However, it is also well established that EPL reduces job hiring. That is, it fails to raise the well-being of outsiders, i.e. non-employed workers and workers not covered by EPL, including workers under probationary periods, temporary workers and part-timers. ${ }^{1}$ This paper argues that this line of reasoning may even understate the adverse effects of EPL and that EPL can also result into more job dissatisfaction of protected employees themselves, which is quite paradoxical. We argue that protection against individual dismissals raises pressures from management, bullying, workers' stress and, to a lesser extent, the incidence of distress and depression.

These ideas may sound counterintuitive. However, such behavior by the management is relatively easy to understand in a context where layoff costs are large and the success of individual dismissal procedures is random: firms can react according to several margins. Our first task is to attempt to decompose the "economics of bullying", and identify the various margins involved. A simple monitoring and effort model is developed in which firms can also affect the working environment of workers, for the better or for the worst. Broadly speaking, we find a rationalization of the behavior of workers and firms in response to high EPL, which fall into two categories, partial vs. general equilibrium effects. In partial equilibrium, firms indeed react to higher layoffs taxes ${ }^{2}$ by adjusting monitoring methods, routines and workplace organization and management techniques. In an environment where layoff is costly, and monitoring may become more intensive with more repetitive routines to simplify monitoring. Firms may induce quitting by deteriorating the work environment and in some extreme cases, harass workers. ${ }^{3}$ None of these aspects is particularly gratifying for workers, resulting in more stress and job dissatisfaction. Since EPL in turn reduces the risk of layoff, the net effect on workers' present-discounted value of holding a job is ambiguous. In general equilibrium, EPL reduces turnover and thus raises unemployment spell and possibly the quasi-rent associated with holding a job. Fear of layoff is thus exacerbated as workers have more to loose. In addition, quitting is more costly even when workers don't like their job anymore.

How sound are these mechanisms? Actually, one can find several indications that they are quite pervasive. For instance, there are a number of monographic studies in France, a high EPL country, emphasizing the poor quality of industrial relations. For instance, Seiler (2000), surveying 1210 employees in Alsace at "Médecine du Travail" in a non-representative sample, found that $9.6 \%$ of the workers met the criterion for moral harassment (bullying), although only $7.3 \%$ reported it. It came from the hierarchy in $49 \%$ of cases, from co-workers in $25 \%$ of cases, from both in $17 \%$ and only in $5 \%$ of cases from employees under supervision. It started after workplace reorganization (29\%), leave of absence by the worker $(26 \%)$, the arrival of a new manager $(28 \%)$ or after some conflict. It led to various disorders $(\operatorname{mood} 72 \%$, sleep

\footnotetext{
${ }^{1}$ e.g. see Lazear (1990), Burda (1992), Mortensen and Pissarides (1999), Kugler and Saint-Paul (2004) and Autor et al. (2006).

${ }^{2}$ To explain the main point here, EPL is first reduced to its most common perception: a pure tax to layoffs. Two potentially important aspects of EPL are thus ignored: redistribution between firm and workers (Lazear 1990, Burda 1992) and the general difficulty for firms to layoff for fault. This last point will be developed later in the text.

${ }^{3}$ There are at least two excellent movies on these themes: Disclosure (1994) with Demi Moore and Michael Douglas, on how to layoff someone for fault ; and Le Placard (2001) with Gérard Depardieu and Daniel Auteuil, on how to avoid such layoffs. Disclosure was translated into French Harcèlement (harassment).
} 
$70 \%$, psychological disorder 52\%) and resulted also in anxiety (60\%) and abnormal fatigue. Finally and most relevant for our purpose, the hostility faced by these employees led to leaving the firm in $61 \%$ of cases, including $44 \%$ after a voluntary quit. Pressures are a substitute to firing. A study carried out by the IPSOS poll institute, in 2000, based on a sample of 471 representative employees, revealed that $30 \%$ answered yes to "Have you ever faced bullying, moral harassment?", including 31\% for men, $29 \%$ for women, $30 \%$ in the private sector, and interestingly, $29 \%$ in public firms! $37 \%$ reported having witnessed bullying, moral harassment, $24 \%$ answered yes to "Did your supervisor avoided or refused to talk, repeatedly and visibly?", $16 \%$ answered yes to "Did your supervisor took away responsibility, gave your workload to colleagues?", $12 \%$ had been once subjected to insults or offending behavior from supervisor (repeatedly), and also, $12 \%$ believed that bullies were intended to make the individual leave or move to another department without indemnity. ${ }^{4}$

To document these ideas more formally, we will examine individual data and attempt to link EPL with various indicators of well-being at work. The empirical strategy requires however solving three main difficulties: a) psychological factors such as stress, distress and depression are difficult to measure; b) it is usually very difficult to test for any of the effects of EPL: there is typically little variance in the data. Some studies rely on cross-country data with difficulties in comparability. Finally, c) we need to separate partial equilibrium effects from general equilibrium effects on the possible negative impact of EPL on workers.

We propose to remedy to these three issues, using original features from Canadian data and Canadian labor legislation. On a) we use a very interesting Canadian database (National Population Health Survey, or NPHS), covering a representative sample of the Canadian population, about 17000 individuals, interviewed throughout 5 cycles of two years each, between 1994-1995 and 2002-2003. In this database, two sets of variables can be used to deal with the question: i) subjective variables, such as answers to detailed questions related to stress at work along various dimensions; ii) objective variables, such as various drug consumption habits (including anti-depressants, tranquilizers, and sleeping pills ${ }^{5}$ ), and health questions potentially related to stress such as blood pressure or, ultimately, depression. Interestingly, the survey also contains a large selection of very useful control variables capturing various psychological factors, notably the ability to cope with stress or to over-report stress (e.g. trauma in childhood). ${ }^{6}$

\footnotetext{
${ }^{4}$ Not suprisingly, France is also often cited as a country where psychotropics are consumed on a massive scale. According to an official study (DREES 2003), consumption of anti-depressants in France in 2000 amounted to 543 billion Euros, or $10 \%$ of the overall social security deficit (including pensions) and about $0.1 \%$ of GDP. Recent international studies in clinical psychology, conducted in five European countries (Alonso et al. 2004), have estimated multivariate models of psychotropic drug use, pooling six European countries and controlling for various individual characteristics-gender, age categories, marital status, education, labor market status and urbanicity. It is highly interesting to notice that the country effects (expressed as odd-ratios of the regression) are, in diminishing order, 3.0 for France, 2.3 for Spain, 2.0 for Italy, 1.69 for Belgium, and 0.8 for Germany, with the Netherlands as the reference. The ranking is fairly close to the stringency of EPL according to the OECD, although a definitive test would attempt to interact the "employment status" coefficient with the country effects.

${ }^{5}$ As noted in several papers in medical as well as economic studies, sleep problems might be the outcome of a working environment that is too tense. For instance, Akerstedt et al. (2002) find that in a "disturbed sleep" logistic regression, the odd ratio (OR) of "high work demand" is 2.15. "Inability to stop thinking about work" results into a OR of 3.20 .

${ }^{6}$ Each type of variables, subjective and objective, has its pros and cons. Objective measures such as depression are in principle more reliable than subjective variables (stress) with the usual caveats (Hamermesh 2004). The quality of regressions with subjective variables will then rely on additional controls. On the other hand, depression typically affects fewer employed workers and raises endogeneity and selection concerns, through "psychological fragility" effects. So we use both variables. We do, in fact, find in our data strong and positive correlations
} 
On b), we have two strategies. A first strategy is to use the large and stable in time crossprovincial differences in the stringency of EPL. ${ }^{7}$ We build regional indicators of individual and collective EPL and check ex-post that these indicators make sense in that they have the expected correlation with other dimensions such as regional unemployment duration. The second strategy exploits additional information from the Canadian Labor Force Survey to generate more precise measures of the degree of effective protection experienced by individuals: we will notably use information on tenure and firms' establishment and impute it into the NPHS survey. Finally, on c) we match NPHS data to 1996 and 2001 Census data to obtain a precise measure of local labor market conditions at the county level (geographical division of the Census). This allows investigating whether higher local unemployment affects the well-being of workers beyond EPL.

A couple of robust results emerge: first, stress at work resulting from conflicting demands is positively associated with individual employment protection. The same is true from stress from relations with co-workers and the management, positively associated with individual EPL. We also find that stress from layoff is negatively associated with employment protection. The net effect on total stress at work, summing up these dimensions, is still positive. The overall effect are not large, but significant: a shift of individual EPL from the lowest to the highest region is associated with about $15 \%$ of a standard deviation of total stress. This fraction reaches $20 \%$ if one adds up the effect of employment protection against mass layoffs. However, up to one standard deviation of stress from conflicting demands or from relations with supervisor and co-workers can be explained by EPL. We can conclude that EPL does not reduce workers' stress. We also find that local labor market conditions do not really affect stress at work. Other factors, such as the incidence of depression or the consumption of psychotropic drugs, are marginally affected by EPL.

A conclusion of the paper is that the quality of labor relations is adversely affected by regulations of labor. In that, we confirm the importance of industrial relations and beyond, of trust in social relations between unions and employers, as recently emphasized by Blanchard and Philippon (2004, 2006). Our paper suggests that EPL can generate individual conflicts and poor industrial relations, explaining both the relative stability of the poor quality of labor relations in Europe. This is also consistent with the recent improvement in industrial relations in the UK pointed out by Blanchard and Philippon (2004, page 24) after the Thatcher's deregulation experience in 1980's. Another lesson of the paper is to understand and generalize other results on the paradoxical adverse consequences of EPL: recently, Postel-Vinay and Saint-Martin (2005), Clark and Postel-Vinay (2004), and Deloffre and Rioux (2004) have documented a strong negative link between the perception of job security and employment protection, using the European Community Panel survey. The NPHS data used here contain a specific question on how respondents perceive the risk of losing their job and the stress derived from it. We are thus able to investigate the same question asked by these three papers, as a special case. Finally, there are to our knowledge no studies in labor economics linking stress and more generally health with employment conditions - in particular EPL. However, there may be economic links of first-order

\footnotetext{
between the intensity of stress experienced by individuals and the incidence of depression or the consumption psychotropic drugs.

${ }^{7}$ One should definitely prefer identification obtained from variations across comparable geographical units, ideally with time-variations such as in Autor et al. (2006) or Kugler and Saint-Paul (2004) in the United States.Data on stress at work are however difficult to find in the US over the relevant period, but the replication of these strategies is the next step in a general research program. This first step is however useful in emphasizing a few unexpected facts regarding the links between EPL and stress.
} 
importance and more work is needed.

\section{A model}

The model is designed to illustrate the various adjustments mechanisms in a firm facing restrictions on its ability to fire workers. It will illustrate that a worker's utility may actually decrease with employment protection, because precisely employers react to EPL.

The setup is as follows. Workers live two periods only and then die. The firm is indefinitely lived. The model focusses on two relevant time periods where the firm and the worker are matched. In the first period, the worker is already employed in the firm: we do not focus on hiring decisions, although this would be a straightforward extension. Productivity and idiosyncratic utility of the worker are revealed only at the end of the first period. Revelation of this information leads to either a quit, a layoff or the continuation of the employment relationship in second period. Layoff costs affect the separation decision, and thus the first-period effort strategy of the worker and the monitoring by the firm.

\section{$1.1 \quad$ Worker and quits}

Each period, the worker chooses an effort level $e$ on the job, and receives a wage $w$. The wage is assumed to be exogenous. ${ }^{8}$ Overall, the flow utility of a worker is

$$
\mathcal{U}=\underset{\text { wage }}{w}+\underbrace{-\left[c(e)+q^{m}\right]}_{\text {non-pecuniary component of the job }}+\underset{\text { firm's effort to affect } \mathcal{U}}{q^{w}}+\underset{\text { random utility of match }}{\nu}),
$$

where the utility of the worker is reduced by $c(e)+q^{m}$, where $q^{m} \geq 0$ is the intensity of monitoring, and $c(e)$ is increasing convex in effort. The quantity $q^{w}$ is a variable chosen by the firm to affect the utility of the worker. It is interpreted as the quality of the working environment. This quantity can be either positive or negative. In addition, $\nu$ is a random variable reflecting unknown factors ex-ante, such as the quality of the relationship of the worker with his/her colleagues or with the management. The modelling choices imply that monitoring and working conditions are perfect substitutes and thus, in this case, are formally the same "object". The quantity $q^{m}-q^{w}+\nu$ reflects the general environment of the firm, which is both random through $\nu$ and chosen by the firm through the $q$ 's.

The worker can obtain a level of utility $\overline{\mathcal{U}}$ outside the firm. This level of utility depends a priori on search frictions and is lower in a more sclerotic labor market, although we do not explicit this link in the paper. Thus, if not fired, the worker will quit the firm at the end of period 1 if utility on the job in period 2 is lower than $\overline{\mathcal{U}}$.

\footnotetext{
${ }^{8}$ By this exogeneity assumption, we want to prevent employers to cut down the wage so that the worker would necessarily quit at zero cost for the firm. This assumption is meant to capture the fact that such an explicit behavior by firms is limied by nominal downards wage rigidity. The fact is that a strong wage cut may be as efficient as bullying to make workers quit, but this can be detected by a judge much more easily and thus ex-post quite costly. We will come back on this point in the conclusion of this Section.
} 


\subsection{Firm and layoff}

Monitoring and affecting working conditions is not costless. Let $C\left(q^{m}, q^{w}\right)$ be the cost function with $q^{m} \geq 0$ and $q^{w} \gtrless 0$. The monitoring intensity $q^{m}$ is set each period. In contrast, working conditions are persistent through the two periods, and are decided in period $1 .{ }^{9}$ So, by the cost of $q^{w}$, we refer here to the cost paid in period 1, which does not has to be repaid in period 2. The cost function is assumed to be increasing and convex in both arguments. Further, the minimum cost is reached in $C(0,0)=0$. This means that it costs some money to affect - either positively or negatively - working conditions of the worker. Note that the cost of a negative $q^{w}$ can be interpreted as a reputation cost.

The effort of the worker enters linearly in the revenue function, as a normalization. There is a random productivity component denoted by $\varepsilon$. So, overall, the flow profit of the firm is

$$
\pi=\underset{\text { worker's effort to affect } \pi}{e}-\underset{\text { wage }}{w}-\underset{\text { cost from monitoring and working conditions }}{C\left(q^{m}, q^{w}\right)}+\underset{\text { random productivity of match }}{\varepsilon} .
$$

At the end of period 1, when $\varepsilon$ and $\nu$ are revealed, the firm may decide to terminate the employment relation which has exogenous value $\bar{\pi}$ minus possible separation costs. Separation can be implemented in several ways. Most simply, the firm can fire the worker the worker for economic reasons (that is, a non-fault layoff denoted hereafter by NF-layoff), which $\operatorname{costs} \tau$ to the firm. A fraction $\alpha \tau$ accrues to the worker. This is a severance payment with $0 \leq \alpha \leq 1$. The case $\alpha=0$ corresponds to termination costs being a pure firing tax: the worker receives no transfer. A pure severance payment is when $\alpha=1 .^{10}$ It can also try to save on firing costs in two different ways: first, by attempting to layoff for fault or for cause (a F-layoff), which has no cost but has uncertain success. Second, by letting the worker quit. In the case of a quit, we assume that there is no cost of separation.

Why would the firm fire for economic reason if it can fire for cause at no cost? The answer is that a F-layoff is a random procedure, in the sense that, as commonly observed in several countries, the conflict between a firm and a worker is arbitrated by an outside party (judge, semi-professional court) and the decision, based on several informal factors, can not always be anticipated. We will denote by $F$ the probability of success of this procedure, and $F$ is a function of the various decisions made by the agents in period 1 . How does this work here? Denote by $\bar{e}$ the exogenous, common-knowledge reference effort; the effort exerted by the worker $e$ may differ from the target $\bar{e}$. When it is below $\bar{e}$, the firm can try to prove a fault. The randomness of the F-procedure is due to the fact that $e$ is not directly observable by a third party. This is a frequent assumption in the contract literature. Accordingly, the success probability $F$ depends positively on $\bar{e}-e$ : the further away from the effort requirement, the easier to establish a fault. Second, we assume that $F$ depends positively on the monitoring intensity: as the information set about the worker's activity is larger due to closer and more accurate control by the firm, it is easier for the firm to establish a fault. Finally, although this is not essential here, we further assume a complementarity between monitoring intensity $q^{m}$ and the effort gap $\bar{e}-e$, as the marginal impact of shirking should be larger, the more intense the monitoring.

Assumption 1. The success of the layoff procedure for fault $F$ positively depends on $q^{m}(\bar{e}-$

\footnotetext{
${ }^{9}$ This is not important: what matters is that the firm sets $q^{w}$ before the information on productivity and idiosyncratic utility is revealed.

${ }^{10} \mathrm{~A}$ strictly positive $\alpha$ makes sure the worker never quits in the NF-regime: she/he is strictly better off in waiting the layoff and receiving $\alpha \tau$.
} 
e):

$$
F=F\left[q^{m}(\bar{e}-e)\right]
$$

where $F^{\prime}>0$.

Finally, being subject to a procedure for fault may generate additional disutility to the worker, denoted by $-\Sigma$. Fixing $\Sigma=0$ has however no implication for the results of the model, but a positive $\Sigma$ helps to understand why in practice, workers under the threat of a procedure for fault may prefer to quit more frequently instead of starting a conflict with the management.

Table A in Appendix summarizes all notations.

\subsection{Timing of events}

The timing of events is as follows.

- First period starts. The firm and the worker only know the distributions of $\varepsilon$ and $\nu$.

- Both jointly determine their levels of $e, q^{m}$ and $q^{w}$ in a Nash equilibrium. Recall that the value of $q^{w}$ is fixed for the two periods of the match.

- Idiosyncratic components of productivity $\varepsilon$ and utility $\nu$ are revealed.

- Knowing this and correctly anticipating the future events, the worker then decides whether or not to quit.

- If he/she does not quit, the firm may continue the employment relationship or instead lay-off the worker, in picking up one of the two available procedures (F or NF).

- Second period starts with predetermined value of $q^{w}$, and known values of $\varepsilon$ and $\nu$.

\section{Solution of the model}

We proceed backward. First, we solve for optimal separation strategies - layoff and then quits in considering $e, q^{m}$ and $q^{w}$ as given. Second, we determine the choices on $e, q^{m}$ and $q^{w}$, when agents correctly anticipate the separation strategies.

\subsection{Optimal separation strategies of the firm}

When the worker has not resigned at the end of period 1 , the firm needs to decide whether or not to keep the worker or to start a dismissal procedure. In period 2 , the firm will face a continuation value $\pi^{\prime}(\varepsilon)$ with the current worker (remember that $\varepsilon$ and $\nu$ are now known from the firm), and an outside profit value $\bar{\pi}$ with another worker. As the second period is terminal for a worker, we will set $e^{\prime}=\underline{e}$ the minimum level of effort; and the firm does not need to reinvest in $q^{w}$ since it was fixed in period 1. Thus, $\pi^{\prime}(\varepsilon)=\varepsilon+\underline{e}-w-C(0,0)=\varepsilon+\underline{e}-w$.

We thus need to compare the relative values of the various strategies.

- NF (no-fault) has value $\bar{\pi}-\tau$

- $\mathrm{F}$ (fault) has value $\bar{\pi} F+(1-F) \pi^{\prime}(\varepsilon)$ 
- $\mathrm{C}$ (continuation) has value $\pi^{\prime}(\varepsilon)=\varepsilon+\underline{e}-w$

These three values for the firm are functions of $\varepsilon$, with a slope respectively of $0,1-F$ and 1 , leading to two reservation rules in $\varepsilon$, denoted by $\bar{\varepsilon}$ and $\widehat{\varepsilon}$ :

$$
\begin{aligned}
\mathrm{C} & \sim \mathrm{F}: \bar{\varepsilon}=\bar{\pi}+w-\underline{e} \\
\mathrm{NF} & \sim \mathrm{F}: \widehat{\varepsilon}=\bar{\varepsilon}-\tau /(1-F)<\bar{\varepsilon} .
\end{aligned}
$$

Note that $\bar{\varepsilon}$ is a function of parameters only and notably exogenous to both effort $e$ and firm's controls $q^{w}$ and $q^{m}$.

Proposition 1. i) If $\varepsilon>\bar{\varepsilon}$, the firm wants to retain the worker ; ii) if $\varepsilon<\widehat{\varepsilon}$, it wants to initiate a no-fault dismissal procedure; iii) if $\varepsilon$ is in between these two quantities, it starts a procedure for fault.

The proof is in Appendix, its intuition is straightforward. When productivity is high, the firms wants to retain the worker. If productivity is very low, since the F-layoff strategy is risky, the firm is ready to pay the full layoff cost $\tau$. In between, the firm hopes to save on layoff costs with a F-layoff strategy that has a limited downside risk if it fails.

Corollary 1. Let $G$ be the cumulative density function of $\varepsilon$. The fraction of workers facing a procedure for fault is $G(w-\underline{e})-G(w-\underline{e}-\tau /(1-F))$. This is increasing in the cost of a no-fault dismissal $\tau$ and the success rate of the procedure for professional fault $F$. With a uniform density function, $w-\underline{e}$ has no impact on that fraction.

Proof: simple calculations.

The corollary states that the higher $\tau /(1-F)$, that is, the easier to use the F-strategy and the higher the NF-layoff costs, the more likely to observe workers under a layoff for cause.

\subsection{Optimal quit strategies of the worker}

Moving one step backward, one can now investigate the optimal quit strategy of workers. Either the worker quits - and obtain $\overline{\mathcal{U}}$ - or he/she remains in the firm. In the latter case, the worker correctly anticipates the strategy of the firm $(\mathrm{C}, \mathrm{NF}, \mathrm{F})$ in the next stage and correctly evaluates utility in each case, as follows:

- Q (quit) has value $\overline{\mathcal{U}}$

- NF (no-fault) has value $\overline{\mathcal{U}}+\alpha \tau$

- $\mathrm{F}$ (fault) has value $F \overline{\mathcal{U}}+(1-F)\left(w+\nu+q^{w}-c(\underline{e})\right)-\Sigma$

- $\mathrm{C}$ (continuation) has value $w+\nu+q^{w}-c(\underline{e})$

We can show that the worker's strategy depends on the revealed random component of utility $\nu$ and is also described by two reservation rules $\bar{\nu}$ and $\widehat{\nu}$ :

$$
\begin{aligned}
& \mathrm{Q} \sim \mathrm{C}: \bar{\nu}=\overline{\mathcal{U}}-w-q^{w}+c(\underline{e}), \\
& \mathrm{Q} \sim \mathrm{F}: \widehat{\nu}=\bar{\nu}+\Sigma /(1-F) .
\end{aligned}
$$


At this stage of period 1 , the worker knows the revealed value of $\varepsilon$, hence:

Proposition 2. i) If the match has low productivity $(\varepsilon<\widehat{\varepsilon})$, the worker never quits because she/he expects a no-fault layoff and thus to obtain severance payment $\alpha \tau>0$; ii) if the match has high productivity, that is, if $\varepsilon>\bar{\varepsilon}$, the worker expects to be retained by the firm but would quit anyhow if and only if its utility in the match is low $(\nu<\bar{\nu})$; iii) for intermediate values of productivity, i.e. if $\widehat{\varepsilon}<\varepsilon<\bar{\varepsilon}$, the worker expects a procedure for fault. He/she then quits if and only if $\nu<\widehat{\nu}$.

Corollary 2 (mismatch) The conditional mean of $\nu$ in surviving matches is decreased by a lower level of higher of $\overline{\mathcal{U}}$. To the extent that EPL affects negatively $\overline{\mathcal{U}}$ in general equilibrium, EPL increases utility mismatch (in the sense of more matches associated with a low idiosyncratic utility).

Most of the effects of the corollaries above are easy to understand. We can now summarize the various mechanisms.

\subsection{Separation decisions}

Figure 1 conveniently summarizes the partition of the plane $(\varepsilon, \nu)$ into different separation / no separation outcomes. The distance between $\widehat{\varepsilon}$ and $\bar{\varepsilon}$ is given by $\tau /(1-F)$ : as said above, employment protection as well as successful $F$ procedures raise the inter-frontier space in which firms wish to layoff for fault. The distance between $\widehat{\nu}$ and $\bar{\nu}$ is given by $\Sigma /(1-F)$ : workers quit when the idiosyncratic component of utility is too low, but there is an extra-quit incentive to quit if workers anticipate stress $\Sigma$ from the F-layoff procedure. Overall, the surface of the F-layoff area is $\left[\nu_{\max }-\bar{U}+w+q^{w}-\Sigma /(1-F)-\underline{e}\right] * \tau /(1-F)$, thus at given $e, q^{m}$ and $q^{w}$, F-layoff is more likely with higher frictions (discouraging workers to quit), with higher wages (workers take a chance to win the case with probability $1-F$ ) and with increased by higher firing $\operatorname{cost} \tau$.

To sum up the impact of EPL derived so far, we have that:

1. The no-fault firing costs $\tau$ raise the likelihood of a procedure for fault and thus the associated stress (see corollary 1 );

2. To the extent that $\tau$ discourages hirings in general equilibrium, that is, reduces outside options of workers $\overline{\mathcal{U}}$, a higher $\tau$ increases the degree of mismatch of employed workers.

\subsection{Optimal effort $e$, monitoring $q^{m}$, and working conditions $q^{w}$}

We now investigate the role of employment protection on the optimal level of $e, q^{w}$ and $q^{m}$. We will assume a Nash equilibrium between the firm and the worker in the choice of these quantities. Recall that the level of effort is chosen before the realization of $\nu$ and $\varepsilon$, but after knowing their distribution, and in taking $q^{w}$ and $q^{m}$ as given.

The worker knows exactly how effort $e$ reduces the success of the fault procedure and thus the separation strategy of the firm, as well as her/his own propensity to quit. See the Appendix equations (A1). Symmetrically, the firm knows how its decisions $q^{w}$ and $q^{m}$ affect quits, its own separation margins and $F$, as indicated in (A2) in Appendix. The full program of the worker and of the firm is also in Appendix (equations A3 and A4). To fix ideas, we assume that the 


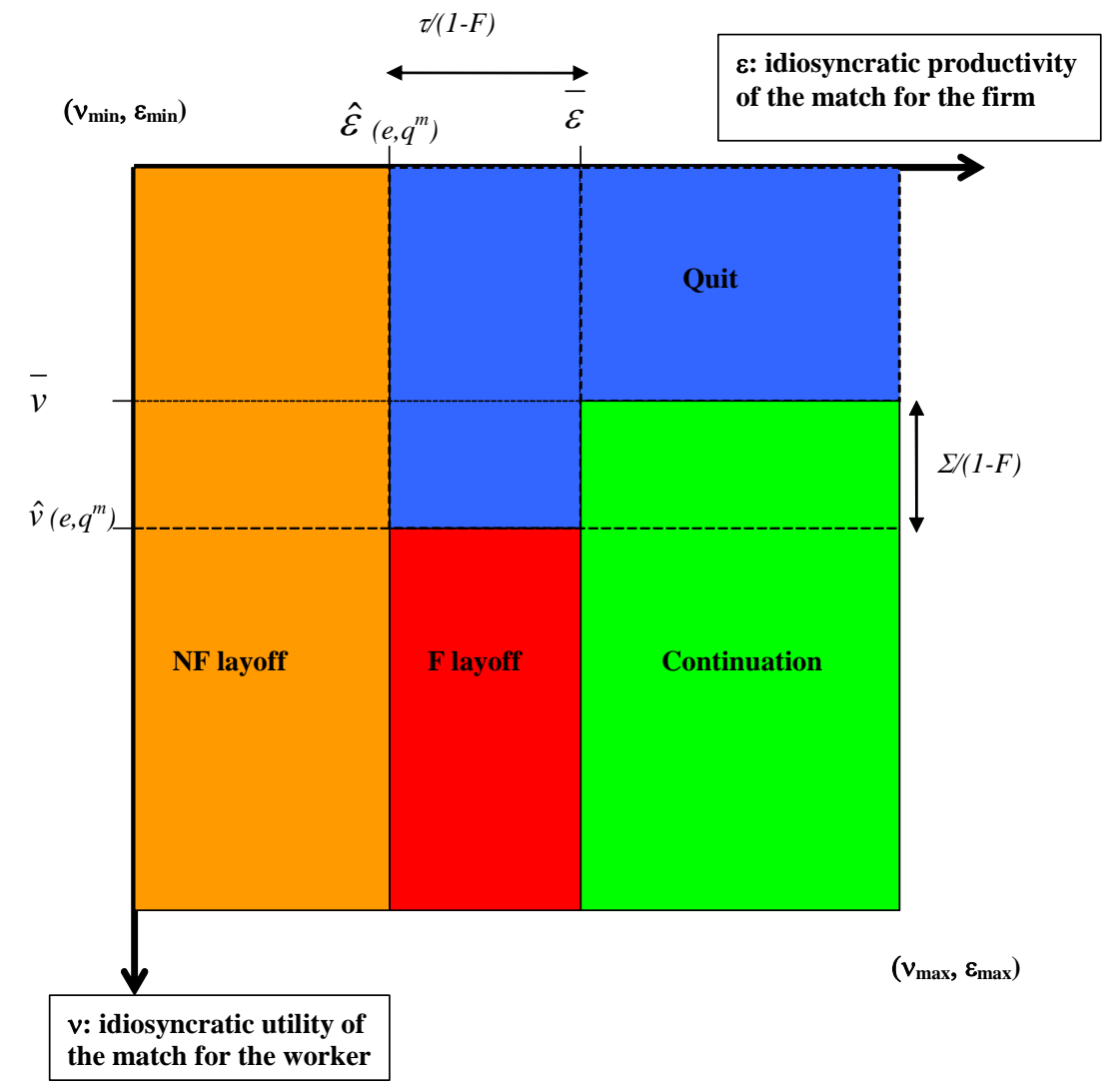

Figure 1: Phase diagram of separation / non-separation decisions, with $\widehat{\varepsilon}=\bar{\pi}+w-\underline{e}-\tau /(1-F)$ $; \bar{\varepsilon}=\bar{\pi}+w-\underline{e} ; \bar{\nu}=\overline{\mathcal{U}}-w-q^{w}+c(\underline{e}) ; \widehat{\nu}=\overline{\mathcal{U}}-w-q^{w}+c(\underline{e})+\Sigma /(1-F)$ 
density of $\varepsilon$ and $\nu$ are uniform, with $g(\varepsilon)=g_{0}$ and $g(\nu)=h_{0}$, but this is not essential. A similar convenient assumption is when costs functions are quadratic with unit scale parameter: $c(e)=e^{2}$ and $C\left(q^{m}, q^{w}\right)=\left(q^{m}\right)^{2}+\left(q^{w}\right)^{2}$. Finally, a more demanding assumption is that $F^{\prime} /(1-F)^{2}$ is constant (see Appendix for the implied $F$ ). We however make this assumption only in the next sub-section in order to obtain closed-form solutions.

\subsection{Special case: density of worker's utility $\nu$ is a mass point (no quit)}

Before solving for the full program of both the agent and the firm, one may study the simpler case in which the density of $\nu$ is collapsed to a mass point higher than $\widehat{\nu}$ : in other words, the worker will never quit the firm, which reduces the problem to studying firms' separation decisions. In this case, the programs of the worker and the firm lead to conveniently simpler first order conditions. All intermediate derivations are in Appendix, as well as a proof of the existence and uniqueness of a Nash equilibrium for general costs functions. In the special case is when $F^{\prime} /(1-F)^{2}=\Phi$ where $\Phi$ is a constant, we can further greatly simplify the solutions and illustrate the role of $\tau$ quite simply. In this case, solutions to the problem are:

$$
\begin{aligned}
e & =\frac{\Delta}{1+\Delta} \bar{e}, q^{m}=\frac{\tau^{2}}{1+\Delta} \frac{g_{0}}{2} \bar{e}, q^{w}=0 \\
\text { where } \Delta & =\tau^{3}(\alpha \tau+\Sigma) g_{0}^{2} \Phi^{2} .
\end{aligned}
$$

Proposition 3. The various effect of EPL are: i) equilibrium effort is increasing in $\tau$ with a local exponent 3 when $\tau$ is small and in severance payment $\alpha \tau$. As $\tau$ goes to infinity, effort converges to the maximum $\bar{e}$; ii) equilibrium monitoring intensity is increasing in $\tau$ for low values of $\tau$, reaches a maximum and then gradually goes down to zero when $\tau \rightarrow \infty$.

Most intuitions are easy to get. The elasticity of effort $e$ to layoff $\operatorname{costs} \tau$ is initially -for low values of $\tau$ - of order 3 or even 4 if $\Sigma$ was small, because several effects reinforce each other: as $\tau$ is higher, firms use $F$-layoffs and for low values of $\tau$, this raises $q^{m}$. Workers counteract in raising effort, and so on and so forth. When $\tau$ becomes large, the effort of the worker approaches its limit $\bar{e}$ and so after a while, the firm reduces its monitoring, hence the negative slope of $q^{m}$ when $\tau$ is large.

In equilibrium, the welfare effect of employment protection of a worker in his job can also be calculated. The impact of $\tau$ on instantaneous utility is equal to $\left(-c^{\prime}(e) \partial e / \partial \tau\right)+\left(-\partial q^{m} / \partial \tau\right)$ : the first term is always negative, while the second one is negative for low values of $\tau$. Intertemporal utility is $\partial U / \partial \tau=\partial U / \partial q^{m} . \partial q^{m} / \partial \tau$ and signs as $-\partial q^{m} / \partial \tau$, i.e. first negative then positive as $\tau$ grows. In other words, the effect of $\tau$ on workers' utility is ambiguous: one the one hand, it reduces the firing probability which is positive on the present discounted value (PDV) of utility evaluated in period 1. On the other hand, $\tau$ raises monitoring $q^{m}$ and in reaction, raises efforts. This reduces worker's flow utility and may also reduce the PDV of utility if the second effect dominates over the first one.

\subsection{General case}

In the general case, it is impossible to derive closed form solution for $e, q^{m}$ and $q^{w}$, and not even to prove uniqueness. The reason is that the model contains both tendencies towards multiple 
equilibria - as $e$ and $q^{m}$ are strategic complements through $F$ - and towards corner solutions, as shown in the simple cases above - as $q^{m}$ and $q^{w}$ are substitute controls variables for the firm. Nevertheless, the first order conditions of the firm and the worker can be derived easily and are fairly intuitive. Thanks to assumption $\Phi=F^{\prime} /(1-F)^{2}$ we can further simplify these first order conditions but this is not needed here. See the Appendix for details. Worker's effort is determined by a first order condition:

$$
e=q^{m} g_{0} \Phi \tau[\alpha \tau+\Sigma(1-H(\widehat{\nu}))]
$$

where $H$ is the c.d.f. of random variable $\nu$. The left-hand side is the marginal cost of effort, equalized to the marginal return, which is the sum of two terms. In equation (A13) in Appendix, we see that the first one is due to the effect of a lower layoff-rate $\partial \widehat{\varepsilon} / \partial e$ and the second one is due to the effect of a higher quit rate $-\partial \widehat{\nu} / \partial e$ to avoid the stress cost $\Sigma$ when the worker quits $(\nu>\widehat{\nu})$ hence the coefficient $(1-H(\widehat{\nu})$. The equation shows that the marginal return on effort is always strictly positive, and is increasing in $q^{m}$ and $\tau$.

Firm's first order conditions in an interior solution for $q^{m}$ and $q^{w}$ imply

$$
\begin{aligned}
q^{m} & =g_{0} \tau^{2}(\bar{e}-e) \Phi\left(1-\frac{1-H(\widehat{\nu})}{2}\right)-\frac{\tau h_{0}}{2}(1-G(\widehat{\varepsilon}))(\Sigma(\bar{e}-e) \Phi) \lessgtr 0 \\
q^{w} & =\frac{\tau h_{0}}{2}\left(\frac{-\tau}{2(1-F)}\right)+\frac{h_{0}}{2}\left(1-G(\bar{\varepsilon})\left(\varepsilon_{\max }-\bar{\varepsilon}\right) \lessgtr 0\right.
\end{aligned}
$$

The left-hand side in the first line is the marginal cost of monitoring for the firm. It is equal to the marginal return on the right-hand side. The marginal return is itself the sum of two terms: the first implies that raising monitoring intensity $q^{m}$ will increase the success of $F$-procedures and thus increase profits because this saves on layoff costs $\tau$. This effect is mitigated by the second term which is negative: a higher $q^{m}$ raises the quit rate by workers even in the case in which the firm would make profits, which occurs with probability $1-G(\widehat{\varepsilon})$. In an interior solution, $q^{m}$ is increasing in $\bar{e}-e$ and in $\tau$, at a fix $\Phi$. When the second term dominates (high profits), the firm reaches a corner solution $q^{m}=0$ : it does not monitor the worker to reduce its quit rate, as monitoring reduces utility. The second line has a similar interpretation. When the first negative term in the right-hand side dominates, the firm expects to makes losses and thus, by setting $q^{w}$ to a negative value, it can induce more quits and save $\tau$. When the second positive term dominates instead, the firm makes profits and can reduce turnover by raising $q^{m}$ above 0 .

These equations point out a key mechanism: the impact of $\tau$ on firm's attitude towards the worker depends on its perception of future profits. If, in period 1, the firm expects jobs to be profitable, that is for large values of $\varepsilon$, it prefers to retain the worker and decrease $q^{m}$ and raise $q^{w}$. In non-viable jobs instead, the firm will make negative profits. It may want to save on layoff $\operatorname{costs} \tau$, and raises $q^{m}$ to establish a fault. Summarizing, we have:

Proposition 4. In viable jobs, firms have to maintain positive working conditions, all the more than current profits are high relative to outside profits. To reduce turnover, firms do not monitor workers.

Proposition 5. ("placardisation") In non-viable jobs, working conditions have to be negative, all the more than $\tau$ is large. 
Unreported numerical resolutions provide additional insights. In the first case, we investigate the role of layoff costs $\tau$ in the context of a relatively viable job. When $\tau$ increases, the firm raises monitoring intensity, so as to induce effort and have an option to fire for fault, but at the same time raise working conditions, in order to retain the worker. The net effects on worker's welfare are ambiguous: instantaneous utility decreases slowly with $\tau$, while the PDV of utility of the worker increases at low $\tau$ but then decreases at higher $\tau$. In constrast, when jobs are non-viable, the firm anticipates that it will have to fire at the end of the period. So, when $\tau$ increases, the firm rapidly raises its monitoring intensity so as to induce effort, but, contrary to the previous case, the firm worsens working conditions to increase the quit propensity of the worker. Per-period utility of the worker decreases very fast, and the PDV of utility is also strongly reduced.

\subsection{Summary and further discussion of the model}

Precisely, coming back to equation (1), we can identify three components which may match the data in the subsequent empirical analysis: $c(e), q^{m}$ and $\Sigma$ will all enter additively and negatively into flow utility. There is in addition a fourth component, $q^{w}$ which can affect utility both ways. Hereafter, by "stress", we will have in mind $c(e)+q^{m}-q^{w}+\Sigma$.

The first effect of EPL identified comes from the fact that firing is a monitoring device (Shapiro and Stiglitz 1984). As it becomes more expensive or more difficult to lay off, managers raise monitoring intensity and psychological pressures, thereby raising stress. We can group these mechanisms under the label "intense monitoring effect". It generates a positive link between individual EPL (as opposed to collective EPL, applying in the event of mass layoffs) and stress. A second set of mechanisms arises when jobs are non-viable, i.e. in recessions or when a task become obsolete. In such cases, an efficient labor market would require firing for economic reasons (no-fault layoff). As this becomes more costly, the firm wants its worker to leave and affects negatively working conditions $q^{w}$. The firm can also try to establish a professional fault by raising monitoring intensity $q^{m}$ and obtain a dismissal at a lower cost, which potentially generates further stress. We call this the "harassment effect".

Through these two partial equilibrium effects, employment protection raises "instantaneous" stress and disutility of work, with some possible adverse effects on the present discounted value of being employed. General equilibrium would reinforce the adverse effects of EPL, if we take as granted that EPL raises frictions and lengthen unemployment spells. Greater frictions indeed reduce the opportunities for workers to quit when they don't like their job, colleagues and manager: in a sclerotic labor market, employees must deal with low idiosyncratic utility seemingly forever. This is referred to as the "mismatch effect". Our model has neglected other potentially relevant and positive channels of EPL: with risk-averse workers, longer-running jobs generate a partial equilibrium positive impact on utility. Further, EPL protects and thus induces specific capital investments, an implication of standard contract theory applied to the labor market, see e.g. Wasmer (2006).

Two additional issues need to be addressed at this stage. The first one is: why does the firm maintain the wage constant when a wage cut could efficiently induce the worker to quit? The answer is: both actions (wage cut and harassment) are considered as unfair. If a third party, say a judge, is called to arbitrate, she/he could command a large fine or a large compensation to the worker. The difference between the two actions is however that psychological pressures are hard to prove, while wage cuts are fairly easy to detect. Raising stress by raising $q^{m}$ and 
reducing $q^{w}$ may be a more effective way of inducing a quit.

A second and related issue is why, if workers anticipate bullying in second period, they do not negotiate a small compensation with the firm and quit, instead of suffering from bullies? There is no easy answer to this question, but the previous argument still apply: to the extent that moral harassment will make the worker quit, the compensation should indeed be very small: from the amount of compensation, a court would infer that there are unfair practices at the workplace. ${ }^{11}$

\section{Data description}

We now attempt to determine the sign and magnitude of the effect of EPL on variables such as stress, conflicts or psychological disorders.

\subsection{NPHS individual data}

The main database used here is the National Population Health Survey - Household component - Longitudinal. ${ }^{12}$ It consists of 5 cycles, starting 1994-1995, then 1996-1997, then 1998-1999, then 2000-2001 and finally 2002-2003. It includes 17276 persons of all age, with a longitudinal dimension and individual identifiers. The survey is designed to be representative of the crosssection and has a longitudinal follow-up. ${ }^{13}$ The target population includes all residents in Canada in 1994, excluding Indian Reserves and Crown Lands, health institutions, Canadian Force bases and some remote areas in Ontario and Quebec. Northern regions (Yukon, Nunavut and Northwest territories) where population density is very low were excluded from the analysis. We provide in Table B1 in Appendix the sample composition per province, with a significant number of individuals in each province. The attrition problem appears to be relatively limited: $73 \%$ of the original sample were interviewed for the five cycles over almost ten years. Attrition includes deaths, while there are quite a few individuals having been temporarily unavailable in a given cycle but re-interviewed in a subsequent cycle. The database is provided with sample weights computed for each respondent in each cycle of the survey, and for each wave following the first wave, various longitudinal weights (for all respondents or full respondents). We used the latter weight.

The following variables are consistent throughout the sample: employment status (in the week of reference and the year before the survey), the sector of activity (16 sectors), occupation (47 occupations) and education, age, usual demographic information, etc.... The analysis will be restricted to the sample of 25-64 y.o., excluding retirees. We decided to take out the 15-24 y.o. population since it is often employed in part-time jobs, and there is no available control for

\footnotetext{
${ }^{11}$ This verifiability argument - the fact that bullying is difficult to observe- has actually further consequences: monographic studies typically indicate that workers themselves typically misperceive what happens to them, in the sense that they generally don't know that they are subject to moral harassment. In our model, we have assumed perfect foresight, but non-standard ingredients such as cognitive issues, as the inability of individuals to realize the origin of the disutility the experience may be relevant. This brings us however far away than from the simple point we wish to make in the model: determine what are the margins of adjustment of the firm facing strong EPL and how they operate.

${ }^{12} \mathrm{~A}$ full, detailed description is available on the website of Statistics Canada, at http://www.statcan.ca/cgi$\mathrm{bin} / \mathrm{imdb} / \mathrm{p} 2 \mathrm{SV} \cdot \mathrm{pl}$ ?Function=getSurvey\&SDDS=3225\&lang $=\mathrm{fr} \& \mathrm{db}=\mathrm{IMDB} \& \mathrm{dbl}=\mathrm{E} \& \mathrm{adm}=8 \& \mathrm{dis}=2$

${ }^{13}$ For instance, the death of a longitudinal panel member is "confirmed against the Canadian Vital Statistics Database - Deaths."
} 
part-time in the relevant cycles, but including the 15-24 population did not change the results much.

\subsubsection{Stress: questions and specification}

The questionnaire has several questions related to stress in several dimensions: family (partner), family (children), at work, and due to financial problems. There are in particular 12 statements related to factors potentially generating stress at work (denoted hereafter the base questions), where the worker has to comment with possible answers being 1: strongly agree, 2: quite agree ; 3 neither agree or disagree ; 4 : quite disagree ; 5: strongly disagree.

These statements are: 1. Your job requires that you learn new things. 2. Your job requires a high level of skill. 3. Your job allows you freedom to decide how you do your job. 4. Your job requires that you do things over and over. 5. Your job is very hectic. 6. You are free from conflicting demands that others make. 7. Your job security is good. 8. Your job requires a lot of physical effort. 9. You have a lot to say about what happens in your job. 10. You are exposed to hostility or conflict from the people you work with. 11. Your supervisor is helpful in getting the job done. 12. The people you work with are helpful in getting the job done. There is also a $13^{\text {th }}$ question on job satisfaction: How satisfied are you with your job? where possible answers range from very satisfied to very unsatisfied.

Based on these questions, derived stress questions were constructed independently by a team of sociologists and made available by Statistic Canada to the research community: the variables are included in the available dataset. ${ }^{14}$ There are 6 indicators of stress at work, a 7 th derived stress index (job strain) which is a combination of three of the previous stress indicators, and finally an aggregate stress index built by the team, which adds up all six first dimensions of stress. ${ }^{15}$ The stress variables are described as follows in the Manual:

- Skill Requirements: (0-12) (lower values means that higher skills are required for the job). This derived variable determines the respondent's task variety at main job in the past 12 months

- Decision Latitude - Decision Authority: (0-8) (higher values indicate lower decision authority). This derived variable indicates whether the respondent's main job in the past 12 months allows them freedom on how to do their job and if they have a lot of say in what happens on their job.

- Psychological Demands: (0-8) (higher values indicate greater psychological demands). This derived variable indicates if the respondent is free from conflicting demands that others make and if their main job in the past 12 months is very hectic.

- Job Insecurity: (0-4) (higher values indicate greater job insecurity). This derived variable indicates whether the respondent feels that their main job security is good.

\footnotetext{
${ }^{14}$ This team is lead by Blair Wheaton from the University of Toronto. The full description of the data can be found page 122-128 in the Derived Variables Documentation 2004, available here http://www.statcan.ca/english/sdds

/document/3225_D10_T9_V1_E.pdf. It is worth noting that the same questions and methodology are used in similar surveys ran in other countries

${ }^{15}$ In the original variables for stress at work created by the team of sociologists, the normalization of all dimensions of stress are such that a higher number corresponds to higher stress, except for the dimension "skill requirement", which is higher, the lower this number. The original overall stress index adds up all dimensions. Instead, I added all dimensions but 'Skill requirement', which was substracted from the total instead. This transformation marginally raises the fit and the significance of the regressions with the overall stress index, without big implication.
} 
- Physical Exertion: (0-4) (higher values indicate greater physical exertion). This derived variable indicates whether the main job in the past 12 months requires a lot of physical effort.

- Social Support: (0-12) (higher values indicate lower social support). This derived variable indicates the social support available to the respondent at his/her main job in the past 12 months. Questions are asked about whether or not the supervisor and the people the respondent worked with were helpful in getting the job done, and whether the respondent was exposed to hostility or conflict from the people they worked with.

- Job Strain: (0.2-5) (higher values indicate greater job strain). This derived variable indicates whether the respondent experiences job strain. Job strain is measured as a ratio of psychological demands and decision latitude which includes skill discretion and decision authority.

- Work Stress Index - All Items: (0-48) (higher values indicate greater work stress). This derived variable determines the respondent's perception about all dimensions of their work. ${ }^{16}$

\subsubsection{Depression, anti-depressants and various other stuff}

We have several distress indicators. Among them, we select those based on objective clinical characteristics of individuals. Notably, a Depression Scale (0-8) based on 21 questions on respondent's psychological and clinical state. ${ }^{17}$ and a Predicted Probability of Depression $(0-1) .{ }^{18}$. We also have questions on drugs use. For all respondents above 12 y.o., the interviewer asks the following question on about 30 medications:

In the past month, that is, from [date one month ago] to yesterday, did [you/FNAME] take:

...tranquilizers such as Valium or Ativan? (yes/no)

...anti-depressants such as Prozac, Paxil or Effexor? (yes/no)

...sleeping pills such as Imovane, Nytol or Starnoc? (yes/no)

The exact name of the medication is also reported and the respondent is asked to look at the bottle, tube or box. We build dummy variables reflecting the use of such drugs, and also a blood pressure indicator taking value 1 if the respondent is currently having abnormally high blood pressure.

\subsection{Firing restrictions}

In Canada, employment protection differs across provinces, along several dimensions such as firing taxes, severance payment, the maximum number of days of temporary layoff and finally

\footnotetext{
${ }^{16}$ The Manual of the longitudinal survey states that, due to a translation problem, "In Quarter 3 of Cycle 1 (1994) collection, not all eligible working people were asked the work stress questions in the French interview. This may result in some bias." Further, a correction for refusals, included in Cycles 4 and 5, has not been implemented for Cycle 1. For this reason, we will do most regressions with Cycle 4 and 5 only, with simply a comparison with the three cycles included as a robustness check. The implication is that most regressions will be based on two observations per individual, excluding the possibility of having efficient fix effect estimators.

${ }^{17}$ The score "assesses the respondent's depression state. The items used to measure depression are based on the work of Kessler and Mroczek (from University of Michigan). They selected a subset of items from the Composite International Diagnostic Interview (CIDI) that measure major depressive episodes (MDE). The CIDI is a structured diagnostic instrument that was designed to produce diagnoses according to the definitions and criteria of both DSM-III-R and the Diagnostic Criteria for Research of the ICD-10."

${ }^{18}$ Internet Site: National Comorbidity Survey: www.hcp.med.harvard.edu/ncs/. Composite International Diagnostic Interview (CIDI): www.who.int/msa/cidi/index.htm
} 
advance notice. No systematic documentation for most of these dimensions exists at the provincial level, because they are often a matter of jurisprudence, with an important exception: advance notice requirements for which no provision existed immediately after World War II were progessively incorporated in regional laws, following courts decisions in specific cases.

Advance notice requirements are an important dimension of EPL: it reduces the discretion of employers as regards to dismissals, it is often an implicit severance payment if the worker is asked to stay at home during the period, and finally it has well-known effects on hiring decisions and the dynamics of labor markets. ${ }^{19}$ Differences across provinces can be seen in Figure B in Appendix, from a table in Friesen et al. (1997) and Human Resources and Social Development Canada (the Federal labor agency). An interesting feature for our purpose is that EPL has two distinct dimensions: advance notice in case of individual layoff, and advance notice in case of mass layoffs. The length of notice depends on worker's seniority. EPL in case of mass layoff is determined by firm's size instead. Protection against individual layoff is the variable we expect to be more particularly associated with stress, given the insights from theory. As regards to collective EPL, some provinces have no provision at all, such as Alberta or British Columbia, while some others have instead some relatively large provisions (up to 4 months in largest firms, as in the case of Quebec). For individual EPL, the total length of the notice period varies across regions and either progress fast or instead remains relatively flat.

Given these information, we develop two strategies to identify the effect of EPL. The first one is to use information on seniority and firm size and compare individuals within provinces. The second one is to use regional differences instead. We now discuss the pros and cons of each procedure.

\subsubsection{Employment protection legislation in provinces}

Since seniority and firm size are not available in NHPS and would be endogenous variables, we first consider using the regional dimension. We build through a simple aggregation procedure described in Appendix $\mathrm{C}$ an aggregate index of regional employment protection for individual dismissals and another index for employment protection for collective dismissals. Both are expressed as the expected number of weeks of advance notice but are meant to proxy more complex dimensions of EPL. Let us denote these regional EPL indices by EPL_ind and EPL_coll. We checked ex-post that these variables make sense. The EPL indicators are positively correlated with regional unemployment duration and with other indicators of employment regulations provided by business surveys. They are also negatively associated with the transition probability from employment to unemployment - see Technical Appendix C for all details. We can thus be reasonably confident that advance notice is a good proxy for other forms of EPL and capture well the fluidity of provincial labor markets. ${ }^{20}$

\footnotetext{
${ }^{19}$ See e.g. Garibaldi (1998) for theory and some data analysis for OECD countries. For Canada, Frisen (1997) has used the same variations to study the impact of advance notice regional differences on the duration of employment and found that longer advance notice both raises the fraction of job-to-job moves and reduces the hazard rate.

${ }^{20}$ There is another reason to believe that these indicators make some sense: advance notice requirements initially reflected the outcome of several local courts decisions before becoming the law - local judges decided that, for a worker with $n$ years of seniority, a $p$ months notice period was fair — so that differences across provinces reflect the philosophy of the provinces towards economic layoffs: it is quite likely that other dimensions of EPL are correlated with the length of advance notice.
} 


\subsubsection{Imputed EPL}

As indicated above, running within-region estimates of the effect of EPL is not directly possible in the absence of information on firm's size and seniority of individuals in NHPS: tenure can be constructed from NPHS questionnaire only from cycles 1, 2 and 3, whereas stress is available from cycles 4 and 5, that is, 2 and 4 years after the last observation of tenure; moreover, employer's size is unavailable in NPHS. In addition, these two variables would be very endogenous: an individual subject to stress might not stay long in firms and might prefer to work in more protected firms.

We can remedy to both problems using an imputation technique, and approximate the degree of protection at the individual level. Another dataset, the Canadian Labor Force Survey (LFS or Enquête sur la Population Active, EPA) contains information on seniority and establishment size as well as all relevant information such as industry, occupation and demographics. We used the monthly files for years 1994, 1996, 1998, 2000 and 2002, that is a total of 60 files, containing overall slightly more than 3 millions observations, and about 500000 thousands different individuals (there is a rotating scheme of about 6 months). The dataset contains information on tenure in months and establishment and firm's size, as well as a set a variables denoted by $Z_{i t}$ common with the NPHS (region, industry, occupation, gender, age).

From the information on tenure and on the region of individuals in EPA-LFS, we built the exact number of weeks of advance notice protecting individuals from individual layoff thanks to the table in Figure B. Similarly, from the information on the establishment's size, we obtain the exact number of weeks of advance notice in case of mass layoff. Let us denote these actual measures of EPL by actEPL_ind $d_{i t}$ and $a c t E P L \_c o l l_{i t}$. We then regress these measures on a set of regional dummies, sectors and occupation, age ( 5 years bands), education (14 dummies) and gender, weighting the regression by the panel weight of EPA-LFS and correcting for clustering per individuals. The imputation models explain about $45 \%$ of the total variance for individual EPL and about $28 \%$ of total variance for collective EPL. We then used the vector of coefficients to obtain the fitted or imputed values in the NHPS dataset, which we will denoted by EPL_fit in tables. ${ }^{21}$

\section{Empirical strategy}

For a given individual $i$ at time $t$, the subjective indicators of disutility are denoted by $\Sigma_{i t}$, such as stress at work; and objective indicators of clinical manifestation of disutility are denoted by $O_{i t}$, such as blood pressure, consumption of psychotropic drugs and depression scores.

\subsection{Subjective data}

Subjective indicators are subject to potential mis-measurement, as self-declared stress may not reflect the true stress of the job's environment. For this reason, estimating an equation such as

$$
\Sigma_{i t}=\alpha+\beta X_{i t}+\delta E P L_{\text {region }(i t)}+\nu_{i t}
$$

\footnotetext{
${ }^{21}$ We also tried an alternative measure where individuals with temporary contracts are assigned a value of 0 for actEPL. This would only marginally improves the t-stat in the stress regressions (a t-stat of 3.30 typically becomes 3.32). We decided to keep the benchmark specification.
} 
in the universe of respondents where $\nu_{i t}$ is an error term of individual $i$ at time $t$ and $X_{i t}$ is a set of personal characteristics, there are two potential problems: first, whether $\Sigma_{i t}$ reflects the characteristics of the job of individual $i$ or instead its ability to cope with stress. Second, whether the measurement error in $\Sigma_{i t}$ affects the estimate. Denote by $\Delta_{i t}$ the 'true' disutility of workers in the job. We thus have

$$
\Sigma_{i t}=\Delta_{i t}+\phi_{i t}+\varepsilon_{i t}
$$

where $\varepsilon_{i t}$ is the measurement error in the response of individual capturing the heterogenous propensity to declare stress ; $\phi_{i t}$ is the (in-)ability to cope with stress. Both error terms do not affect the estimate of $\delta$ to the extent that they are uncorrelated with $\nu_{i t}$, which amounts to the question of the quality of controls, described in next sub-section.

Another potential problem is the selection issue: workers experiencing more stress may be likely i) to quit or ii) not to participate to the labor market. Item i) is not a problem here since our data on stress cover workers having been employed in the year of the survey: even quitters or non-employed answer the stress questions. Item ii) is not a problem if we postulate that the relevant universe of the model is the universe of those currently employed: since we are interested in job characteristics, we are not interested in what could be the stress for jobs that do not exist: in this interpretation, there is no selection issue.

\subsection{Controls}

As controls, denoted by $X_{i t}$, we shall use: sex, 9 age categories, marital status, type of household, living arrangement of the selected respondent, urban/rural, household size, six weight categories, highest level of education (14 dummies), whether the individual has immigrated in the last ten years, whether he has immigrated more than ten years ago (based on age at time of immigration), country/area of origin (among areas: Canada, Europe, US, South America, Asia,...), year dummies, 16 sectors and 47 occupation. To control for other characteristics linked to the ability to cope with stress, we have a number of possible variables in this rich dataset. For instance, there is a variable reflecting trauma in the childhood of the individuals. ${ }^{22}$ There are also variables on the amount of stress experienced in other dimensions than work, so-called chronic stress ${ }^{23}$, which we will not use in benchmark regressions but will be useful in the falsification exercises. The idea is that these additional controls will remove most of the correlation between $\phi_{i t}$ and $\nu_{i t}$. See the full list of controls in the regression tables. A valuable suggestion to remove individual heterogeneity would be to rely on fixed effects estimators. However, there is only a tiny fraction of region movers: fixed effects in equation (11) lead to a considerable loss of efficiency.

A last potential control is union density at the provincial level, which may be used as an additional regressor. The data can be obtained from Statistic Canada. Given a break in the

\footnotetext{
22 "This index measures the number of traumatic events respondents have been exposed to during their childhood, adolescence or adulthood. Events included are parental divorce, a lengthy hospital stay, prolonged parental unemployment, frequent parental alcohol or drug use. A higher score indicates more stressors."

23 "This (trauma) index measures the number of traumatic events respondents have been exposed to during their childhood, adolescence or adulthood. Events included are parental divorce, a lengthy hospital stay, prolonged parental unemployment, frequent parental alcohol or drug use. A higher score indicates more stressors."

The exact definition of chronic stress is: "The stressors include activity overload, financial difficulties and problems with relationships in day-to-day encounters." and the construction of the index does not include the 'W-stress' variables, i.e. stress at work.
} 
series in 1996, we have used an average for 1997-2003 and use that variable in regressions. ${ }^{24}$ Unfortunately, the individual's membership status is not available in NHPS.

\subsection{Objective data}

The questionnaire has a section on quantitative measure of psychological disorders and other health variables of interest. Contrary to work stress questions available for employees only, the universe of respondent is the total working age population. This is an interesting feature of the data since the essence of the test will be to interact the employment status with EPL to control for regional effects possibly affecting the propensity to consume antidepressants or local genetic factors affecting, say, blood pressure. In that sense, we can estimate an equation such as

$$
O_{i t}=\alpha+\beta X_{i t}+\delta \cdot E P L_{\text {region }(i t)} * e m p_{i t}+\gamma \cdot e m p_{i t}+D_{i} \operatorname{Region}_{i t}+\nu_{i t}
$$

where $D_{i}$ is a regional fixed effect and Region $i t$ is the region of the individual at time $t$, and emp is a dummy variable indicating that the individual surveyed is currently employed. We will also control for whether the individual is covered by health insurance. An immediate difficulty here is that, in OLS regressions, whatever the variable chosen $O_{i t}$, the coefficient $\gamma$ is always very negatively significant: ceteris paribus, employed individuals have a propensity to cope with stress that is higher than that of non-employed. Said otherwise, depressed individuals, those taking psychotropic drugs and those with severe pathology are less likely to be at work. One way to express this fact is to assume that there is an employment equation, such as

$$
e m p_{i t}^{*}=\alpha^{\prime}+\beta^{\prime} \cdot Z_{i t}+\eta_{i t}
$$

where the star denotes a latent variable, $Z_{i t}$ is a set of variables determining the employment probability and $\eta_{i t}$ is an individual noise, likely to be negatively correlated with $\nu_{i t}$. The set of variables $Z_{i t}$ contains most of variables in $X_{i t}$ (age, gender, family, etc...). As an identification, we chose to add local labor market conditions, such as the unemployment rate or the activity rate. Such variables happen to be well correlated with the employment status of the individual and are not a priori correlated with the individual propensity to suffer from any pathology as it is an aggregate over about 100000 individuals and is obtained from a distinct survey. Accordingly, equation (13) will be estimated using IV estimators. ${ }^{25}$

Appendix B5 discusses several econometric issues linked to individual clustering, regional clustering and the correction of standard errors when EPL is imputed from the LFS survey.

\section{Results}

\subsection{Sample statistics and correlations}

Table 1 displays summary statistics in a sample restricted to the 25-64 y.o. who are not selfemployed. The share of men is slightly below 0.5 ; there are almost $20 \%$ of non-native Canadians. The average age is 43.3 years. In the sample, on a trauma scale of (0-7), the average is 1.06

\footnotetext{
${ }^{24}$ From table 279-0025 for 1976-1995: all employees coverage and from table 282-0073 for 1997-2004: full-time employee coverage. Both come from the Labor Force Surveys.

${ }^{25}$ About s.e. correction with IV techniques and notably the comparison between Moulton (1986) and robust methods of estimation with clustering, see page 11 in Hoxby (2005).
} 
with a standard deviation (s.d.) of 1.23. Almost a quarter of the population is not covered by a health insurance. The fraction of users of psychotropic drugs (antidepressants, tranquilizers and sleeping pills) is relatively small (3 to $4 \%$ ), but there are 2 to $3 \%$ of refusals - later on, attempts to impute a yes to a refusal don't change the results. A fraction of $8.5 \%$ of respondents has used one of these three medications within the last four weeks. The last four rows give the mean and s.d. of imputed employment protection, with or without using information on temporary work: in the last two rows, temporary workers are assumed to have no employment protection and their associated index is zero. This correction for temporary employment makes little difference in sample means, and did almost no change to subsequent regressions.

Figures 2-5 next present a scatter plot of unconditional provincial means of various stress indicators and provincial EPL. They illustrate the relatively high and positive correlation between individual employment protection and overall stress, psychological stress and stress from skill needs. There is a weaker but reinsuringly negative correlation between individual EPL and the stress associated with job loss. The next key question is whether these correlations or other survive once various covariates are included, notably individual variables, sectors, occupation and local labor market conditions as well as collective EPL and unionization.

\section{$5.2 \quad$ Stress regressions}

In all stress regressions, the sample is restricted to those having answered the questions on stress at work, that is, those having worked in the year preceding the survey. We further exclude the self-employed.

\subsubsection{Cross-province identification}

Table 2 displays the baseline regression on overall stress at work, where the EPL variables are those of the region where the individuals currently live. Column 1 is the baseline regression with sample weights. Column 2 is a random effect regression. Column 3 adds a union density variable to the baseline specification. Column 4 adds the 1994-95 wave which is subject to the translation error in the stress questionnaire, as a comparison with column 1. Column 5 adds 342 interactions dummies terms between industry and occupation. All specifications include gender, age, family, immigration, place of birth, education and year dummies. As expected, female workers, older workers and workers having experienced traumatic events when they were young report higher stress at work. Notably, the 'trauma in the past' variable is remarkably significant and will be kept in most regressions where they are relevant.

In all specifications, it appears that both types of EPL (individual and collective) raise total stress at work. Individual EPL is the most significant variable of the two, whereas collective EPL is only marginally significant. Adding the union rate in the specification marginally raises the significance of collective EPL but reduces the coefficient of individual EPL. Including 342 interaction dummies (occupation times industry) reduces the coefficients of EPL, but they remain significant. The inclusion of the first wave (1994-95) reduces the significance of the coefficients.

How large are the effects? In the baseline equation, moving from the level of EPL of New Foundland to the one of British Columbia (from 2 to 5) would raise stress by 0.6 units, when the standard deviation of stress is $4.33: 14 \%$ of one s.d. of stress can be explained by individual EPL, while another 0.2 units of stress are accounted for by collective EPL when it goes from the level of Alberta to the level of Quebec, that is, another $5 \%$ of one standard deviation. It 
looks small but this is an average effect for all stress dimensions. Sub-components of stress will be shown to be quantitatively much more affected by EPL.

\subsubsection{Imputation of EPL and within-region estimates}

The alternative estimation strategy discussed above is to impute actual employment protection to individuals, as described in Section 3.2.2, using for this purpose various years of the Canadian labor force survey (EPA-LFS). Results are displayed in Table 3. Generally speaking, the estimates obtained through this method are marginally smaller and slightly less significant: t-stat of EPL_ind_fit are around 3.0 instead of 3.3, while coefficients go from 0.24 to 0.19 . Note here that we do not need to implement Moulton's correction or regional clustering correction since the explanatory variable is no longer constant within regions.

The imputation method makes it possible to include regional effects in the econometric specification. In such specifications, we found that EPL variables are no longer significant. In contrast, if we run the benchmark specification with the imputed EPL in removing industry dummies and occupation dummies (both being the main determinant of imputed EPL) and without regional dummies, we obtain positive coefficients with t-stat of 6.85 and 1.63 respectively for individual and collective EPL. Now adding regional dummies but still in the absence of industry and occupation dummies leads to EPL to have a t-stat of 4.76 and 3.70. This suggests that the impact of EPL on stress is actually both between regions and within regions but between industries and occupations. Once region, industry and occupation effects are added, nothing is left of the correlation.

\subsubsection{Regional vs. individual clustering}

To address the multilevel clustering issue (individual+regional), Table 4 re-runs the benchmark regression for specific years. Interestingly, controlling for regional clustering in cross-sections estimates raise standard errors (especially in 2000), indicating that the correlation within provinces is negative rather than positive. ${ }^{26}$

We can also note the stability of coefficients across years. This confirms that most of the results are driven by the cross-section. Unreported between-estimators regressions in the pooled cross-sections bring the same results, while fixed-effects estimators lead to insignificant coefficients of EPL. Finally, Hausman tests on random effects, which tests for coefficients being different between random effects and between-estimators regressions actually show mixed results: sometimes the null is rejected, sometimes not.

In the last column of Table 4, we also tried Wooldridge's (2003, Sn III) suggestion to proceed in two steps: first, regress the stress indicator on all variables which are not clustered and a set of regional dummy indicators (denoted by $\delta_{k}, k=1, \ldots, 10$ ). Then, to regress the fixed effects themselves on the two variables $E P L$ ind and $E P L \_$coll. We obtained the following coefficients respectively: $0.2007(2.40)$ and $0.0342(1.83)$ respectively, and a $R^{2}$ and $a d j-R^{2}$ of 0.53 and 0.38 . The t-stat in parenthesis correspond to significance levels in the $t_{10-2}$ distribution which are respectively: $2.2 \%$ and $5.3 \%$. To sum up, regional clustering is not a major issue here especially

\footnotetext{
${ }^{26}$ An interpretation is that provinces are large and diverse. They notably have both rural and urban areas which dramatically differ in the perception of stress, while the urbanicity variable we have is only a $0 / 1$ indicator thus possibly insufficient.
} 
after accounting for individual clustering and hereafter, we exclusively focus on robust estimates with individual clustering. ${ }^{27}$

\subsection{Various components of stress and job's characteristics}

Table 5 investigates the impact of EPL on the various components of stress at work. In the first specification displayed in the top part of the table, we have the same controls as in Table 2, column 1. We find that individual EPL increases psychological stress, reduces the stress from layoff, raises physical stress and stress from strain. The effect of collective EPL is more balanced as it sometimes reduces stress (physical exertion, psychological and strain) but raises the stress from layoff. However, this last result appears to be due to a lack of controls. This is why we replicate all regressions in adding the union density variable, as displayed in the bottom panel of the table. The positive effect of collective EPL on stress from layoff is now no longer significant. We also find that unions raise the stress from layoff. This may be due to unions succeeding in raising wages but at the cost of increasing job fragility.

We now have an explanation for why the effect of EPL on total stress at work is positive and not negative: in the total stress indicator, job insecurity is given a quite small weight. Job insecurity has a range $(0,4)$ whereas total stress at work ranges from 0 to 48 . If one arbitrarily increased the weight of job insecurity, the sum of all dimensions of stress could actually be negatively correlated with EPL. The positive coefficient of EPL is thus partly the outcome of a normalization chosen by the team of sociologists having derived, totally independently of this work, the various stress variables.

Given these rich data, other specifications are possible. An interesting idea would be, for instance, to use stress from job insecurity as an individual proxy for the effective degree of employment protection faced by the individual. However, this variable is correlated both to employment protection - the direct effect we wish to measure - and to the economic conditions of the firm. And we know from the theory part that the non-viability of the job is a key determinant of pressures from management, hence the interpretation the effect of job insecurity on other dimensions of stress is unclear: from theory, the sign can be both ways.

Finally, we return to the 13 base questions used to generate the stress variables and replicate the same analysis with these questions. Since the answers take discrete values in $(1,5)$, we run an ordered logit estimates unless they do not converge, in which case we run linear regressions despite biased standard errors. We have the same list of controls as in Table 2. Results are in Table 6. The title of each column gives a summary of the question and the table reads as follows: a positive coefficient in column 1 for instance means that it is more likely that "No learning required". Focussing on the effect of individual EPL, we find that it is associated with more hectic jobs, more conflicting demands, more hostility and the supervisor is (with marginal significance) less helpful, but there is no systematic relation with job satisfaction neither job security. The second line indicates that high EPL_coll jobs have less learning, are low skill

\footnotetext{
${ }^{27}$ Table B3 in Appendix adds several controls, many of which turn out to be significant: health status (selfperceived), social support (self-perceived), body weight, language (french speakers are not significantly difference from the reference group, English speakers, but other groups are less stressed). Local unemployment (in one of the 382 geographical Census divisions) reduces slightly both the coefficient on EPL and its significance. Other local controls do not change the broad picture. A "chronic stress" variable, i.e. stress in other dimensions than work, shows up to be extremely significant. One interpretation is that the ability to cope with stress depends very much on other sources of stress. Table B4 in Appendix investigates further the role of local conditions, in adding interaction terms between local unemployment and EPL, with mixed results.
} 
jobs, there is little freedom, they are not repetitive, they are not hectic, have no particular physical exertion, but there is a quite high level of hostility, the supervisor is not helpful and workers, very significantly, don't receive much help in getting the job done. Interestingly, there is no correlation between EPL and job satisfaction, as the last column (bottom panel) indicates.

\subsection{Elements of falsification}

An obvious question at this stage is whether the identification strategy based on provincial differences in 10 regions is valid. Could it be simply by accident that we found a positive correlation between EPL and stress? Part of our confidence in the results comes from the large list of controls: have we introduced enough individual's characteristics: this reduces the risk that the correlation is due to unobserved factors. Further, the negative sign of EPL on stress is an indicator that the EPL variables makes sense.

Here, we propose additional elements of falsification, as follows: are there dimensions of stress unrelated to work that are indeed uncorrelated with EPL? This is precisely what Table 7 does. We regress three components of stress a priori unrelated to work on EPL and the same individual characteristics as in Table 2. We do so in the same sample of employed workers. These alternative stress dimensions are "chronic stress", adding up stress in all dimensions except stress at work, stress associated with personal life and finally stress associated with financial problems. We would expect the coefficients of EPL to be now insignificant and the coefficients to be smaller. As columns 1 to 3 indicate, this is indeed the case for EPL_ind: t-statistics are reduced from 3.5 to 2.1 or even 1.3. For EPL_coll, the falsification is even stronger since coefficients turn negative in some case with marginal significance.

The residual positive correlation between EPL_ind and the "stress of work" variables can actually be explained: the ability to cope with stress in one's dimension of life is affected by stress in other dimensions: a seemingly innocuous event in the family could become stressful if the job is already stressful. Columns 4 to 6 , where stress at work is added among the regressors, is consistent with this interpretation: it is highly significant, and all positive coefficients of EPL_ind become insignificant. The falsification exercise is thus relatively coherent: there is little chance that the impact of EPL on stress at work is obtained by chance, or because workers in high EPL regions are structurally more stressed people. It is more likely that this effect is related to management techniques and industrial relations, as suggested in the theory part.

\subsection{Psychotropic drugs and depression}

Even though the imputation and the various falsification regressions suggest that the positive link between individual EPL and stress is not spurious, one may want to use the additional information on health conditions of individuals, the so-called objective measures, to confirm our findings. Indeed, as shown in Table B5 in Appendix, there is a strong positive link between general stress and depression. ${ }^{28}$ This is sometimes referred too as a burnout effect: workers have a stock of energy that becomes depleted after a while

\footnotetext{
${ }^{28}$ Specifications with chronic stress as a variable are available only for waves 1,4 and 5 (18 000 obs.), while specification without this variable are available for all five waves (33 000 obs.). We find that the correlation between current stress and depression scores (and probability) is very large. Trauma and female gender are also very strongly positively associated with depression. Local conditions, in contrast, do not appear to play a major role.
} 
Equation (13) can be thought as a depression equation, where we use as regressors the interaction between being employed and provincial EPL. As detailed above, we need instruments: local labor market conditions and household size interacted with gender work fairly well, as shown in Table 8. Local unemployment is largely negatively associated with individual employment, while local activity rates raise individual's probability of being employed.

Table 9 must be read two columns by two columns, where we systematically compares the regular probit regressions and their IV-probit counterparts. The successive variables on the left hand-side are: a depression indicator, the consumption of one of the psychotropic drugs discussed in Section 3.1.4, and an indicator for abnormally high blood pressure. The null of exogeneity of instruments fails to be rejected at conventional significance levels. The presence or absence of coverage by an health insurance is added among regressors. For the depression indicator, antidepressants and tranquilizers, we find here evidence of a slight causal role of individual EPL. We found no effect on blood pressure.

\section{Concluding comments}

Does EPL improve the well-being of employed workers? In this paper, we have developed a model in which stress and strain at work depend on EPL according to an inverted U-shape pattern (positive for low EPL levels, negative for high EPL levels, and in particular negative for non-viable jobs). The theory is not rejected by the data analysis: we even find positive effects of EPL on some dimensions of stress. We also found weaker but positive links between depression of employed workers and EPL, and similar links between the use of some psychotropic drugs among employed workers and EPL.

This is a provocative idea which the data do not seem to reject. This is however only a starting point. Future work should notably investigate the relation between EPL and stress in other countries. The United States are a good candidate, since a number of works have been done here on wrongful discharge laws introduced in the 1970's or 1980's (e.g. Autor et al. 2006). Unfortunately, rare are the datasets where stress at work can be measured in the US: there are such surveys for the post 2002 period, at a time where there is little or no variation in EPL across US states. At best, we could replicate our cross-sectional empirical strategy for those year, which is our next task.

More generally, the hypothesis could be tested in virtually all countries, as long as data on stress are collected and that there is a source of exogenous variation in EPL. Another way to approach the same set of questions is to focus on firm's data. For instance, it may be interesting to find evidence of variations in the quality of industrial relations, size of firms, human resources management, that would be correlated with the stringency of EPL.

As a final remark, it is important to have a better understanding of the unexpected negative effects of EPL on workers wellbeing. This may open the way to labor market reforms in several European countries. Many observers appear to agree that EPL harms outsiders (unemployed, female, and young workers), but if in addition it can be established that it affects groups of workers closer to the political core (protected workers), the terms of the debate drastically change, which implies even more scope for reform. 


\section{Appendix}

\section{A Model appendix}

\section{A.1 Summary of notations}

See Table A.

\section{A.2 Proof of Proposition 1}

The proof amounts to calculating the cut-off values of $\varepsilon$ for which $\mathrm{NF} \sim \mathrm{F}, \mathrm{NF} \sim \mathrm{C}$ and $\mathrm{F} \sim \mathrm{C}$. The first and third values correspond to $\widehat{\varepsilon}$ and $\bar{\varepsilon}$, while the second one is a shadow margin $\underline{\varepsilon}=\bar{\varepsilon}-\tau>\widehat{\varepsilon}$ and $\underline{\varepsilon}>\widehat{\varepsilon}$. Indeed, for $\varepsilon>\widehat{\varepsilon}, \mathrm{F} \succ \mathrm{NF}$; for $\varepsilon>\underline{\varepsilon}, \mathrm{C} \succ \mathrm{NF}$ and for $\varepsilon>\bar{\varepsilon}, \mathrm{C} \succ \mathrm{F}$. Then, to sum up, if $\varepsilon<\widehat{\varepsilon}, \mathrm{NF} \succ \mathrm{F} \succ \mathrm{C}$ and the firm prefers $\mathrm{NF}$; if $\widehat{\varepsilon}<\varepsilon<\underline{\varepsilon}, \mathrm{F} \succ \mathrm{NF} \succ \mathrm{C}$ and the firm prefer $\mathrm{F}$; if $\underline{\varepsilon}<\varepsilon<\bar{\varepsilon}, \mathrm{F} \succ \mathrm{C} \succ \mathrm{NF}$ and the firm still prefer $\mathrm{F}$; if $\varepsilon>\bar{\varepsilon}, \mathrm{C} \succ \mathrm{F} \succ \mathrm{NF}$ and the firms prefers to continue with the worker.

\section{A.3 General case}

Workers knows its effort leads to changing margins and $F$, as follows:

$$
\begin{aligned}
& \frac{\partial F}{\partial e}=-q^{m} F^{\prime}<0 ; \\
& \frac{\partial \bar{\varepsilon}}{\partial e}=0 ; \frac{\partial \widehat{\varepsilon}}{\partial e}=\tau q^{m} \Phi>0 ; \\
& \frac{\partial \bar{\nu}}{\partial e}=0 ; \frac{\partial \widehat{\nu}}{\partial e}=-\Sigma \Phi<0 .
\end{aligned}
$$

where $\Phi=F^{\prime} /(1-F)^{2}$. Note the interesting simpler case where

$$
F(x)=\frac{K x}{1-K x} \text { with } F(0)=0 \text { and } K x<1
$$

leads to a constant $\Phi=K$, where $x=q^{m}(\bar{e}-e)$. Similarly, we have that

$$
\begin{aligned}
& \frac{\partial F}{\partial q^{m}}=(\bar{e}-e) F^{\prime}>0 ; \\
& \frac{\partial \bar{\varepsilon}}{\partial q^{m}}=0 ; \frac{\partial \widehat{\varepsilon}}{\partial q^{m}}=-\tau(\bar{e}-e) \Phi<0 ; \\
& \frac{\partial \bar{\nu}}{\partial q^{m}}=0 ; \frac{\partial \widehat{\nu}}{\partial q^{m}}=\Sigma(\bar{e}-e) \Phi ; \\
& \frac{\partial \bar{\varepsilon}}{\partial q^{w}}=\frac{\partial \widehat{\varepsilon}}{\partial q^{w}}=0 ; \frac{\partial \widehat{\nu}}{\partial q^{w}}=\frac{\partial \bar{\nu}}{\partial q^{w}}=-1 .
\end{aligned}
$$

Denote by $\nu^{e}$ the unconditional mean of $\nu$ and by $\mid$ the conditioning operator. The program of the 
worker can be decomposed as follows:

$$
\begin{aligned}
& \underset{e}{\operatorname{Max} U}=\underbrace{w-c(e)+q^{w}-q^{m}+\nu^{e}}_{\text {First period utility }}+\underset{\text { Firm initiates a no-fault layoff, worker does not quit }}{\underset{(G(\widehat{\varepsilon})(\overline{\mathcal{U}}+\alpha \tau)}{\rightleftarrows}} \\
& +\underset{\text { Firm initiates a layoff for faul }}{\stackrel{(G(\bar{\varepsilon})-G(\widehat{\varepsilon})) \times}{(}} \\
& \left\{\underset{\text { Worker quits }}{\stackrel{H(\widehat{\nu}) \overline{\mathcal{U}}}{\longrightarrow}}+\underset{\text { Worker does not quit }}{\stackrel{(1-H(\widehat{\nu}))}{\longrightarrow}}[\underset{\text { Procedure succeeds }}{\stackrel{\overline{\mathcal{U}} F}{\longrightarrow}}+\underbrace{(1-F)\left(w+q^{w}+\left.\nu^{e}\right|_{\nu>\widehat{\nu}}-c(\underline{e})\right)}_{\text {Procedure fails }}-\underset{\text { Stress }}{\left.\sum_{1}\right]}\}\right.
\end{aligned}
$$

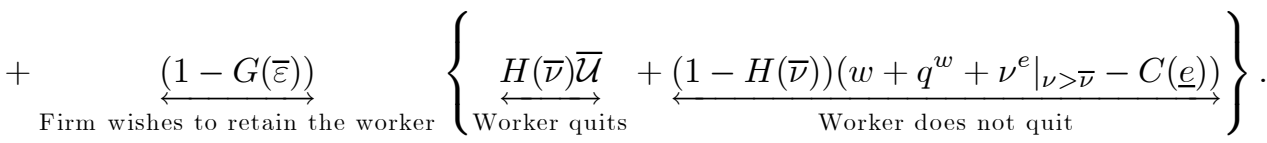

Denote by $\varepsilon^{e}$ the unconditional mean of $\varepsilon$. The first order conditions on monitoring $q^{m}$ and working conditions $q^{w}$ can be decomposed in a similar way. The program of the firm is

$$
\begin{aligned}
& \underset{q^{m}, q^{w}}{\operatorname{Max} \Pi}=\underbrace{\varepsilon^{e}+e-w-C\left(q^{m}, q^{w}\right)}_{\text {first period profits }}+G(\widehat{\varepsilon})(\bar{\pi}-\tau) \\
& +\underset{\text { Firm initiate a layoff for fault }}{\stackrel{(G(\bar{\varepsilon})-G(\widehat{\varepsilon}))}{\longrightarrow}} \times \\
& \left\{\underset{\text { Worker quits }}{\stackrel{H(\widehat{\nu}) \bar{\pi}}{\longrightarrow}}+\underset{\text { Worker does not quit }}{\stackrel{(1-H(\widehat{\nu}))}{\longrightarrow}}\left[\underset{\underset{\text { Procedure succeeds }}{F \bar{\pi}}}{\left.\left.\stackrel{(1-F)\left(\varepsilon^{e} \mid\right.}{(1->\varepsilon>\widehat{\varepsilon}}+\underline{e}-w\right)\right]}\right\}\right.
\end{aligned}
$$

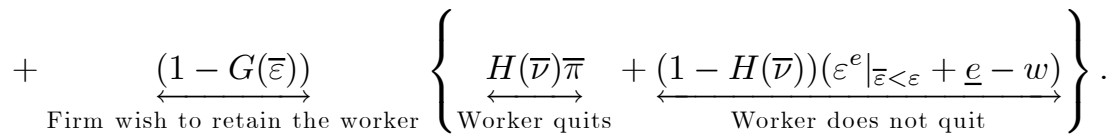

Rewrite and simplify the program of the worker in introducing the notations $\bar{\nu}$ and $\widehat{\nu}$ :

$$
\begin{aligned}
\operatorname{Max}_{e} & =w-c(e)+q^{w}-q^{m}+\nu^{e}+\overline{\mathcal{U}}+G(\widehat{\varepsilon}) \alpha \tau \\
& +[G(\bar{\varepsilon})-G(\widehat{\varepsilon})] \times[1-H(\widehat{\nu})](1-F)\left(\left.\nu^{e}\right|_{\nu>\widehat{\nu}}-\widehat{\nu}\right) \\
& +[1-G(\bar{\varepsilon})][1-H(\bar{\nu})]\left(\left.\nu^{e}\right|_{\nu>\bar{\nu}}-\bar{\nu}\right) .
\end{aligned}
$$

while on the firm's side, introducing

$$
\begin{aligned}
\underset{q^{m}, q^{w}}{\operatorname{Max} \Pi} & =\varepsilon^{e}+e-w-C\left(q^{m}, q^{w}\right)+\bar{\pi}+G(\widehat{\varepsilon})(-\tau) \\
& +[G(\bar{\varepsilon})-G(\widehat{\varepsilon})] \times[1-H(\widehat{\nu})](1-F)\left(\left.\varepsilon^{e}\right|_{\bar{\varepsilon}>\varepsilon>\widehat{\varepsilon}}-\bar{\varepsilon}\right) \\
& +[1-G(\bar{\varepsilon})](1-H(\bar{\nu}))\left(\left.\varepsilon^{e}\right|_{\bar{\varepsilon}<\varepsilon}-\bar{\varepsilon}\right) .
\end{aligned}
$$

When $\varepsilon$ follows a uniform distribution with density $g_{0}=\left(\varepsilon_{\max }-\varepsilon_{\min }\right)^{-1}$, we have

$$
\begin{aligned}
G(\bar{\varepsilon})-G(\widehat{\varepsilon}) & =\frac{g_{0} \tau}{1-F} \\
1-G(\bar{\varepsilon}) & =g_{0}\left(\varepsilon_{\max }-\bar{\varepsilon}\right) \\
G(\widehat{\varepsilon}) & =g_{0}\left(\widehat{\varepsilon}-\varepsilon_{\min }\right) \\
\left.\varepsilon^{e}\right|_{\bar{\varepsilon}>\varepsilon>\widehat{\varepsilon}}-\bar{\varepsilon} & =\frac{\widehat{\varepsilon}-\bar{\varepsilon}}{2}=-\frac{\tau}{2(1-F)} \\
\left.\varepsilon^{e}\right|_{\bar{\varepsilon}<\varepsilon}-\bar{\varepsilon} & =\frac{\varepsilon_{\text {max }}-\bar{\varepsilon}}{2}
\end{aligned}
$$


which further simplifies the expressions above, as

$$
\begin{aligned}
M_{e} a x U & =w-c(e)+q^{w}-q^{m}+\nu^{e}+\overline{\mathcal{U}}+g_{0}\left(\widehat{\varepsilon}-\varepsilon_{\min }\right) \alpha \tau \\
& +g_{0} \tau[1-H(\widehat{\nu})]\left(\left.\nu^{e}\right|_{\nu>\widehat{\nu}}-\widehat{\nu}\right)+g_{0}\left(\varepsilon_{\max }-\bar{\varepsilon}\right)[1-H(\bar{\nu})]\left(\left.\nu^{e}\right|_{\nu>\bar{\nu}}-\bar{\nu}\right) . \\
\underset{q^{m}, q^{w}}{\operatorname{Max} \Pi} & =\varepsilon^{e}+e-w-C\left(q^{m}, q^{w}\right)+\bar{\pi}+g_{0}\left(\widehat{\varepsilon}-\varepsilon_{\min }\right)(-\tau) \\
& +g_{0} \tau[1-H(\widehat{\nu})]\left(\frac{\widehat{\varepsilon}-\bar{\varepsilon}}{2}\right)+g_{0}\left(\varepsilon_{\max }-\bar{\varepsilon}\right)[1-H(\bar{\nu})]\left(\frac{\varepsilon_{\max }-\bar{\varepsilon}}{2}\right) .
\end{aligned}
$$

\section{A.4 Case of fixed $\nu$ : proofs}

In that case, denote by $\nu_{0}$ the single value of utility, we assume $\nu_{0}$ such that $H(\widehat{\nu})=0$ and $H(\bar{\nu})=0$ (no quit). Thus, from (A5), we obtain

$$
\begin{aligned}
c^{\prime}(e) & =g_{0}\left(\frac{\partial \widehat{\varepsilon}}{\partial e}\right) \alpha \tau-g_{0} \tau\left(\frac{\partial \widehat{\nu}}{\partial e}\right) \\
\text { marginal cost } & \\
\text { or } c^{\prime}(e) & =\frac{\partial \widehat{\varepsilon}}{\partial e} g_{0}(\alpha \tau+\Sigma)=\Phi q^{m} g_{0} \tau(\alpha \tau+\Sigma) .
\end{aligned}
$$

On the worker's side, the first order condition in Appendix equation (A7) states that the marginal cost of effort $C^{\prime}(e)$ equals the sum of two terms, one proportional to $\partial \widehat{\varepsilon} / \partial e$ reflecting by how much the marginal effort reduces the propensity of the firm to use a F-layoff procedure instead of a NF-layoff procedure, and a second term proportional to $\partial F / \partial e$, reflecting by how much, in case the F-procedure is being used, the worker reduces its success rate $F$.

Assuming $\frac{F^{\prime}}{(1-F)^{2}}=\Phi$, we obtain equation (A8): effort increases in the intensity of monitoring and in the square root of non-fault layoff $\operatorname{cost} \tau$, for two reasons. First, when $\alpha>0$, workers obtain a severance payment which induce them to work more in order to avoid the firm to undertake a F-layoff procedure. And second, the layoff-elasticity of the response by the firm to a change in $e$, reflected by $\partial \widehat{\varepsilon} / \partial e$, is higher, the higher $\tau$, as the incentive of firms to undertake a F-layoff is higher.

On the firm's side, the first order condition on $q^{w}$ is simple:

$$
\partial C(q) / \partial q^{w}=0
$$

which means that, in the absence of quits, firms have no incentive to affect working conditions in one way (positively) or the other (i.e. negatively). As regards to the effect of $q^{m}$ on profits, we have:

$$
\begin{aligned}
\partial C(q) / \partial q^{m} & =-g_{0} \tau \frac{\partial \widehat{\varepsilon}}{\partial q^{m}}+\frac{g_{0} \tau}{2} \frac{\partial \widehat{\varepsilon}}{\partial q^{m}} \\
\text { or } \partial C(q) / \partial q^{m} & =g_{0} \tau^{2}(\bar{e}-e) \Phi .
\end{aligned}
$$

The first order condition A9 shows that, the higher the effort of the worker, the lower the rate of return on monitoring. Further assuming $\frac{F^{\prime}}{(1-F)^{2}}=\Phi$, we obtain equation (A10). Firing $\operatorname{costs} \tau$ raise the return on monitoring for firm because a higher $q^{m}$ at a given $e$ makes the F-layoff option more secure.

Finally, a Nash equilibrium exists and is unique by intersection of the downward sloping curve (A10) and the upward sloping curve (A8). 


\section{A.5 Other cases: $\nu$ uniform}

When $\nu$ follows a uniform distribution with density $h_{0}=\left(\nu_{\max }-\nu_{\min }\right)^{-1}$, we have

$$
\begin{aligned}
H(\bar{\nu})-H(\widehat{\nu}) & =-\frac{h_{0} \Sigma}{1-F} \\
1-H(\bar{\nu}) & =h_{0}\left(\nu_{\max }-\bar{\nu}\right) \\
1-H(\widehat{\nu}) & =h_{0}\left(\nu_{\max }-\widehat{\nu}\right) \\
\left.\nu^{e}\right|_{\nu>\bar{\nu}}-\bar{\nu} & =\frac{\nu_{\max }-\bar{\nu}}{2} \\
\left.\nu^{e}\right|_{\nu>\widehat{\nu}}-\widehat{\nu} & =\frac{\nu_{\max }-\widehat{\nu}}{2}
\end{aligned}
$$

leading to further simplifications of (A5) and (A6), as follows:

$$
\begin{aligned}
& \underset{e}{\operatorname{Max} U}=w-c(e)+q^{w}-q^{m}+\nu^{e}+\overline{\mathcal{U}}+g_{0}\left(\widehat{\varepsilon}-\varepsilon_{\min }\right) \alpha \tau \\
& +\tau \frac{g_{0} h_{0}}{2}\left(\nu_{\max }-\widehat{\nu}\right)^{2}+\frac{g_{0} h_{0}}{2}\left(\varepsilon_{\max }-\bar{\varepsilon}\right)\left(\nu_{\max }-\bar{\nu}\right)^{2} . \\
& \underset{q^{m}, q^{w}}{\operatorname{Max}} \Pi=\varepsilon^{e}+e-w-C\left(q^{m}, q^{w}\right)+\bar{\pi}+g_{0}\left(\widehat{\varepsilon}-\varepsilon_{\min }\right)(-\tau) \\
& +\tau g_{0} h_{0}\left(\nu_{\max }-\widehat{\nu}\right)\left(\frac{\widehat{\varepsilon}-\bar{\varepsilon}}{2}\right)+\frac{g_{0} h_{0}}{2}\left(\varepsilon_{\max }-\bar{\varepsilon}\right)^{2}\left(\nu_{\max }-\bar{\nu}\right) .
\end{aligned}
$$

First order conditions immediately follow:

$$
\begin{gathered}
c^{\prime}(e)=\alpha \tau g_{0}\left(\frac{\partial \widehat{\varepsilon}}{\partial e}\right)+\tau g_{0} h_{0}\left(\nu_{\max }-\widehat{\nu}\right)\left(-\frac{\partial \widehat{\nu}}{\partial e}\right) \\
\partial C / \partial q^{m}=C_{0} q^{m}=(-\tau) g_{0}\left(\frac{\partial \widehat{\varepsilon}}{\partial q^{m}}\right)+\frac{\tau g_{0}}{2}(1-H(\widehat{\nu}))\left(\frac{\partial \widehat{\varepsilon}}{\partial q^{m}}\right) \\
+\frac{\tau h_{0}}{2}(1-G(\widehat{\varepsilon}))\left(-\frac{\partial \widehat{\nu}}{\partial q^{m}}\right) \\
\partial C / \partial q^{w}=C_{0} q^{w}=\frac{\tau h_{0}}{2}(1-G(\widehat{\varepsilon}))\left(-\frac{\partial \widehat{\nu}}{\partial q^{w}}\right)+\frac{h_{0}}{2}\left(1-G(\bar{\varepsilon})\left(\varepsilon_{\max }-\bar{\varepsilon}\right)\left(-\frac{\partial \bar{\nu}}{\partial q^{w}}\right)\right.
\end{gathered}
$$

Replacing derivatives of $\widehat{\nu}$ and $\widehat{\varepsilon}$ from (A1) and (A2), we obtain equations (8), (9) and (10) in the text.

\section{B Data Appendix}

Number of longitudinal panel members: 17,276 ; Number of panel members who have died: 1,279 ; Number of panel members who have been institutionalized: 161 ; Number of respondent panel members: 12,484 ; Number of non-respondent panel members: 3,352. A full description of the survey can be found here: http://www.statcan.ca/cgi-bin/imdb/p2SV.pl?Function=getSurvey\&SDDS

$=3225 \&$ lang $=\mathrm{en} \& \mathrm{db}=\mathrm{IMDB} \& \mathrm{dbg}=\mathrm{f} \& \mathrm{adm}=8 \& \mathrm{dis}=2$, or simply in finding the website in googling NHPS Canada.

\section{B.1 Response and attrition}

\section{B.1.1 Response rates}

In this specific case of a health survey, non-response is a particular concern. The appendix (Table B2) thus provides various details on death, attrition and non-response. In short, the response rate varies 
between 80 and $92 \%$. Conditional on being a respondent, the refusal to reply to individual questions, including those on drug consumption, is generally around $2 \%$ or less. The next table provides some overview of these problems. Further, according to the documentation, "the income variables have refusal rates of close to 4\%. Some of the labour force submodules and the mastery submodule (stress module) have the highest refusal rates at $0.11 \%$ and $0.12 \%$ respectively". In other words, people are sometime reluctant to talk about money, but seem unconcerned about talking about stress.

\section{B.1.2 Attrition rates}

Attrition is a loss in sample size due to non-respondents i.e. refusals, no-contacts, unable to trace cases, etc. Note that decease respondents are not considered part of attrition for the NPHS longitudinal sample. The cumulative attrition rate is presented for each cycle. Each attrition rate is calculated using the number of individuals found in the Full subset of respondents i.e. those who completed the questionnaire in all cycles. The main cause of attrition is due to an increasing number of respondents who refuse to continue to participate to the survey. Cycle Attrition rate. Cycle $2: 9.3 \%$. Cycle $3: 15.4 \%$. Cycle 4 : $21.4 \%$. Cycle $5: 27.4 \%$

\section{B.2 Weighting}

"Weight WT64LS is called the "square weight" and applies to the 17,276 members that make up the original longitudinal sample. All non-response should be taken into account for any calculation. Weight WT62LF is called the "Longitudinal Full" weight and applies to the 12,546 records that are included in the "Full" subset of respondents. Weight WT62LFE is called the "Longitudinal Full C1 and C5" weight and applies to the 13,629 records that are included in the "Full C1 and C5" subset of respondents. Weight WT62SLF is called "Longitudinal Full Share" weight and applies to the 12,226 respondents that are included in the "Full Share" subset of respondents." Source. Longitudinal Documentation, Cycle 5.

\section{B.3 Confidentiality}

"Confidentiality concerns preclude general dissemination of longitudinal NPHS data in public use microdata file (PUMF) format. However, access to all the longitudinal master microdata files including the Cycle 4 and Cycle 5 data (as well as access to the cross-sectional master microdata files, which exist for the first three cycles of the NPHS) is available through Statistics Canada's Research Data Centres (RDCs) program. (...) RDCs provide researchers with access, in a secure university setting, to microdata from population and household surveys. The centres are staffed by Statistics Canada employees. They are operated under the provisions of the Statistics Act in accordance with all the confidentiality rules and are accessible only to researchers with approved projects who have been sworn in as "deemed employees". RDCs are located throughout the country, so researchers do not need to travel to Ottawa to access Statistics Canada microdata. More information is available at the Research Data Centre Program web site: http://www.statcan.ca/english/rdc/index.htm.

A second option, if the RDCs are not accessible for the researcher, is Health Statistics Division's Remote Access service. This service provides researchers with a means to develop and test their own computer programs using synthetic files that mimic the actual master files. Researchers then submit their programs to a dedicated e-mail address. The programs are run against the master microdata files on an internal secure server, outputs are vetted for confidentiality, and sent back to the researcher by return e-mail. For more information on this service, please contact the Data Access team at nphsensp@statcan.ca."

\section{B.4 Match with local labor markets}

The NPHS survey includes detailed geographical variables: region of residence, census divisions, census sub-divisions and zip code. we matched the census divisions defining 382 local areas of size approximately 
80000 persons to variables extracted from the 1996 and 2001 census: local unemployment rate; local activity rate ; local density of population ; local share of male in the population ; and the growth rate of population between 1996 and 2001. Except for the last variables, we attributed the values of the 1996 Census to Cycle 1 and 2 ; the values of the 2001 Census to Cycles 4 and 5 ; and the mean of the two Census for Cycle 3. Future work will attempt to match individuals with the exact longitude and latitude.

\section{B.5 Clustering and s.e. corrections}

\section{B.5.1 Individual clustering}

In both the "subjective variable" approach and the "objective variable" approach, we have various problems with the covariance structure of error terms that must be discussed and solved. The first problem is that the panel structure of individuals leads to individual clustering, that is usually accounted for by within-panel clustering or random effects models. In general and unless specified, we use the Huber-White sandwich robust estimators augmented to account of cluster correlation.

\section{B.5.2 Regional clustering}

Since we use a provincial indicators of employment protection, the correlation of error terms within provinces may bias the s.e. of OLS estimates (Moulton 1986, 1987 and 1990, Moulton and Randolph 1989). See also technical Appendix 3 for a description of the covariance structure. We will use a pragmatic approach here: instead of programming a multi-level correction for clustering which turns out to be computationally too demanding at this stage ${ }^{29}$, we will present, in a robustness sub-section, the results of regional clustering correction ${ }^{30}$ in the two cross-sections available (2000 and 2002) and show that, overall, the within-region correlation in error terms does not appear to be a big problem.

\section{B.5.3 Correction of s.e. after imputation}

The imputation approach, whereby, in some robustness regressions, the level of EPL of a given individual is generated from another dataset, increases the variance of the explanatory variables but generates per se a number of additional issues: indeed, we now have two sources of randomness: error terms in equation (11) and error in the fitted variable. A standard method discussed in Little and Rubin (1987, chapter 12 ) is to bootstrap (here, 20 times) the imputation and estimate 20 times equation (11). The coefficients and s.e. are a weighted average of each individual estimate. All displayed t-stats of regressions using generated regressors are corrected according to their formula (see Appendix D.2). The same correction of standard errors will be applied to equation (13).

\section{References}

[1] Akerstedt, T., Knutsson, A., Westerholm, P., Theorell T., Alfredsson, L. and Keclung, G., J. (2002). "Sleep disturbances, work stress and work hours: a cross-sectional study", J. Psychosom. Res., Sept.:53(3), pp. 741-748

\footnotetext{
${ }^{29}$ See also Bertrand et al. (2004) on how to account for both intra-class and serial correlation, and Angrist and Lavy (2002) on the role of small number of clusters on the correction of s.e. It may be fruitful to rotate the various dimensions (time, states) of these diff-in-diff approaches to obtain a similar problem with intra-states and intra-individuals correlation in error terms.

${ }^{30}$ See Hoxby (2005), pp. 8-12 for a detailed discussion of the pros and cons of programming Moulton's (1986) corrected s.e. vs. the Stata robust cluster corrected standard errors. In short, while Moulton's strategy is more efficient in that it impose more structure to the covariance structure of error terms, it is less robust to additional forms of intraclass correlation. In large provinces such as in Canada, where moreover population density is extremely heterogeneous, it is probably better to be more flexible in terms of intraclass correlation.
} 
[2] Autor, David H., John J. Donohue III and Stewart J. Schwab (2006). "The Costs of WrongfulDischarge Laws", The Review of Economics and Statistics, May, 88(2), pp. 211-231.

[3] Allen, Steven, G. (1981). "An Empirical Model of Work Attendance", The Review of Economics and Statistics, Vol. 63, No1 (Feb.), pp. 77-87.

[4] Alonso, J., Angermeyer C., Bernert S., Bruffaerts, R., Brugha, T.S", Bryson, H., de Girolamo, de Graaf, R., Demyttenaere, K., Gasquet, I., Haro, J.M., Katz, S.J., Kessler, R.C., Kovess, V., Lépine, J.P., Ormel, J., Polidori, G., Russo, L.J., Vilagut, J. et al. (2004). "Psychotropic drug utilization in Europe: results from the European Study of the Epidemiology of Mental Disorders (ESEMeD) project", Acta Psychatrica Scandinavia 2004:109 (Suppl. 420), PP. 55-64

[5] Angrist, Joshua D. and Victor Lavy. (2002). "The Effect of High School Matriculation Awards: Evidence from Randomized Trials", NBER working paper 9389

[6] Bertrand, Marianne, Esther Duflo and Sendhil Mullainathan; "How Much Should We Trust Differences-in-Differences Estimates?" Quarterly Journal of Economics, 2004, 119(1), pp. 249-75.

[7] Blanchard, Olivier. J. and Philippon, Thomas. (2004). "The Quality of Labor Relations and Unemployment", NBEr wp 10590

[8] Blanchard, Olivier. J. and Philippon, Thomas. (2006). "Trust, Strikes and Unemployment", mimeo, MIT

[9] Burda, M. (1992), "A Note on Firing Costs and Severance Benefits in Equilibrium Unemployment" Scandinavian Journal of Economics, 94, pp. 479-89.

[10] Clark, Andrew and Postel-Vinay, Fabien. (2005). "Job Security and Job Protection", mimeo PSEJourdan

[11] Clemens, Jason, Karabegovic, Amela and Veldhuis Niels. (2003). "Measuring Labour Markets in Canada and the United States, 2003 Edition", a report of the Fraser Institute, August.

[12] Deloffre, Alexandre and Rioux, Laurence. (2004). "Do workers correctly evaluate their job security? A European comparison", mimeo, CERC

[13] DREES (Elise Amar and Didier Balsan). "Les ventes d'anti-dépresseurs entre 1980 et 2001", wp. DREE 36, Oct. 2003.

[14] Frese, Michael. (1985). "Stress at work and psychosomatic complaints: A causal interpretation", Journal of Applied Psychology, May, Vol. 70(2), pp.314-328.

[15] Friesen, Jane. (1997). "Mandatory Notice and the Jobless Durations of Displaced Workers", Industrial and Labor Relations Review, Vol. 50, No 4., July, pp. 652-666

[16] Friesen, Jane, Kuhn, Peter, et al. (1997). "Jobs and Labour Market Policy: A Strategic Scan of International Research", report for the Human Resources Directorate, Gov. of Canada

[17] Galdòn-Sànchez, José E. and Güell, Maia, (2003). "Dismissal conflicts and unemployment", European Economic Review 47, pp. 323-335.

[18] Garibaldi, Pietro. (1998). "Job Flow Dynamics and Firing Restrictions", European Economic Review, Vol. 42 Num 2., pp. 245-75.

[19] Hamermesh, Daniel S. (2004). "Subjective Outcomes in Economics", NBER wp. 10361, forthcoming, Southern Economic Journal.

[20] Hoxby, Caroline (2005). "Competition among public schools: a reply to Rothstein (2004)", NBER w.p. 11216, March.

[21] Lazear, Edward P. (1990). "Job Security Provisions and Employment", Quarterly Journal of Economics, $105: 3$, pp. $699-726$ 
[22] Lépine, J.P., Gastpar, M., Mendlewicz, J. and Tylee, A. (1997). "Depression in the Community: the first pan-European study DEPRES (Depression Research in European Society), Int. Clinical Psychopharmacology, Jan: 12(1), pp. 19-29

[23] Little, R.J.A. and Rubin, D.B. (1987). Statistical Analysis with Missing Data. New York: John Wiley.

[24] Mortensen, Dale T. and Christopher A. Pissarides (1999). "Job Reallocation, Employment Fluctuations and Unemployment", Handbook of Macroeconomics,, J. Taylor and M. Woodford (eds.) Amsterdam,: North-Holland.

[25] Moulton, Brent R., "Random group effects and the precision of regression estimates", Journal of Econometrics, Volume 32, Issue 3, August 1986, Pages 385-397

[26] Moulton, Brent R., 1987. "Diagnostics for Group Effects in Regression Analysis," Journal of Business \& Economic Statistics, American Statistical Association, vol. 5(2), pages 275-82.

[27] Moulton, Brent R., "An Illustration of a Pitfall in Estimating the Effects of Aggregate Variables on Micro Units", The Review of Economics and Statistics, Vol. 72, No. 2 (May, 1990), pp. 334-338

[28] Moulton, Brent R. \& Randolph, William C, 1989. "Alternative Tests of the Error Components Model" Econometrica, vol. 57(3), pages 685-93.

[29] Murphy, K. and R. Topel (1985), "Estimation and inference in two step econometric models", Journal of Business and Economic Statistics 3, 370-379.

[30] Pepper, John V. "Robust inferences from random clustered samples: an application using data from the panel study of income dynamics", Economics Letters Volume 75, Issue 3 , May 2002, Pages $341-345$

[31] Postel-Vinay, Fabien and Saint-Martin, Anne. (2004). "Comment les salariés perçoivent la protection de l'emploi...", forthcoming, Economie et Statistiques.

[32] Kugler, Adriana and Saint-Paul, Gilles.(2004). "How Do Firing Costs Affect Worker Flows in a Word with Adverse Selection", Journal of Labor Economics, 22:3, pp. 553-584

[33] Seiler-Van Daal B. (2000). "Evaluation du harcèlement moral (enquête dans une population de 1210 salariés et exploitation dans le but de construire un outil de dépistage)", Thèse de Doctorat en Médecine, Strasbourg.

[34] Shapiro M. and Stiglitz Joseph. (1984). "Unemployment as a Monitoring Device", American Economic Review, 74 (1984) June, pp. 433-44

[35] Wasmer, E. (2006). "General vs. Specific Skills in Labor Markets with Search Frictions and Firing Costs", American Economic Review, June, Volume 96(3), pp 811-831.

[36] Wooldridge, Jeffrey M. "Cluster-Sample Methods in Applied Econometrics," American Economic Review 93(2), 133-138, papers and proceedings, May 2003.

[37] Wooldridge, Jeffrey M. Econometric Analysis of Cross-Section and Panel Data, MIT Press, 2002. 
Table 1. Various sample statistics

\begin{tabular}{|c|c|c|c|}
\hline & Mean & s.d. & \\
\hline Male & 49.7 & & \\
\hline Immigrants & 19.6 & & \\
\hline Urban area & 81.4 & & \\
\hline Age $(\mu)$ & 43.3 & $(10.9)$ & \\
\hline Household size $(\mu)$ & 3.06 & $(1.39)$ & \\
\hline Primary education & 17.8 & & \\
\hline Secondary education & 15.5 & & \\
\hline Some post seconsdary education. & 26.6 & & \\
\hline Tertiary & 40.7 & & \\
\hline Trauma (0-7) & 1.06 & $(1.23)$ & \\
\hline No medical insurance & 0.23 & & \\
\hline Psychotropic drugs & yes & no & missing \\
\hline 1.Tranquilizer & 0.030 & 0.947 & 0.030 \\
\hline 2.Anti-depressant & 0.047 & 0.930 & 0.023 \\
\hline 3.Sleeping pill & 0.034 & 0.943 & 0.026 \\
\hline Yes to one psychotropic drug & 0.085 & & \\
\hline Other variables & mean & sd. & \\
\hline Depression (score, 0-8) & 0.38 & $(1.44)$ & \\
\hline Depression (proba, 0-1) & 0.058 & $(0.22)$ & \\
\hline Blood pressure & 0.095 & $(0.29)$ & \\
\hline Overall (0-48) & 10.42 & $(4.33)$ & \\
\hline Stress from skill requirement $(0-12)$ & 4.78 & $(2.20)$ & \\
\hline Stress from decision lattitude $(0-8)$ & 2.53 & $(1.64)$ & \\
\hline Stress from psychological demands $(0-8)$ & 4.52 & $(1.71)$ & \\
\hline Stress from physical exertion $(0-4)$ & 1.84 & $(1.22)$ & \\
\hline Stress from job insecurity $(0-4)$ & 1.24 & $(0.96)$ & \\
\hline Stress from supervisor or coworkers $(0-12)$ & 4.12 & $(1.29)$ & \\
\hline Stress from job strain strain $(0.2-5)$ & 0.95 & $(0.31)$ & \\
\hline Imputed EPL variables (from EPA-LFS) & mean & sd. & \\
\hline EPL_ind & 4.18 & $(2.88)$ & \\
\hline EPL_coll & 6.14 & $(4.60)$ & \\
\hline $\mathrm{EPL}_{-}^{-}$ind ${ }^{(a)}$ & 4.06 & $(2.96)$ & \\
\hline $\mathrm{EPL}^{-} \operatorname{coll}^{(a)}$ & 5.80 & $(4.65)$ & \\
\hline
\end{tabular}

notice in this case. 
Table 2. Baseline regressions for overall stress

\begin{tabular}{|c|c|c|c|c|c|}
\hline $\begin{array}{l}\text { Estimation } \\
\text { Dep. variable: }\end{array}$ & "robust LS & R.E. & $\begin{array}{c}\text { adds union } \\
\text { stress }\end{array}$ & $\begin{array}{l}\text { adds cycle } 1 \\
\text { wrk }\end{array}$ & adds Ind.* Occ. \\
\hline EPL_ind & $\begin{array}{c}0.243 \\
(3.2)^{* * *} \\
{[3.7]^{* * *}}\end{array}$ & $\begin{array}{c}0.176 \\
(3.3)^{* * *}\end{array}$ & $\begin{array}{c}0.222 \\
(2.9)^{* * *} \\
{[3.3]^{* * *}}\end{array}$ & $\begin{array}{c}0.174 \\
(2.7)^{* * *} \\
{[3.2]^{* * *}}\end{array}$ & $\begin{array}{c}0.193 \\
(2.4)^{* *} \\
{[2.7]^{* * *}}\end{array}$ \\
\hline EPL_coll & $\begin{array}{l}0.023 \\
(1.5) \\
{[1.8]^{*}}\end{array}$ & $\begin{array}{l}0.021 \\
(1.9)^{*}\end{array}$ & $\begin{array}{l}0.025 \\
(1.6) \\
{[1.8]^{*}}\end{array}$ & $\begin{array}{l}0.023 \\
(1.8)^{*} \\
{[2.2]^{* *}}\end{array}$ & $\begin{array}{l}0.018 \\
(1.2) \\
{[1.3]}\end{array}$ \\
\hline Trauma & $\begin{array}{c}0.300 \\
(6.0)^{* * *} \\
{[6.9]^{* * *}}\end{array}$ & $\begin{array}{c}0.284 \\
(7.4)^{* * *}\end{array}$ & $\begin{array}{c}0.300 \\
(6.0)^{* * *} \\
{[6.9]^{* * *}}\end{array}$ & $\begin{array}{c}0.401 \\
(8.9)^{* * *} \\
{[10.5]^{* * *}}\end{array}$ & $\begin{array}{c}0.298 \\
(6.1)^{* * *} \\
{[6.9]^{* * *}}\end{array}$ \\
\hline Sex & $\begin{array}{c}-0.103 \\
(0.7) \\
{[0.8]}\end{array}$ & $\begin{array}{c}-0.016 \\
(0.1)\end{array}$ & $\begin{array}{c}-0.104 \\
(0.7) \\
{[0.8]}\end{array}$ & $\begin{array}{c}-0.030 \\
(0.2) \\
{[0.3]}\end{array}$ & $\begin{array}{c}-0.088 \\
(0.6) \\
{[0.7]}\end{array}$ \\
\hline Urban & $\begin{array}{l}0.001 \\
(0.0) \\
{[0.0]}\end{array}$ & $\begin{array}{c}0.015 \\
(0.2)\end{array}$ & $\begin{array}{l}0.001 \\
(0.0) \\
{[0.0]}\end{array}$ & $\begin{array}{c}-0.027 \\
(0.2) \\
{[0.3]}\end{array}$ & $\begin{array}{c}-0.024 \\
(0.2) \\
{[0.2]}\end{array}$ \\
\hline EducD1 & $\begin{array}{l}0.280 \\
(0.3) \\
{[0.3]}\end{array}$ & ref. & ref. & ref. & ref. \\
\hline EducD2 & $\begin{array}{c}-0.367 \\
(0.4) \\
{[0.5]}\end{array}$ & $\begin{array}{c}-1.172 \\
(1.5)\end{array}$ & $\begin{array}{c}-0.618 \\
(0.8) \\
{[0.8]}\end{array}$ & $\begin{array}{c}-0.472 \\
(0.3) \\
{[0.3]}\end{array}$ & $\begin{array}{l}0.960 \\
(1.2) \\
{[1.3]}\end{array}$ \\
\hline EducD3 & $\begin{array}{c}-0.580 \\
(0.7) \\
{[0.9]}\end{array}$ & $\begin{array}{c}-1.063 \\
(1.6)\end{array}$ & $\begin{array}{c}-0.828 \\
(1.2) \\
{[1.2]}\end{array}$ & $\begin{array}{c}-0.499 \\
(0.4) \\
{[0.4]}\end{array}$ & $\begin{array}{l}0.723 \\
(1.0) \\
{[1.2]}\end{array}$ \\
\hline EducD4 & $\begin{array}{c}-0.388 \\
(0.5) \\
{[0.6]}\end{array}$ & $\begin{array}{c}-0.661 \\
(1.0)\end{array}$ & $\begin{array}{c}-0.640 \\
(0.9) \\
{[0.9]}\end{array}$ & $\begin{array}{c}-0.117 \\
(0.1) \\
{[0.1]}\end{array}$ & $\begin{array}{l}0.922 \\
(1.3) \\
{[1.5]}\end{array}$ \\
\hline EducD5 & $\begin{array}{c}-0.214 \\
(0.2) \\
{[0.3]}\end{array}$ & $\begin{array}{c}-0.106 \\
(0.1)\end{array}$ & $\begin{array}{c}-0.465 \\
(0.5) \\
{[0.6]}\end{array}$ & $\begin{array}{l}0.120 \\
(0.1) \\
{[0.1]}\end{array}$ & $\begin{array}{l}1.078 \\
(1.3) \\
{[1.5]}\end{array}$ \\
\hline EducD6 & $\begin{array}{c}-0.179 \\
(0.2) \\
{[0.3]}\end{array}$ & $\begin{array}{c}-0.429 \\
(0.7)\end{array}$ & $\begin{array}{c}-0.427 \\
(0.6) \\
{[0.6]}\end{array}$ & $\begin{array}{c}0.206 \\
(0.2) \\
{[0.2]}\end{array}$ & $\begin{array}{l}1.217 \\
(1.7)^{*} \\
{[2.0]^{* *}}\end{array}$ \\
\hline EducD7 & $\begin{array}{c}-0.262 \\
(0.3) \\
{[0.4]}\end{array}$ & $\begin{array}{c}-0.284 \\
(0.4)\end{array}$ & $\begin{array}{c}-0.513 \\
(0.7) \\
{[0.7]}\end{array}$ & $\begin{array}{l}0.154 \\
(0.1) \\
{[0.1]}\end{array}$ & $\begin{array}{l}1.250 \\
(1.7)^{*} \\
{[2.0]^{* *}}\end{array}$ \\
\hline EducD8 & $\begin{array}{c}-0.573 \\
(0.7) \\
{[0.9]}\end{array}$ & $\begin{array}{c}-0.621 \\
(0.9)\end{array}$ & $\begin{array}{c}-0.828 \\
(1.1) \\
{[1.2]}\end{array}$ & $\begin{array}{c}-0.169 \\
(0.1) \\
{[0.1]}\end{array}$ & $\begin{array}{l}0.694 \\
(0.9) \\
{[1.1]}\end{array}$ \\
\hline
\end{tabular}


Table 2. Baseline regressions for overall stress (continued)

\begin{tabular}{|c|c|c|c|c|c|}
\hline EducD9 & $\begin{array}{c}-0.042 \\
(0.1) \\
{[0.1]}\end{array}$ & $\begin{array}{c}-0.434 \\
(0.7)\end{array}$ & $\begin{array}{c}-0.290 \\
(0.4) \\
{[0.4]}\end{array}$ & $\begin{array}{c}0.136 \\
(0.1) \\
{[0.1]}\end{array}$ & $\begin{array}{c}1.293 \\
(1.8)^{*} \\
{[2.1]^{* *}}\end{array}$ \\
\hline EducD10 & $\begin{array}{c}-0.077 \\
(0.1) \\
{[0.1]}\end{array}$ & $\begin{array}{c}-0.176 \\
(0.3)\end{array}$ & $\begin{array}{c}-0.328 \\
(0.4) \\
{[0.5]}\end{array}$ & $\begin{array}{l}0.270 \\
(0.2) \\
{[0.2]}\end{array}$ & $\begin{array}{c}1.415 \\
(2.0)^{* *} \\
{[2.3]^{* *}}\end{array}$ \\
\hline EducD11 & $\begin{array}{l}0.049 \\
(0.1) \\
{[0.1]}\end{array}$ & $\begin{array}{c}-0.195 \\
(0.3)\end{array}$ & $\begin{array}{c}-0.202 \\
(0.3) \\
{[0.3]}\end{array}$ & $\begin{array}{l}0.453 \\
(0.3) \\
{[0.3]}\end{array}$ & $\begin{array}{c}1.438 \\
(2.0)^{* *} \\
{[2.4]^{* *}}\end{array}$ \\
\hline EducD12 & $\begin{array}{c}-0.524 \\
(0.7) \\
{[0.8]}\end{array}$ & $\begin{array}{c}-0.943 \\
(1.3)\end{array}$ & $\begin{array}{c}-0.770 \\
(1.0) \\
{[1.1]}\end{array}$ & $\begin{array}{c}0.114 \\
(0.1) \\
{[0.1]}\end{array}$ & $\begin{array}{l}0.784 \\
(1.1) \\
{[1.2]}\end{array}$ \\
\hline EducD13 & ref. & $\begin{array}{c}0.373 \\
(0.4)\end{array}$ & $\begin{array}{c}-0.258 \\
(0.3) \\
{[0.3]}\end{array}$ & $\begin{array}{c}0.243 \\
(0.2) \\
{[0.2]}\end{array}$ & $\begin{array}{c}0.000 \\
(.) \\
{[.]}\end{array}$ \\
\hline EducD14 & $\begin{array}{c}0.216 \\
(0.2) \\
{[0.3]}\end{array}$ & $\begin{array}{c}-0.323 \\
(0.4)\end{array}$ & $\begin{array}{c}-0.033 \\
(0.0) \\
{[0.0]}\end{array}$ & $\begin{array}{c}0.475 \\
(0.3) \\
{[0.3]}\end{array}$ & $\begin{array}{l}1.180 \\
(1.2) \\
{[1.4]}\end{array}$ \\
\hline Immi $<10$ yrs. & $\begin{array}{c}-0.917 \\
(1.2) \\
{[1.2]}\end{array}$ & $\begin{array}{c}-0.681 \\
(0.9)\end{array}$ & $\begin{array}{c}-0.928 \\
(1.2) \\
{[1.2]}\end{array}$ & $\begin{array}{c}-0.206 \\
(0.3) \\
{[0.3]}\end{array}$ & $\begin{array}{c}-0.678 \\
(0.9) \\
{[0.9]}\end{array}$ \\
\hline $\operatorname{Immi}>=10$ yrs. & $\begin{array}{c}-0.000 \\
(0.0) \\
{[0.0]}\end{array}$ & $\begin{array}{c}-0.276 \\
(0.4)\end{array}$ & $\begin{array}{c}-0.008 \\
(0.0) \\
{[0.0]}\end{array}$ & $\begin{array}{c}-0.029 \\
(0.0) \\
{[0.1]}\end{array}$ & $\begin{array}{c}-0.037 \\
(0.1) \\
{[0.1]}\end{array}$ \\
\hline Gr. Age 2 & $\begin{array}{c}1.671 \\
(5.0)^{* * *} \\
{[5.3]^{* * *}}\end{array}$ & $\begin{array}{c}1.617 \\
(6.5)^{* * *}\end{array}$ & $\begin{array}{c}1.667 \\
(5.0)^{* * *} \\
{[5.3]^{* * *}}\end{array}$ & $\begin{array}{c}1.983 \\
(7.3)^{* * *} \\
{[7.6]^{* * *}}\end{array}$ & $\begin{array}{c}1.344 \\
(4.1)^{* * *} \\
{[4.3]^{* * *}}\end{array}$ \\
\hline Gr. Age 3 & $\begin{array}{c}1.804 \\
(5.7)^{* * *} \\
{[6.0]^{* * *}}\end{array}$ & $\begin{array}{c}1.690 \\
(6.9)^{* * *}\end{array}$ & $\begin{array}{c}1.803 \\
(5.7)^{* * *} \\
{[6.0]^{* * *}}\end{array}$ & $\begin{array}{c}2.159 \\
(8.3)^{* * *} \\
{[8.7]^{* * *}}\end{array}$ & $\begin{array}{c}1.492 \\
(4.7)^{* * *} \\
{[5.0]^{* * *}}\end{array}$ \\
\hline Gr. Age 4 & $\begin{array}{c}2.108 \\
(6.8)^{* * *} \\
{[7.2]^{* * *}}\end{array}$ & $\begin{array}{c}1.830 \\
(7.5)^{* * *}\end{array}$ & $\begin{array}{c}2.107 \\
(6.8)^{* * *} \\
{[7.2]^{* * *}}\end{array}$ & $\begin{array}{c}2.203 \\
(8.5)^{* * *} \\
{[8.9]^{* * *}}\end{array}$ & $\begin{array}{c}1.733 \\
(5.6)^{* * *} \\
{[5.9]^{* * *}}\end{array}$ \\
\hline Gr. Age 5 & $\begin{array}{c}1.840 \\
(5.9)^{* * *} \\
{[6.3]^{* * *}}\end{array}$ & $\begin{array}{c}1.727 \\
(7.2)^{* * *}\end{array}$ & $\begin{array}{c}1.840 \\
(5.9)^{* * *} \\
{[6.3]^{* * *}}\end{array}$ & $\begin{array}{c}1.933 \\
(7.5)^{* * *} \\
{[7.8]^{* * *}}\end{array}$ & $\begin{array}{c}1.532 \\
(4.9)^{* * *} \\
{[5.2]^{* * *}}\end{array}$ \\
\hline Gr. Age 6 & $\begin{array}{c}1.635 \\
(5.3)^{* * *} \\
{[5.6]^{* * *}}\end{array}$ & $\begin{array}{c}1.626 \\
(6.8)^{* * *}\end{array}$ & $\begin{array}{c}1.636 \\
(5.3)^{* * *} \\
{[5.6]^{* * *}}\end{array}$ & $\begin{array}{c}1.582 \\
(6.1)^{* * *} \\
{[6.4]^{* * *}}\end{array}$ & $\begin{array}{c}1.431 \\
(4.7)^{* * *} \\
{[5.0]^{* * *}}\end{array}$ \\
\hline
\end{tabular}


Table 2. Baseline regressions for overall stress (continued)

\begin{tabular}{|c|c|c|c|c|c|}
\hline Gr. Age 7 & $\begin{array}{c}1.551 \\
(5.0)^{* * *} \\
{[5.3]^{* * *}}\end{array}$ & $\begin{array}{c}1.480 \\
(6.2)^{* * *}\end{array}$ & $\begin{array}{c}1.551 \\
(5.0)^{* * *} \\
{[5.3]^{* * *}}\end{array}$ & $\begin{array}{c}1.569 \\
(6.1)^{* * *} \\
{[6.3]^{* * *}}\end{array}$ & $\begin{array}{c}1.351 \\
(4.4)^{* * *} \\
{[4.6]^{* * *}}\end{array}$ \\
\hline Gr. Age 8 & $\begin{array}{c}0.711 \\
(2.3)^{* *} \\
{[2.4]^{* *}}\end{array}$ & $\begin{array}{c}0.802 \\
(3.4)^{* * *}\end{array}$ & $\begin{array}{c}0.713 \\
(2.3)^{* *} \\
{[2.4]^{* *}}\end{array}$ & $\begin{array}{c}0.769 \\
(3.0)^{* * *} \\
{[3.0]^{* * *}}\end{array}$ & $\begin{array}{l}0.500 \\
(1.6) \\
{[1.7]^{*}}\end{array}$ \\
\hline Union density & - & - & $\begin{array}{c}-0.667 \\
(0.53) \\
{[0.6]}\end{array}$ & - & - \\
\hline 2000 & ref. & $\begin{array}{c}-0.005 \\
(0.1)\end{array}$ & - & $\begin{array}{c}-0.498 \\
(5.2)^{* * *} \\
{[4.7]^{* * *}}\end{array}$ & - \\
\hline 2002 & $\begin{array}{c}0.005 \\
(0.1) \\
{[0.1]}\end{array}$ & ref. & $\begin{array}{c}0.005 \\
(0.1) \\
{[0.0]}\end{array}$ & $\begin{array}{c}-0.472 \\
(4.4)^{* * *} \\
{[4.2]^{* * *}}\end{array}$ & $\begin{array}{c}0.013 \\
(0.1) \\
{[0.1]}\end{array}$ \\
\hline Constant & $\begin{array}{c}14.6 \\
(6.4)^{* * *} \\
{[6.7]^{* * *}}\end{array}$ & $\begin{array}{c}21.1 \\
(16.1)^{* * *}\end{array}$ & $\begin{array}{c}15.5 \\
(7.8)^{* * *} \\
{[7.9]^{* * *}}\end{array}$ & $\begin{array}{c}20.7 \\
(12.4)^{* * *} \\
{[13.3]^{* * *}}\end{array}$ & $\begin{array}{c}10.1 \\
(6.7)^{* * *} \\
{[7.4]^{* * *}}\end{array}$ \\
\hline Birth continent (D1-D7) & Yes & Yes & Yes & Yes & Yes \\
\hline Living arrangement (D1-D7) & Yes & Yes & Yes & Yes & Yes \\
\hline Household type (D1-D6) & Yes & Yes & Yes & Yes & Yes \\
\hline Household size (D1-D9) & Yes & Yes & Yes & Yes & Yes \\
\hline Industry (D1-D16) & Yes & Yes & Yes & Yes & No \\
\hline Occupation (D1-D47) & Yes & Yes & Yes & Yes & No \\
\hline Ind. * Occ. (D1-D342) & No & No & No & No & Yes \\
\hline Observations & 11421 & 11421 & 11421 & 17069 & 11421 \\
\hline R-squared & 0.08 & - & 0.08 & 0.09 & 0.12 \\
\hline Number of clusters & 6752 & 6752 & 6752 & 8386 & 6752 \\
\hline
\end{tabular}


Table 3. Impact of EPL on stress when ELP is imputed thanks to EPA-LFS survey

\begin{tabular}{|c|c|c|c|c|c|}
\hline $\begin{array}{l}\text { Estimation. } \\
\text { Dep. variable: }\end{array}$ & "robust LS & R.E. & $\begin{array}{c}\text { adds union } \\
\text { stress }\end{array}$ & $\begin{array}{l}\text { adds cycle } 1 \\
\text { wrk }\end{array}$ & "adds Ind. ${ }^{*}$ Occ. \\
\hline EPL_ind_fit & $\begin{array}{c}0.187 \\
(3.0)^{* * *} \\
{[3.4]^{* * *}}\end{array}$ & $\begin{array}{c}0.128 \\
(2.8)^{* * *}\end{array}$ & $\begin{array}{c}0.163 \\
(2.6)^{* * *} \\
{[3.0]^{* * *}}\end{array}$ & $\begin{array}{c}0.126 \\
(2.3)^{* *} \\
{[2.8]^{* * *}}\end{array}$ & $\begin{array}{c}0.169 \\
(2.5)^{* *} \\
{[2.9]^{* * *}}\end{array}$ \\
\hline EPL_coll_fit & $\begin{array}{c}0.013 \\
(0.8) \\
{[0.9]}\end{array}$ & $\begin{array}{l}0.017 \\
(1.3)\end{array}$ & $\begin{array}{l}0.022 \\
(1.2) \\
{[1.4]}\end{array}$ & $\begin{array}{l}0.019 \\
(1.3) \\
{[1.5]}\end{array}$ & $\begin{array}{l}0.018 \\
(1.0) \\
{[1.2]}\end{array}$ \\
\hline Observations & 11421 & 11421 & 11421 & 11421 & 17069 \\
\hline $\mathrm{R}^{2}$ & 0.08 & - & 0.08 & 0.12 & 0.12 \\
\hline Number of clusters & 6752 & 6752 & 6752 & 6752 & 6752 \\
\hline
\end{tabular}

Table 4. Regional clustering \& variable clustering

\begin{tabular}{|c|c|c|c|c|}
\hline $\begin{array}{l}\text { Estimation } \\
\text { Cross-sections: } \\
\text { Dep. variable: }\end{array}$ & $\begin{array}{l}\text { robust LS } \\
2000 \& 2002 \\
\text { stress_wrk }\end{array}$ & $\begin{array}{l}\text { robust LS } \\
2000 \\
\text { stress_wrk }\end{array}$ & $\begin{array}{l}\text { robust LS } \\
2002 \\
\text { stress_wrk }\end{array}$ & $\begin{array}{c}\text { two-step } \\
2000 \& 2002 \\
\text { reg. dummies } \\
\text { from first stage }\end{array}$ \\
\hline \multirow[t]{2}{*}{$\mathrm{EPL}$ _ind } & $\begin{array}{c}0.243 \\
(3.43)^{* * *}\end{array}$ & $\begin{array}{c}0.298 \\
(5.48)^{* * *}\end{array}$ & $\begin{array}{c}0.193 \\
(2.04)^{* *}\end{array}$ & $\begin{array}{l}0.207 \\
-\end{array}$ \\
\hline & {$[3.71]^{* * *}$} & {$[3.39]^{* * *}$} & {$[1.97]^{* *}$} & {$[2.40]^{* *}$} \\
\hline \multirow[t]{3}{*}{ EPL_coll } & 0.023 & 0.023 & 0.024 & 0.034 \\
\hline & $(2.32)$ & $(2.82)^{* * *}$ & (1.14) & - \\
\hline & {$[1.76]^{*}$} & [1.33] & {$[1.27]$} & {$[1.83]^{*}$} \\
\hline Observations & 11421 & 5942 & 5479 & 10 \\
\hline R-squared & 0.08 & 0.09 & 0.09 & 0.53 \\
\hline Number of clusters & 10 & 10 & 10 & - \\
\hline
\end{tabular}


Table 5. Sub components of stress

\begin{tabular}{|c|c|c|c|c|c|c|c|c|}
\hline 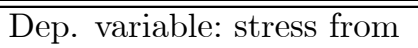 & "Work (total) & Skills need & Latitude dec. & Psych. demands & Job insec. & Phy. exertion & Superv.-cowk & Job strain \\
\hline \multirow[t]{3}{*}{ EPL_ind } & 0.257 & -0.014 & 0.039 & 0.186 & -0.034 & 0.037 & -0.019 & 0.028 \\
\hline & $(3.4)^{* * *}$ & $(0.4)$ & (1.4) & $(6.2)^{* * *}$ & $(2.0)^{* *}$ & $(2.0)^{* *}$ & $(0.6)$ & $(5.4)^{* * *}$ \\
\hline & {$[3.9]^{* * *}$} & {$[0.5]$} & [1.6] & {$[7.1]^{* * *}$} & {$[2.3]^{* *}$} & {$[2.3]^{* *}$} & {$[0.7]$} & {$[5.9]^{* * *}$} \\
\hline \multirow[t]{3}{*}{ EPL_coll } & 0.023 & -0.008 & 0.006 & -0.025 & 0.009 & -0.013 & 0.043 & -0.003 \\
\hline & $(1.5)$ & (1.3) & (1.1) & $(4.3)^{* * *}$ & $(2.7)^{* * *}$ & $(3.5)^{* * *}$ & $(7.0)^{* * *}$ & $(3.1)^{* * *}$ \\
\hline & {$[1.8]^{*}$} & [1.5] & [1.3] & {$[4.9]^{* * *}$} & {$[2.9]^{* * *}$} & {$[4.1]^{* * *}$} & {$[7.6]^{* * *}$} & {$[3.5]^{* * *}$} \\
\hline \multirow[t]{3}{*}{ Sex } & -0.072 & 0.557 & 0.477 & 0.080 & 0.088 & -0.084 & -0.172 & 0.073 \\
\hline & $(0.5)$ & $(8.2)^{* * *}$ & $(8.9)^{* * *}$ & (1.4) & $(2.7)^{* * *}$ & $(2.3)^{* *}$ & $(2.8)^{* * *}$ & $(7.0)^{* * *}$ \\
\hline & {$[0.5]$} & {$[9.5]^{* * *}$} & {$[10.1]^{* * *}$} & {$[1.6]$} & {$[3.0]^{* * *}$} & {$[2.7]^{* * *}$} & {$[3.0]^{* * *}$} & {$[7.7]^{* * *}$} \\
\hline Observations & 11224 & 11340 & 11335 & 11326 & 11332 & 11344 & 11258 & 11315 \\
\hline R-squared & 0.08 & 0.32 & 0.18 & 0.10 & 0.06 & 0.34 & 0.04 & 0.11 \\
\hline Number of clusters & 6696 & 6715 & 6714 & 6713 & 6714 & 6716 & 6702 & 6710 \\
\hline \multicolumn{9}{|c|}{ Adding regional union density } \\
\hline Dep. variable: stress from & Work (total) & Skill need & Latitude dec. & Psych. demands & Job insec. & Phy. exertion & Superv.-cowk & Job strain \\
\hline \multirow{3}{*}{ EPL_ind } & 0.248 & -0.038 & 0.008 & 0.094 & 0.007 & 0.002 & 0.079 & 0.014 \\
\hline & $(3.2)^{* * *}$ & $(1.2)$ & $(0.3)$ & $(3.0)^{* * *}$ & $(0.4)$ & $(0.1)$ & $(2.4)^{* *}$ & $(2.6)^{* * *}$ \\
\hline & {$[3.6]^{* * *}$} & [1.4] & {$[0.3]$} & {$[3.5]^{* * *}$} & {$[0.5]$} & {$[0.1]$} & {$[2.6]^{* * *}$} & {$[2.9]^{* * *}$} \\
\hline \multirow{3}{*}{ EPL_coll } & 0.024 & -0.005 & 0.010 & -0.014 & 0.003 & -0.008 & 0.031 & -0.001 \\
\hline & $(1.5)$ & $(0.8)$ & $(1.7)^{*}$ & $(2.2)^{* *}$ & $(1.0)$ & $(2.1)^{* *}$ & $(4.5)^{* * *}$ & $(1.3)$ \\
\hline & {$[1.7]^{*}$} & {$[0.9]$} & {$[1.9]^{*}$} & {$[2.5]^{* *}$} & [1.1] & {$[2.4]^{* *}$} & {$[5.0]^{* * *}$} & [1.4] \\
\hline \multirow[t]{3}{*}{ Sex } & -0.073 & 0.555 & 0.474 & 0.072 & 0.092 & -0.088 & -0.162 & 0.072 \\
\hline & $(0.5)$ & $(8.2)^{* * *}$ & $(8.9)^{* * *}$ & (1.3) & $(2.8)^{* * *}$ & $(2.4)^{* *}$ & $(2.6)^{* * *}$ & $(6.9)^{* * *}$ \\
\hline & {$[0.6]$} & {$[9.5]^{* * *}$} & {$[10.1]^{* * *}$} & [1.4] & {$[3.1]^{* * *}$} & {$[2.8]^{* * *}$} & {$[2.8]^{* * *}$} & {$[7.6]^{* * *}$} \\
\hline \multirow[t]{3}{*}{ Union density } & -0.301 & -0.747 & -0.958 & -2.852 & 1.298 & -1.099 & 3.052 & -0.436 \\
\hline & $(0.2)$ & (1.4) & $(2.2)^{* *}$ & $(5.8)^{* * *}$ & $(4.5)^{* * *}$ & $(3.7)^{* * *}$ & $(5.7)^{* * *}$ & $(5.1)^{* * *}$ \\
\hline & {$[0.3]$} & {$[1.6]$} & {$[2.4]^{* *}$} & {$[6.5]^{* * *}$} & {$[5.1]^{* * *}$} & {$[4.2]^{* * *}$} & {$[6.3]^{* * *}$} & {$[5.6]^{* * *}$} \\
\hline Observations & 11224 & 11340 & 11335 & 11326 & 11332 & 11344 & 11258 & 11315 \\
\hline R-squared & 0.08 & 0.32 & 0.18 & 0.11 & 0.06 & 0.34 & 0.05 & 0.11 \\
\hline Number of clusters & 6696 & 6715 & 6714 & 6713 & 6714 & 6716 & 6702 & 6710 \\
\hline
\end{tabular}

at $10 \%$; $* *$ significant at $5 \%$; *** significant at $1 \%$; Other controls: same as listed in table 2 (age, urbanicity, family, education, immigration,

birth place, year, industry, occupation, + body weight dummies). See the text for the full description of left handside variables. 
Table 6. "Base" questions

\begin{tabular}{|c|c|c|c|c|c|c|c|}
\hline "Dep. variable: & "No learning & " No high skills & $\bar{~}_{\text {No } \text { freedom }^{(a)}}$ & No repetitivity & Not hectic & Conflicting & 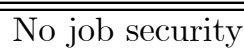 \\
\hline \multirow[t]{3}{*}{ EPL_ind } & -0.055 & -0.052 & 0.012 & -0.001 & -0.088 & 0.086 & 0.012 \\
\hline & $(1.6)$ & $(1.4)$ & $(0.8)$ & $(0.0)$ & $(2.5)^{* *}$ & $(2.6)^{* *}$ & $(0.3)$ \\
\hline & {$[1.8]^{*}$} & {$[1.6]$} & {$[0.8]$} & {$[0.0]$} & {$[2.9]^{* * *}$} & {$[2.8]^{* * *}$} & {$[0.4]$} \\
\hline \multirow[t]{3}{*}{ EPL_coll } & 0.020 & 0.020 & 0.009 & 0.048 & 0.017 & -0.008 & 0.005 \\
\hline & $(2.9)^{* * *}$ & $(2.6)^{* * *}$ & $(2.7)^{* * *}$ & $(6.6)^{* * *}$ & $(2.3)^{* *}$ & $(1.2)$ & $(0.7)$ \\
\hline & {$[3.1]^{* * *}$} & {$[3.0]^{* * *}$} & {$[3.0]^{* * *}$} & {$[7.4]^{* * *}$} & {$[2.6]^{* * *}$} & [1.3] & {$[0.8]$} \\
\hline \multirow[t]{3}{*}{ Union density } & 2.866 & 1.513 & 0.302 & 5.927 & 3.900 & -1.074 & 2.359 \\
\hline & $(5.0)^{* * *}$ & $(2.6)^{* *}$ & $(1.2)$ & $(10.1)^{* * *}$ & $(6.8)^{* * *}$ & $(2.0)^{* *}$ & $(3.8)^{* * *}$ \\
\hline & {$[5.4]^{* * *}$} & {$[2.8]^{* * *}$} & {$[1.3]$} & {$[11.4]^{* * *}$} & {$[7.7]^{* * *}$} & {$[2.1]^{* *}$} & {$[4.3]^{* * *}$} \\
\hline \multirow[t]{3}{*}{ Trauma } & -0.030 & -0.028 & 0.015 & -0.080 & -0.079 & 0.072 & 0.075 \\
\hline & $(1.3)$ & $(1.2)$ & $(1.4)$ & $(3.5)^{* * *}$ & $(3.7)^{* * *}$ & $(3.3)^{* * *}$ & $(3.3)^{* * *}$ \\
\hline & {$[1.4]$} & {$[1.4]$} & {$[1.6]$} & {$[3.9]^{* * *}$} & {$[4.1]^{* * *}$} & {$[3.6]^{* * *}$} & {$[3.5]^{* * *}$} \\
\hline \multirow[t]{3}{*}{ Sex } & 0.318 & 0.541 & 0.202 & -0.280 & -0.182 & -0.034 & 0.203 \\
\hline & $(4.7)^{* * *}$ & $(7.7)^{* * *}$ & $(6.7)^{* * *}$ & $(3.9)^{* * *}$ & $(2.7)^{* * *}$ & $(0.5)$ & $(2.9)^{* * *}$ \\
\hline & {$[5.0]^{* * *}$} & {$[8.6]^{* * *}$} & {$[7.4]^{* * *}$} & {$[4.4]^{* * *}$} & {$[3.0]^{* * *}$} & {$[0.6]$} & {$[3.2]^{* * *}$} \\
\hline Observations & 11346 & 11343 & 11344 & 11344 & 11343 & 11328 & 11332 \\
\hline Dep. variable: & No physical & No discretion & No hostility $(a)$ & Superv. not help & $\begin{array}{c}\text { No help in getting } \\
\text { job done }{ }^{(a)}\end{array}$ & $\begin{array}{c}\text { Satisfied } \\
\text { with job? }^{(a)}\end{array}$ & \\
\hline \multirow[t]{3}{*}{$\overline{E P L}$ _ind } & -0.004 & -0.015 & -0.037 & 0.055 & 0.007 & 0.017 & \\
\hline & $(0.1)$ & $(0.4)$ & $(2.0)^{* *}$ & $(1.6)$ & $(0.6)$ & $(1.4)$ & \\
\hline & {$[0.1]$} & {$[0.5]$} & {$[2.2]^{* *}$} & {$[1.8]^{*}$} & {$[0.7]$} & {$[1.5]$} & \\
\hline \multirow[t]{3}{*}{ EPL_coll } & 0.015 & 0.003 & -0.010 & 0.014 & 0.013 & -0.000 & \\
\hline & $(2.0)^{* *}$ & $(0.4)$ & $(2.7)^{* * *}$ & $(2.0)^{*}$ & $(5.7)^{* * *}$ & $(0.2)$ & \\
\hline & {$[2.3]^{* *}$} & {$[0.4]$} & {$[3.0]^{* * *}$} & {$[2.1]^{* *}$} & {$[6.0]^{* * *}$} & {$[0.2]$} & \\
\hline \multirow[t]{3}{*}{ Union density } & 2.260 & -2.713 & -0.340 & 2.844 & 1.246 & 0.092 & \\
\hline & $(3.9)^{* * *}$ & $(4.7)^{* * *}$ & $(1.1)$ & $(5.2)^{* * *}$ & $(6.2)^{* * *}$ & $(0.5)$ & \\
\hline & {$[4.4]^{* * *}$} & {$[5.1]^{* * *}$} & {$[1.3]$} & {$[5.5]^{* * *}$} & {$[6.5]^{* * *}$} & {$[0.5]$} & \\
\hline \multirow[t]{3}{*}{ Trauma } & -0.089 & 0.010 & -0.061 & 0.046 & 0.024 & 0.024 & \\
\hline & $(4.0)^{* * *}$ & $(0.4)$ & $(5.1)^{* * *}$ & $(2.1)^{* *}$ & $(3.2)^{* * *}$ & $(2.9)^{* * *}$ & \\
\hline & {$[4.5]^{* * *}$} & {$[0.5]$} & {$[5.7]^{* * *}$} & {$[2.2]^{* *}$} & {$[3.1]^{* * *}$} & {$[3.3]^{* * *}$} & \\
\hline \multirow[t]{3}{*}{ Sex } & 0.138 & 0.598 & 0.068 & -0.259 & 0.025 & 0.064 & \\
\hline & $(1.9)^{*}$ & $(8.9)^{* * *}$ & $(1.9)^{*}$ & $(4.0)^{* * *}$ & $(1.1)$ & $(2.8)^{* * *}$ & \\
\hline & {$[2.2]^{* *}$} & {$[9.9]^{* * *}$} & {$[2.1]^{* *}$} & {$[4.3]^{* * *}$} & {$[1.1]$} & {$[3.0]^{* * *}$} & \\
\hline Observations & 11344 & 11337 & 11338 & 11273 & 11314 & 11344 & \\
\hline
\end{tabular}

at $10 \%$; ** significant at $5 \%$; ** significant at $1 \%$; Dependent: 1 : strongly agree . . 5 disagree ; For instance, in thecolumn no learning,

a positive coefficient means that the higher the variable, the more likeley there is "no learning" on the job.Other controls: same as listed in 
Table 7. Elements of falsification: impact of EPL on other forms of stress (unrelated to work)

\begin{tabular}{|c|c|c|c|c|c|c|}
\hline Dep. variable: & "Stress_chron & "Stress_perso & Stress_fin & "Stress_chron & Stress_perso & Stress_fin \\
\hline \multirow[t]{3}{*}{ EPL_ind } & 0.057 & 0.036 & -0.013 & 0.035 & 0.021 & -0.015 \\
\hline & $(1.8)^{*}$ & $(1.7)$ & $(1.3)^{*}$ & $(1.2)$ & $(1.0)$ & $(1.4)$ \\
\hline & {$[2.1]^{* *}$} & {$[2.0]^{* *}$} & {$[1.3]^{*}$} & {$[1.4]$} & {$[1.2]$} & {$[1.5]$} \\
\hline \multirow[t]{3}{*}{ EPL_coll } & -0.011 & -0.003 & -0.004 & -0.013 & -0.004 & -0.004 \\
\hline & $(1.9)^{*}$ & $(0.7)$ & $(2.0)^{* *}$ & $(2.3)^{* *}$ & $(1.1)$ & $(2.1)^{* *}$ \\
\hline & {$[2.2]^{*}$} & {$[0.8]$} & {$[2.1]^{* *}$} & {$[2.7]^{* * *}$} & {$[1.2]$} & {$[2.1]^{* *}$} \\
\hline \multirow[t]{3}{*}{ Trauma } & 0.221 & 0.109 & 0.030 & 0.191 & 0.087 & 0.028 \\
\hline & $(10.3)^{* * *}$ & $(7.6)^{* * *}$ & $(4.6)^{* * *}$ & $(9.3)^{* * *}$ & $(6.4)^{* * *}$ & $(4.1)^{* * *}$ \\
\hline & {$[12.0]^{* * *}$} & {$[8.9]^{* * *}$} & {$[4.8] * * *$} & {$[10.7]^{* * *}$} & {$[7.4]^{* * *}$} & {$[4.3]^{* * *}$} \\
\hline \multirow[t]{3}{*}{ Sex } & 0.218 & 0.231 & -0.072 & 0.241 & 0.248 & -0.071 \\
\hline & $(4.5)^{* * *}$ & $(7.0)^{* * *}$ & $(4.7)^{* * *}$ & $(5.2) * * *$ & $(7.8)^{* * *}$ & $(4.6)^{* * *}$ \\
\hline & {$[3.2]^{* * *}$} & {$[8.0]^{* * *}$} & {$[4.0]^{* * *}$} & {$[5.9]^{* * *}$} & {$[8.8]^{* * *}$} & {$[4.9]^{* * *}$} \\
\hline Observations & 11441 & 11437 & 11468 & 11441 & 11437 & 11468 \\
\hline \multirow[t]{3}{*}{ Stress_wrk } & - & - & - & 0.095 & 0.069 & 0.007 \\
\hline & & & & $(19.0)^{* * *}$ & $(19.6)^{* * *}$ & $(4.2)^{* * *}$ \\
\hline & & & & {$[20.1] * * *$} & {$[20.9]^{* * *}$} & {$[4.3]^{* * *}$} \\
\hline R-squared & 0.08 & 0.05 & 0.03 & 0.13 & 0.11 & 0.04 \\
\hline Number of clusters & 6773 & 6771 & 6780 & 6773 & 6771 & 6780 \\
\hline
\end{tabular}

controls: same as listed in table 2 (age, urbanicity, family, education, immigration, birth place, year, EXCEPT industry, occupation) 
Table 8. IV model. Individual determinants of employment: local labor market variables as instruments

\begin{tabular}{lcc}
\hline \hline First stage: individual employment probability & WLS & RE \\
Dep. variable: & Individual employment & Individual employment \\
\hline & & \\
Local Unemp. rate & -0.004 & -0.015 \\
& $(4.1)^{* * *}$ & $(3.8)^{* * *}$ \\
Local Activity rate & 0.003 & 0.014 \\
& $(3.3)^{* * *}$ & $(3.3)^{* * *}$ \\
Local population density & 0.000 & 0.000 \\
& $(1.5)$ & $(1.5)$ \\
Local share of male & 0.381 & 1.681 \\
& $(0.8)$ & $(0.9)$ \\
Population growth 1996-01 & 0.001 & 0.003 \\
& $(0.8)$ & $(1.0)$ \\
EPL_ind & 0.010 & 0.037 \\
& $(2.0)^{* *}$ & $(1.9)^{*}$ \\
EP_coll & -0.001 & -0.004 \\
Trauma & $(1.3)$ & $(1.0)$ \\
& -0.018 & -0.075 \\
Sex & $(6.4)^{* * *}$ & $(6.9)^{* * *}$ \\
Observations & -0.177 & -0.799 \\
R-squared & $(19.0)^{* * *}$ & $(19.1)^{* * *}$ \\
Number of clusters & 41357 & 41357 \\
Robust t-statistics in parentheses ( ) : individual clustering; $;$ significant at $10 \% ; * *$ significant at 5\%;*** significant at $1 \% ;$ other
\end{tabular}

controls: same as listed in table 2 (age, urbanicity, family, education, immigration, birth place, year EXCEPT industry, occupation, and in addition, household size interacted with gender). NB: no correction for clustering within local labor markets. Local controls: Census division (county) level. 
Table 9. IV probit models. Anti-depressors and EPL

\begin{tabular}{|c|c|c|c|c|c|c|c|c|c|c|}
\hline Dep. variable: & $\begin{array}{c}\text { Probit } \\
\text { Depress }\end{array}$ & $\begin{array}{c}\text { IV-Prob } \\
\text { Depress } \\
\end{array}$ & $\begin{array}{c}\text { Probit } \\
\text { Antidepr }\end{array}$ & $\begin{array}{l}\text { IV-Prob } \\
\text { Antidepr }\end{array}$ & $\begin{array}{c}\text { Probit } \\
\text { Tranquil }\end{array}$ & $\begin{array}{l}\text { IV-Prob } \\
\text { Tranquil }\end{array}$ & $\begin{array}{c}\text { Probit } \\
\text { Sleeping }\end{array}$ & $\begin{array}{l}\text { IV-Prob } \\
\text { Sleeping }\end{array}$ & $\begin{array}{c}\text { Probit } \\
\text { Highbld }\end{array}$ & $\begin{array}{l}\text { IV-Prob } \\
\text { Highbld }\end{array}$ \\
\hline Empl.*EPL_ind & $\begin{array}{c}0.041 \\
(2.6)^{* *}\end{array}$ & $\begin{array}{c}0.057 \\
(2.8)^{* * *}\end{array}$ & $\begin{array}{c}0.024 \\
(1.1)\end{array}$ & $\begin{array}{c}0.081 \\
(2.9)^{* * *}\end{array}$ & $\begin{array}{l}0.045 \\
(1.9)^{*}\end{array}$ & $\begin{array}{l}0.060 \\
(2.0)^{*}\end{array}$ & $\begin{array}{c}0.010 \\
(0.4)\end{array}$ & $\begin{array}{c}0.013 \\
(0.5)\end{array}$ & $\begin{array}{l}-0.037 \\
(1.7)^{*}\end{array}$ & $\begin{array}{c}0.000 \\
(0.0)\end{array}$ \\
\hline Empl.*EPL_coll & $\begin{array}{c}0.003 \\
(0.8)\end{array}$ & $\begin{array}{c}0.003 \\
(0.7)\end{array}$ & $\begin{array}{c}-0.005 \\
(1.0)\end{array}$ & $\begin{array}{c}-0.006 \\
(1.1)\end{array}$ & $\begin{array}{c}0.015 \\
(2.6)^{* *}\end{array}$ & $\begin{array}{c}0.022 \\
(3.3)^{* * *}\end{array}$ & $\begin{array}{l}-0.009 \\
(1.8)^{*}\end{array}$ & $\begin{array}{l}-0.010 \\
(1.7)^{*}\end{array}$ & $\begin{array}{c}0.007 \\
(1.4)\end{array}$ & $\begin{array}{l}0.008 \\
(1.4)\end{array}$ \\
\hline Empl. & $\begin{array}{c}-0.517 \\
(7.4)^{* * *}\end{array}$ & $\begin{array}{l}-0.622 \\
(2.3)^{* *}\end{array}$ & $\begin{array}{c}-0.495 \\
(5.0)^{* * *}\end{array}$ & $\begin{array}{l}-0.835 \\
(2.2)^{* *}\end{array}$ & $\begin{array}{c}-0.707 \\
(6.7)^{* * *}\end{array}$ & $\begin{array}{l}-1.020 \\
(2.4)^{* *}\end{array}$ & $\begin{array}{c}-0.363 \\
(3.5)^{* * *}\end{array}$ & $\begin{array}{c}-0.237 \\
(0.6)\end{array}$ & $\begin{array}{c}-0.133 \\
(1.4)\end{array}$ & $\begin{array}{c}-1.077 \\
(3.0)^{* * *}\end{array}$ \\
\hline Trauma & $\begin{array}{c}0.153 \\
(17.3)^{* * *}\end{array}$ & $\begin{array}{c}0.151 \\
(15.4)^{* * *}\end{array}$ & $\begin{array}{c}0.126 \\
(10.3)^{* * *}\end{array}$ & $\begin{array}{c}0.122 \\
(9.0)^{* * *}\end{array}$ & $\begin{array}{c}0.122 \\
(8.8)^{* * *}\end{array}$ & $\begin{array}{c}0.119 \\
(7.6)^{* * *}\end{array}$ & $\begin{array}{c}0.104 \\
(8.0)^{* * *}\end{array}$ & $\begin{array}{c}0.107 \\
(7.3)^{* * *}\end{array}$ & $\begin{array}{c}0.034 \\
(2.5)^{* *}\end{array}$ & $\begin{array}{c}0.019 \\
(1.3)\end{array}$ \\
\hline Sex & $\begin{array}{c}0.216 \\
(8.3)^{* * *}\end{array}$ & $\begin{array}{c}0.210 \\
(5.2)^{* * *}\end{array}$ & $\begin{array}{c}0.331 \\
(8.9)^{* * *}\end{array}$ & $\begin{array}{c}0.306 \\
(5.4)^{* * *}\end{array}$ & $\begin{array}{c}0.113 \\
(2.7)^{* * *}\end{array}$ & $\begin{array}{c}0.087 \\
(1.4)\end{array}$ & $\begin{array}{c}0.155 \\
(4.1)^{* * *}\end{array}$ & $\begin{array}{c}0.166 \\
(2.7)^{* * *}\end{array}$ & $\begin{array}{c}0.074 \\
(2.1)^{* *}\end{array}$ & $\begin{array}{c}-0.030 \\
(0.6)\end{array}$ \\
\hline Urban & $\begin{array}{c}0.000 \\
(0.0)\end{array}$ & $\begin{array}{c}-0.006 \\
(0.2)\end{array}$ & $\begin{array}{c}0.050 \\
(1.3)\end{array}$ & $\begin{array}{c}0.034 \\
(0.9)\end{array}$ & $\begin{array}{c}0.060 \\
(1.3)\end{array}$ & $\begin{array}{c}0.058 \\
(1.3)\end{array}$ & $\begin{array}{c}0.046 \\
(1.1)\end{array}$ & $\begin{array}{c}0.041 \\
(1.0)\end{array}$ & $\begin{array}{c}0.017 \\
(0.5)\end{array}$ & $\begin{array}{c}0.022 \\
(0.6)\end{array}$ \\
\hline No social insurance & & & $\begin{array}{c}-0.105 \\
(2.9)^{* * *}\end{array}$ & $\begin{array}{c}-0.058 \\
(1.6)\end{array}$ & $\begin{array}{c}-0.117 \\
(2.8)^{* * *}\end{array}$ & $\begin{array}{l}-0.072 \\
(1.8)^{*}\end{array}$ & $\begin{array}{c}-0.129 \\
(3.3)^{* * *}\end{array}$ & $\begin{array}{l}-0.091 \\
(2.4)^{* *}\end{array}$ & $\begin{array}{c}-0.114 \\
(3.4)^{* * *}\end{array}$ & $\begin{array}{c}-0.102 \\
(3.0)^{* * *}\end{array}$ \\
\hline Constant & $\begin{array}{c}-6.818 \\
(39.8)^{* * *}\end{array}$ & $\begin{array}{c}-6.740 \\
(30.3)^{* * *}\end{array}$ & $\begin{array}{c}-1.989 \\
(3.1)^{* * *}\end{array}$ & $\begin{array}{c}-1.990 \\
(2.9)^{* * *}\end{array}$ & $\begin{array}{c}-1.703 \\
(4.1)^{* * *}\end{array}$ & $\begin{array}{c}-0.640 \\
(0.8)\end{array}$ & $\begin{array}{c}-1.471 \\
(3.5)^{* * *}\end{array}$ & $\begin{array}{c}-1.503 \\
(3.0)^{* * *}\end{array}$ & $\begin{array}{c}-0.414 \\
(1.0)\end{array}$ & $\begin{array}{c}0.582 \\
(0.7)\end{array}$ \\
\hline Observations & 40450 & 40354 & 32272 & 32222 & 32319 & 32269 & 32281 & 32231 & 32327 & 32277 \\
\hline Pseudo R-squared & 0.07 & 0.06 & 0.09 & 0.07 & 0.08 & 0.07 & 0.07 & 0.06 & 0.18 & 0.17 \\
\hline Number of clusters & 10955 & 10950 & 10193 & 10191 & 10198 & 10196 & 10195 & 10193 & 10197 & 10195 \\
\hline Hansen J-test exog 6 instr. & & 2.76 & & 7.226 & & 3.861 & & 7.001 & & 6.745 \\
\hline$\chi^{2}(6): p$-value & & 0.838 & & 0.300 & & 0.700 & & 0.320 & & 0.345 \\
\hline
\end{tabular}

at $10 \%$; $*$ significant at $5 \%$; *** significant at $1 \%$; Other controls: same as listed in table 2 (age, urbanicity, family, education, immigration,

birth place, year EXCEPT industry, occupation). 
Table A. Summary of notations

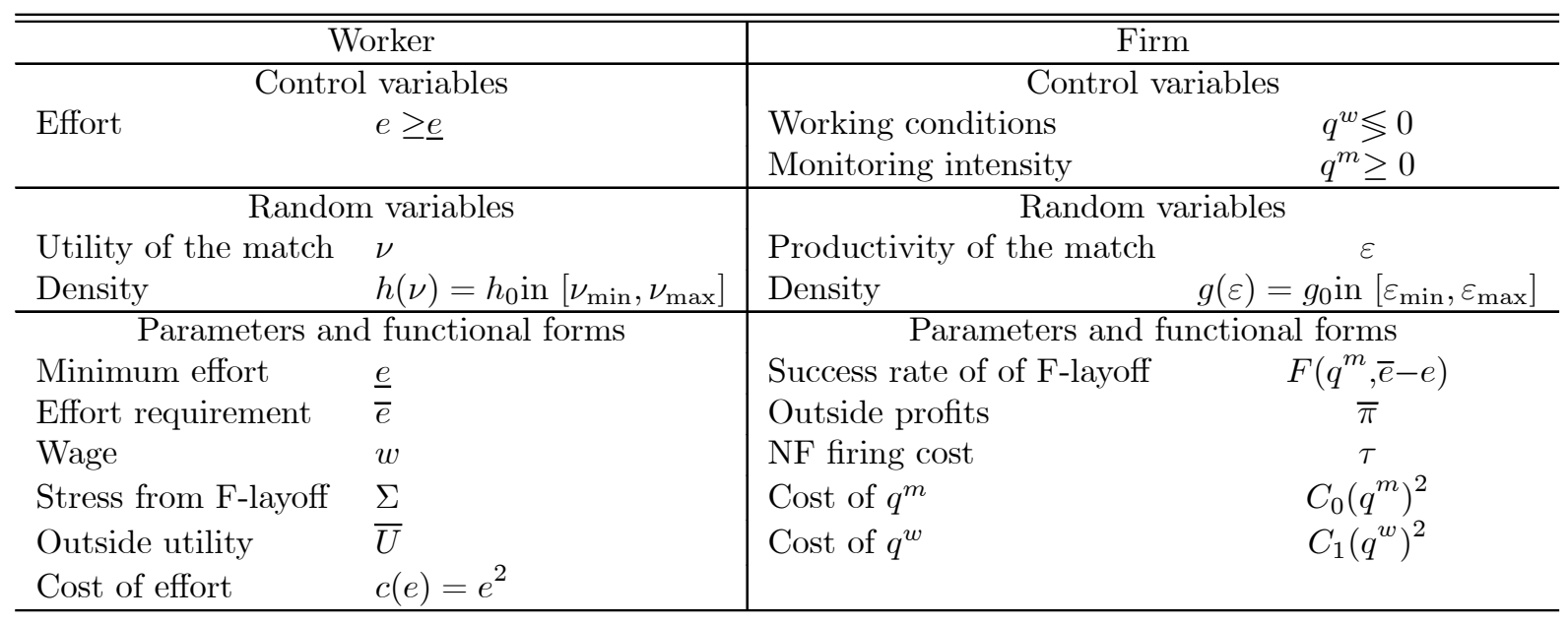

Table B1. NPHS Longitudinal Household Component Sample Size by Province in 1994-1995, Number of Persons

\begin{tabular}{ll|cc}
\hline \hline & & $\begin{array}{c}\text { Longitudinal Sample } \\
\text { Cycle 1 (1994-1995) }\end{array}$ & $\begin{array}{c}\text { Records providing a full response } \\
\text { in Cycles 1, 2, 3, 4 and 5 }\end{array}$ \\
\hline Newfoundland & Terre-Neuve & 1,082 & 822 \\
Prince Edward Island & Île-du-Prince-Édouard & 1,037 & 803 \\
Nova Scotia & Nouvelle-Écosse & 1,085 & 775 \\
New Brunswick & Nouveau-Brunswick & 1,125 & 824 \\
Québec & Québec & 3,000 & 2,189 \\
Ontario & Ontario & 4,307 & 2,990 \\
Manitoba & Manitoba & 1,205 & 921 \\
Saskatchewan & Saskatchewan & 1,168 & 922 \\
Alberta & Alberta & 1,544 & 1,111 \\
British Columbia & Colombie-Britannique & 1,723 & 1,189 \\
TOTAL & TOTAL & 17,276 & 12,546 \\
\hline
\end{tabular}




\begin{tabular}{|l|c|c|c|c|c|c|}
\hline & $\begin{array}{c}\text { Refusals to } \\
\text { O\% of } \\
\text { questions }\end{array}$ & $\begin{array}{c}\text { Refusals to } \\
\text { less than 1\% } \\
\text { of questions }\end{array}$ & $\begin{array}{c}\text { Refusals to } \\
\text { less than 3\% } \\
\text { of questions }\end{array}$ & $\begin{array}{c}\text { Don't know } \\
\text { to 0\% of } \\
\text { questions }\end{array}$ & $\begin{array}{c}\text { Don't know } \\
\text { to less than } \\
1 \% \text { of } \\
\text { questions }\end{array}$ & $\begin{array}{c}\text { Don't know } \\
\text { to less than } \\
5 \% \text { of } \\
\text { questions }\end{array}$ \\
\hline Overall & $92.3 \%$ & $98.1 \%$ & $98.8 \%$ & $62.6 \%$ & $93.7 \%$ & $99.4 \%$ \\
\hline Males & $92.2 \%$ & $97.7 \%$ & $98.6 \%$ & $63.7 \%$ & $93.9 \%$ & $99.3 \%$ \\
\hline Females & $92.3 \%$ & $98.5 \%$ & $98.9 \%$ & $61.6 \%$ & $93.6 \%$ & $99.5 \%$ \\
\hline Under 12 & $94.5 \%$ & $95.7 \%$ & $98.0 \%$ & $82.9 \%$ & $95.5 \%$ & $99.5 \%$ \\
\hline $12-24$ & $93.2 \%$ & $98.5 \%$ & $98.6 \%$ & $46.5 \%$ & $88.6 \%$ & $98.3 \%$ \\
\hline $25-44$ & $94.4 \%$ & $98.9 \%$ & $99.2 \%$ & $72.4 \%$ & $97.6 \%$ & $99.8 \%$ \\
\hline $45-64$ & $92.4 \%$ & $98.5 \%$ & $99.0 \%$ & $65.9 \%$ & $96.3 \%$ & $99.7 \%$ \\
\hline $65+$ & $86.8 \%$ & $96.6 \%$ & $97.9 \%$ & $48.0 \%$ & $86.6 \%$ & $99.0 \%$ \\
\hline Proxy & $91.6 \%$ & $95.9 \%$ & $97.9 \%$ & $69.5 \%$ & $88.3 \%$ & $98.6 \%$ \\
\hline Non-Proxy & $92.3 \%$ & $98.3 \%$ & $98.8 \%$ & $61.9 \%$ & $94.2 \%$ & $99.5 \%$ \\
\hline
\end{tabular}

Table B2. Refusal and Don't Know Rates at the Respondent Level. Source: Longitudinal Documentation, ENSP-Cycle 5 


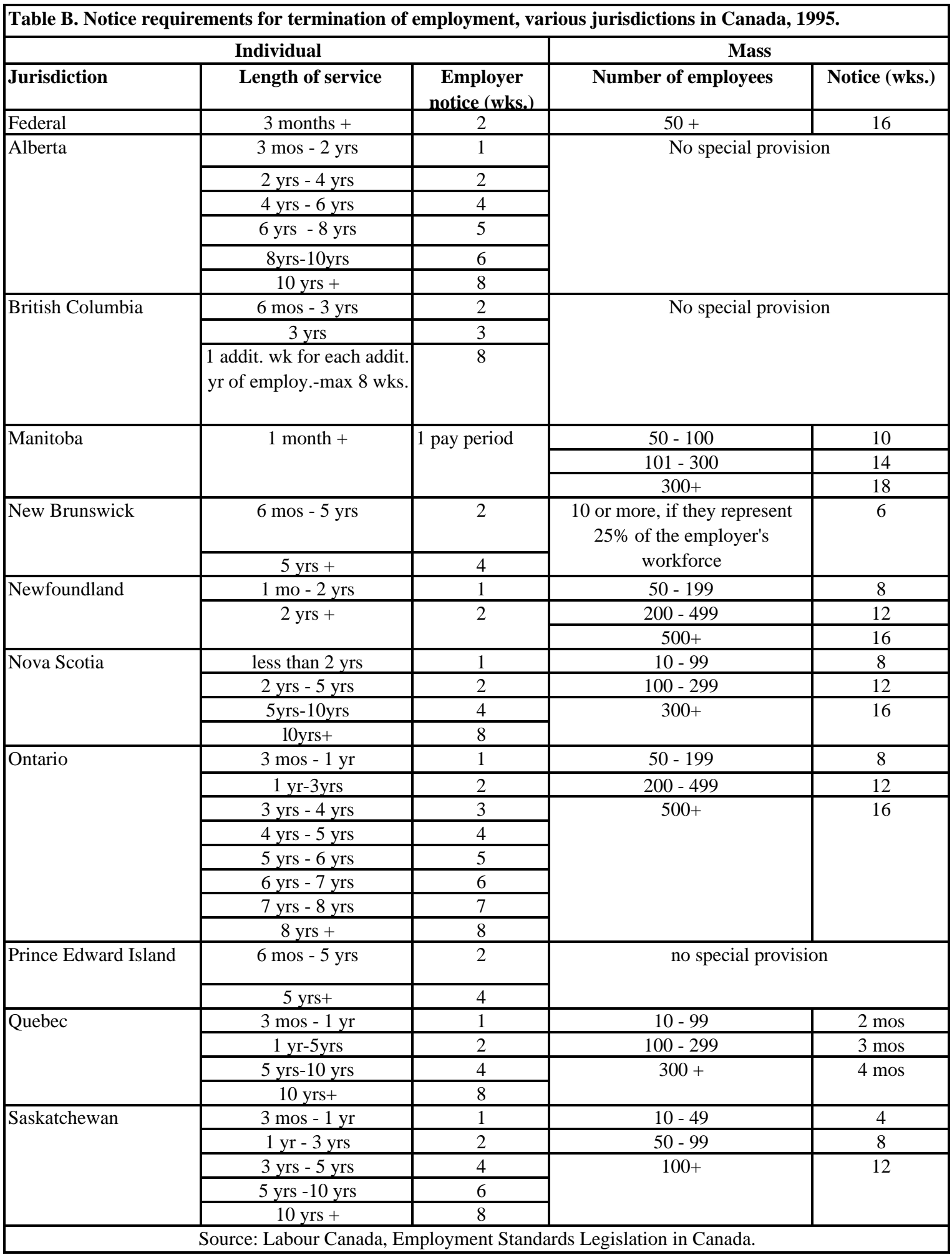


Table B3. Regressions for overall stress, additional controls

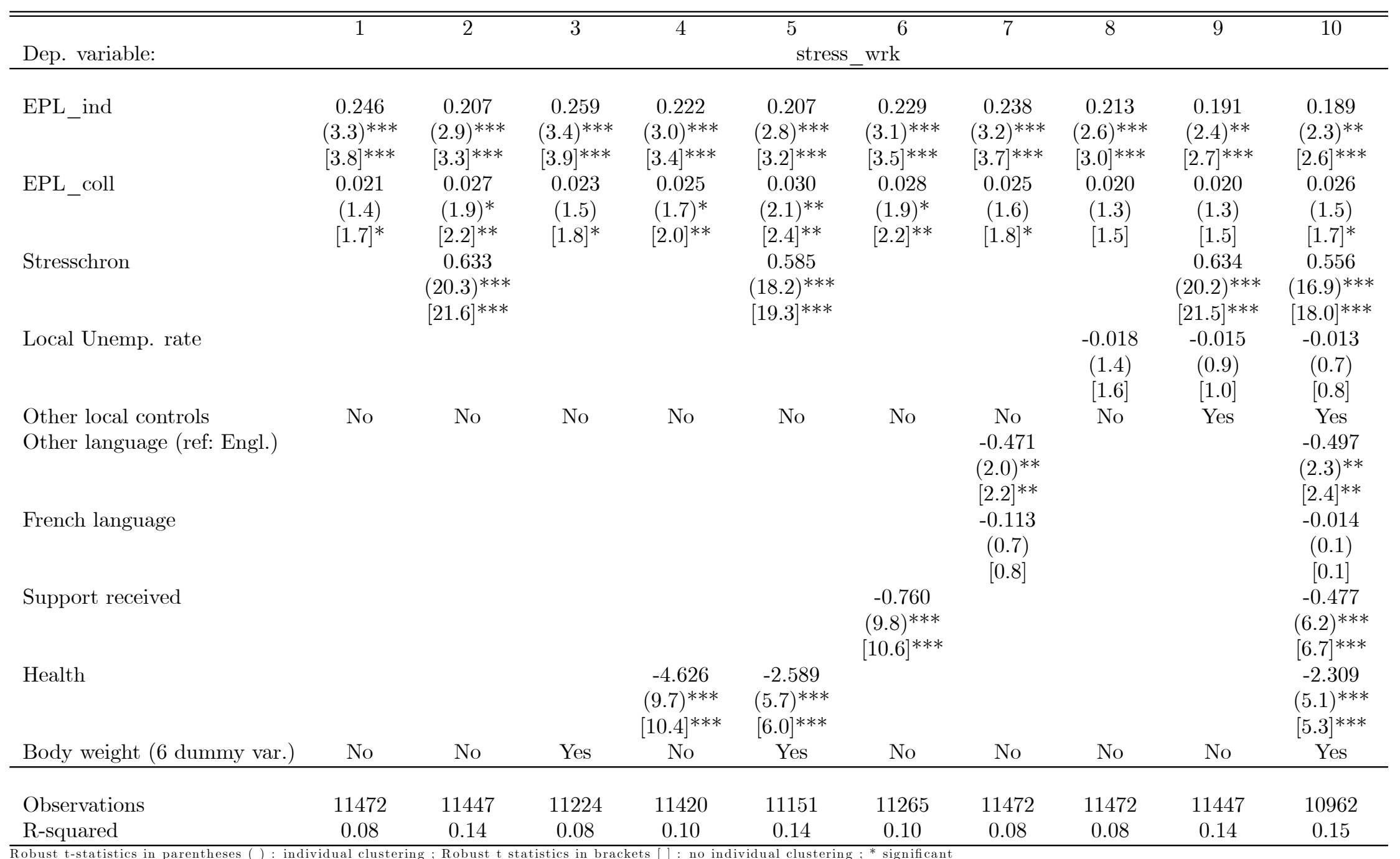

at $10 \%$; $* *$ significant at $5 \%$; ** significant at $1 \%$; Other controls: same as listed in table 2 (gender, age, urbanicity, family, education,

immigration, birth place, year, industry, occupation, trauma) 
Table B4. Regressions for components of stress, interaction of EPL with local labor markets

\begin{tabular}{|c|c|c|c|c|c|c|c|c|}
\hline Dep. variable: stress from & 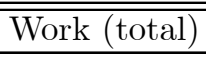 & S Skill need & Latitude dec. & Conflicts & Layoff & Phy. exert. & Cowk-manag. & Strain \\
\hline \multirow[t]{3}{*}{ EPL_ind } & 0.188 & 0.081 & 0.091 & 0.247 & -0.070 & 0.112 & -0.167 & 0.042 \\
\hline & $(1.5)$ & $(1.4)$ & $(2.0)^{*}$ & $(4.8)^{* * *}$ & $(2.4)^{* *}$ & $(3.5)^{* * *}$ & $(3.0)^{* * *}$ & $(4.7)^{* * *}$ \\
\hline & {$[1.7]^{*}$} & {$[1.6]$} & {$[2.2]^{* *}$} & {$[5.4]^{* * *}$} & {$[2.7]^{* * *}$} & {$[4.1]^{* * *}$} & {$[3.3]^{* * *}$} & {$[5.2] * * *$} \\
\hline \multirow[t]{3}{*}{ EPL_coll } & 0.058 & -0.001 & 0.016 & -0.031 & 0.015 & -0.011 & 0.069 & -0.002 \\
\hline & $(1.7)^{*}$ & $(0.0)$ & $(1.4)$ & $(2.3)^{* *}$ & $(2.0)^{* *}$ & $(1.3)$ & $(4.8)^{* * *}$ & $(0.7)$ \\
\hline & {$[1.9]^{*}$} & {$[0.0]$} & {$[1.5]$} & {$[2.6]^{* * *}$} & {$[2.2]^{* *}$} & {$[1.4]$} & {$[5.2]^{* * *}$} & {$[0.8]$} \\
\hline \multirow[t]{3}{*}{ Local unemp. rate } & 0.009 & 0.048 & 0.034 & 0.015 & -0.004 & 0.030 & -0.030 & 0.007 \\
\hline & $(0.2)$ & $(2.2)^{* *}$ & $(2.0)^{* *}$ & $(0.8)$ & $(0.4)$ & $(2.6)^{* * *}$ & $(1.5)$ & $(2.1)^{* *}$ \\
\hline & {$[0.2]$} & {$[2.5]^{* *}$} & {$[2.3]^{* *}$} & {$[0.9]$} & {$[0.4]$} & {$[2.9]^{* * *}$} & {$[1.6]$} & {$[2.4]^{* *}$} \\
\hline \multirow[t]{3}{*}{$\mathrm{EPL}$ ind ${ }^{*} \mathrm{u}$-rate } & 0.004 & -0.008 & -0.004 & -0.009 & 0.006 & -0.009 & 0.014 & -0.002 \\
\hline & $(0.3)$ & $(1.5)$ & $(1.0)$ & $(2.0)^{* *}$ & $(2.3)^{* *}$ & $(3.0)^{* * *}$ & $(2.9)^{* * *}$ & $(2.1)^{* *}$ \\
\hline & {$[0.3]$} & {$[1.7]^{*}$} & {$[1.1]$} & {$[2.2]^{* *}$} & {$[2.6]^{* * *}$} & {$[3.4]^{* * *}$} & {$[3.1]^{* * *}$} & {$[2.3]^{* *}$} \\
\hline \multirow[t]{3}{*}{$\mathrm{EPL} \_$coll $*$ u-rate } & -0.005 & -0.001 & -0.001 & 0.001 & -0.001 & -0.000 & -0.004 & -0.000 \\
\hline & $(1.2)$ & $(0.5)$ & $(1.0)$ & $(0.4)$ & $(0.8)$ & $(0.3)$ & $(2.0)^{* *}$ & $(0.7)$ \\
\hline & {$[1.4]$} & {$[0.6]$} & {$[1.1]$} & {$[0.4]$} & {$[0.9]$} & {$[0.3]$} & {$[2.2]^{* *}$} & {$[0.8]$} \\
\hline \multirow[t]{3}{*}{ Trauma } & 0.300 & 0.019 & 0.030 & 0.081 & 0.042 & 0.045 & 0.106 & 0.018 \\
\hline & $(5.9)^{* * *}$ & $(0.9)$ & $(1.7)^{*}$ & $(4.3)^{* * *}$ & $(3.8) * * *$ & $(3.9)^{* * *}$ & $(5.1)^{* * *}$ & $(5.1)^{* * *}$ \\
\hline & {$[6.8]^{* * *}$} & {$[1.0]$} & {$[1.9]^{*}$} & {$[4.8]^{* * *}$} & {$[4.1]^{* * *}$} & {$[4.5]^{* * *}$} & {$[5.4]^{* * *}$} & {$[5.6]^{* * *}$} \\
\hline \multirow[t]{3}{*}{ Sex } & -0.076 & 0.553 & 0.470 & 0.074 & 0.092 & -0.088 & -0.165 & 0.072 \\
\hline & $(0.5)$ & $(8.2)^{* * *}$ & $(8.7)^{* * *}$ & $(1.3)$ & $(2.7)^{* * *}$ & $(2.4)^{* *}$ & $(2.7)^{* * *}$ & $(6.9)^{* * *}$ \\
\hline & {$[0.6]$} & {$[9.4]^{* * *}$} & {$[10.0]^{* * *}$} & {$[1.5]$} & {$[3.1]^{* * *}$} & {$[2.8]^{* * *}$} & {$[2.9]^{* * *}$} & {$[7.5]^{* * *}$} \\
\hline Observations & 11224 & 11340 & 11335 & 11326 & 11332 & 11344 & 11258 & 11315 \\
\hline R-squared & 0.08 & 0.32 & 0.18 & 0.10 & 0.06 & 0.34 & 0.04 & 0.11 \\
\hline
\end{tabular}

at $10 \%$; ** significant at $5 \%$; *** significant at $1 \%$; Other controls: same as listed in table 2 (age, urbanicity, family, education, immigration,

birth place, year, industry, occupation). A higher level of unemployment interact positively with individual EPL on stress associated with the

risk of loosing one's job, as expected, and stress due to co-workers and managers. It interacts negatively on physical, psychological stress and

stress associated with strain. 
Table B5. What determines depression? A first attempt (sc refer to score ; pp to probability ; cf. text)

\begin{tabular}{|c|c|c|c|c|c|c|c|c|}
\hline Dep. variable: & Depress sc & Depress sc & Depress sc & Depress sc & Depress pp & Depress pp & Depress pp & Depress pp \\
\hline \multirow[t]{2}{*}{ Stresschron } & $\begin{array}{c}0.149 \\
(14.0)^{* * *}\end{array}$ & & $\begin{array}{c}0.149 \\
(14.0)^{* * *}\end{array}$ & $\begin{array}{c}0.149 \\
(13.9)^{* * *}\end{array}$ & $\begin{array}{c}0.022 \\
(14.4)^{* * *}\end{array}$ & & $\begin{array}{c}0.022 \\
(14.4)^{* * *}\end{array}$ & $\begin{array}{c}0.022 \\
(14.4)^{* * *}\end{array}$ \\
\hline & {$[14.9]^{* * *}$} & & {$[14.9]^{* * *}$} & {$[14.9]^{* * *}$} & {$[15.0]^{* * *}$} & & {$[15.1]^{* * *}$} & {$[15.0]^{* * *}$} \\
\hline \multirow[t]{3}{*}{ EPL_ind } & 0.003 & 0.006 & 0.001 & 0.005 & -0.001 & 0.001 & 0.000 & 0.000 \\
\hline & $(0.2)$ & $(0.4)$ & $(0.1)$ & $(0.3)$ & $(0.2)$ & $(0.4)$ & $(0.1)$ & $(0.0)$ \\
\hline & {$[0.2]$} & {$[0.5]$} & {$[0.1]$} & {$[0.3]$} & {$[0.2]$} & {$[0.5]$} & {$[0.1]$} & {$[0.0]$} \\
\hline \multirow[t]{3}{*}{ EPL_coll } & -0.004 & -0.001 & -0.004 & -0.003 & -0.001 & -0.000 & -0.001 & -0.001 \\
\hline & $(1.1)$ & $(0.5)$ & $(1.1)$ & $(0.9)$ & $(1.4)$ & $(0.9)$ & $(1.4)$ & $(1.1)$ \\
\hline & {$[1.2]$} & {$[0.6]$} & {$[1.2]$} & {$[0.9]$} & {$[1.6]$} & {$[1.0]$} & {$[1.5]$} & {$[1.2]$} \\
\hline \multirow[t]{3}{*}{ Trauma } & 0.088 & 0.121 & 0.087 & 0.087 & 0.013 & 0.018 & 0.014 & 0.013 \\
\hline & $(6.7)^{* * *}$ & $(10.1)^{* * *}$ & $(6.6)^{* * *}$ & $(6.6)^{* * *}$ & $(6.8)^{* * *}$ & $(10.4)^{* * *}$ & $(6.8)^{* * *}$ & $(6.8)^{* * *}$ \\
\hline & {$[6.9]^{* * *}$} & {$[12.4]^{* * *}$} & {$[6.8]^{* * *}$} & {$[6.8]^{* * *}$} & {$[7.0]^{* * *}$} & {$[12.7]^{* * *}$} & {$[7.1]^{* * *}$} & {$[7.0]^{* * *}$} \\
\hline \multirow[t]{3}{*}{ Sex } & 0.095 & 0.124 & 0.098 & 0.098 & 0.017 & 0.020 & 0.016 & 0.017 \\
\hline & $(2.7)^{* * *}$ & $(4.1)^{* * *}$ & $(2.7)^{* * *}$ & $(2.7)^{* * *}$ & $(3.1)^{* * *}$ & $(4.5)^{* * *}$ & $(3.1)^{* * *}$ & $(3.1)^{* * *}$ \\
\hline & {$[2.9]^{* * *}$} & {$[4.9]^{* * *}$} & {$[3.0]^{* * *}$} & {$[2.9]^{* * *}$} & {$[3.3]^{* * *}$} & {$[5.3]^{* * *}$} & {$[3.3]^{* * *}$} & {$[3.3]^{* * *}$} \\
\hline \multirow[t]{3}{*}{ Local unemp. rate } & & & -0.001 & 0.003 & -0.000 & & & 0.000 \\
\hline & & & $(0.2)$ & $(0.8)$ & $(0.8)$ & & & $(0.3)$ \\
\hline & & & {$[0.3]$} & {$[0.8]$} & {$[0.8]$} & & & {$[0.3]$} \\
\hline \multirow[t]{3}{*}{ Local activity rate } & & & & 0.005 & & & & 0.001 \\
\hline & & & & $(1.4)$ & & & & $(1.3)$ \\
\hline & & & & {$[1.4]$} & & & & {$[1.3]$} \\
\hline \multirow[t]{3}{*}{ Local density } & & & & 0.000 & & & & 0.000 \\
\hline & & & & $(0.2)$ & & & & $(0.1)$ \\
\hline & & & & {$[0.2]$} & & & & {$[0.1]$} \\
\hline \multirow[t]{3}{*}{ Local share of male } & & & & -1.575 & & & & -0.192 \\
\hline & & & & $(0.9)$ & & & & $(0.7)$ \\
\hline & & & & {$[0.9]$} & & & & {$[0.7]$} \\
\hline \multirow[t]{3}{*}{ Population growth 1996-01 } & & & & -0.001 & & & & -0.000 \\
\hline & & & & $(0.2)$ & & & & $(0.3)$ \\
\hline & & & & {$[0.2]$} & & & & {$[0.3]$} \\
\hline Observations & 18664 & 32273 & 18623 & 18623 & 18623 & 32273 & 18664 & 18623 \\
\hline R-squared & 0.08 & 0.04 & 0.08 & 0.08 & 0.07 & 0.04 & 0.07 & 0.07 \\
\hline
\end{tabular}

birth place, year, EXCEPT industry, occupation). 
Figure 2. Correlation between EPL_ind and Stress at work (total)

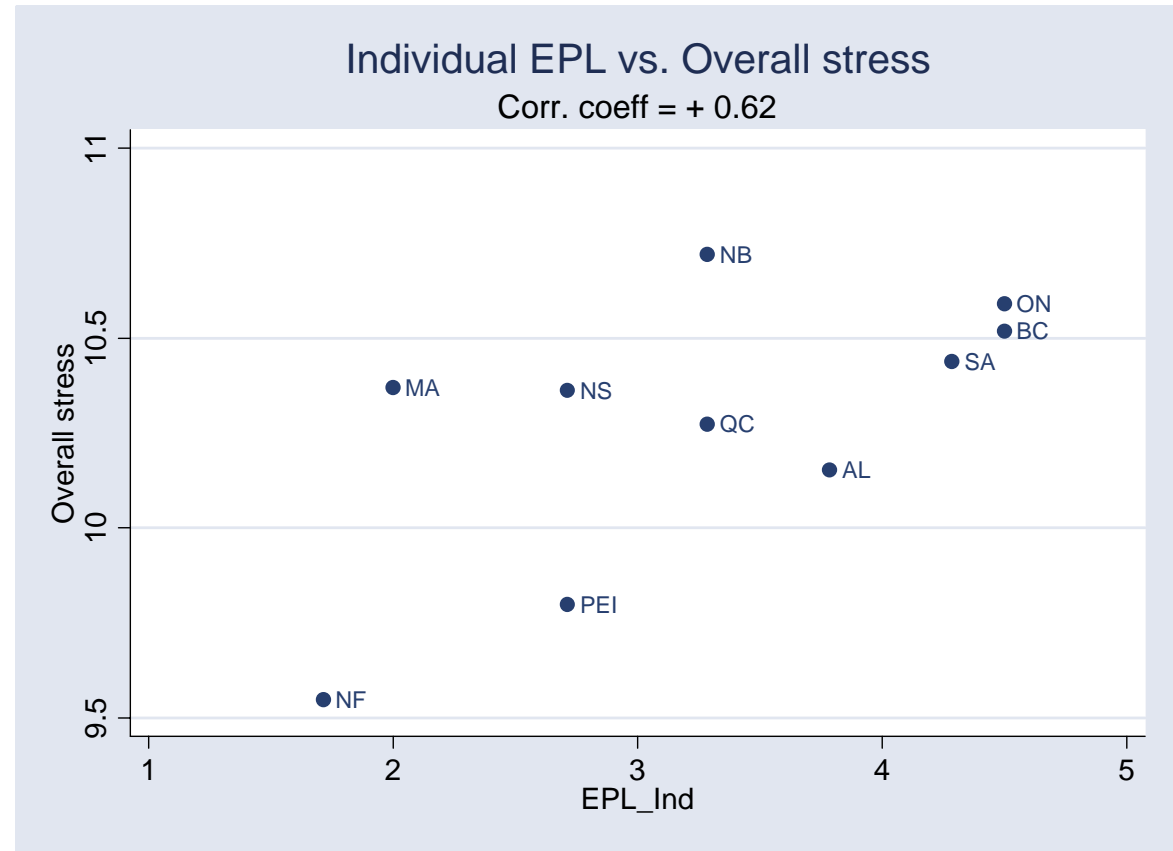

Individual EPL vs. Stress

Figure 3. Correlation between EPL_ind and Psychological Stress at work

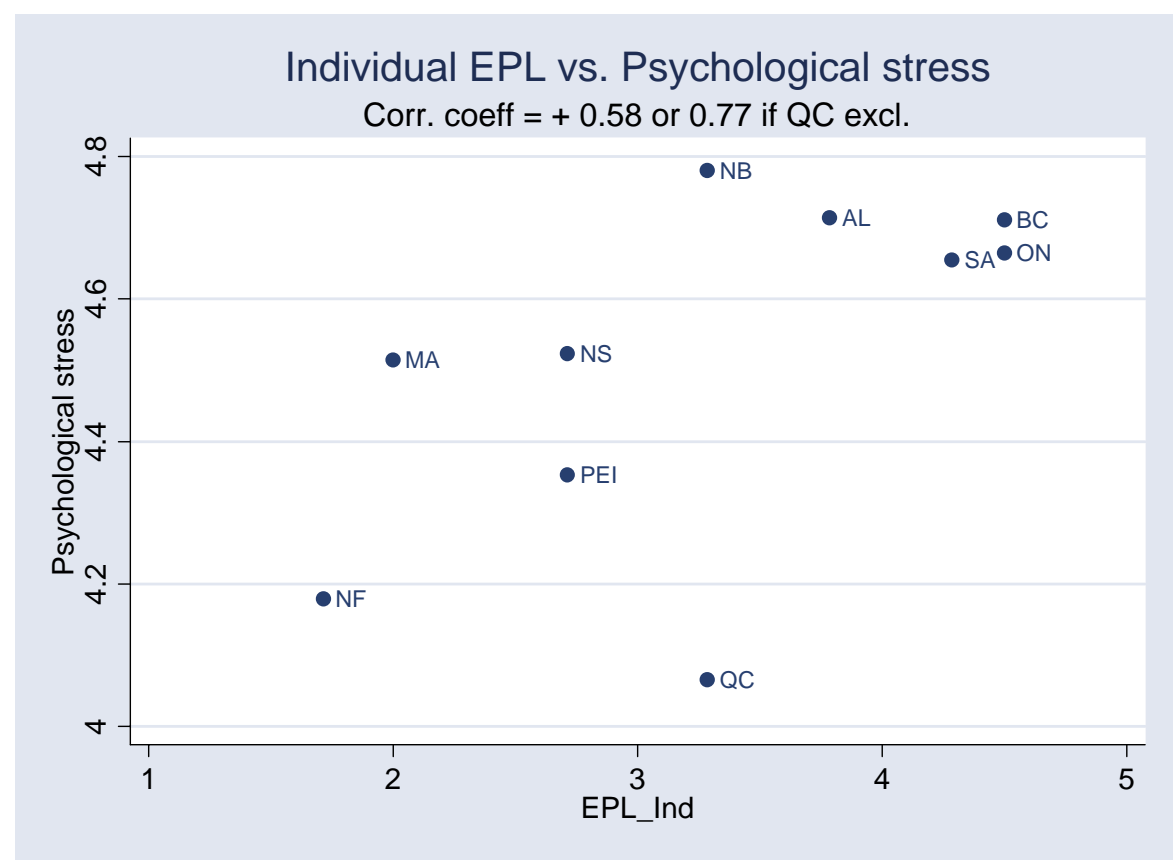

Individual EPL vs. Stress 
Figure 4. Correlation between EPL_ind and Stress from Skill needs at work

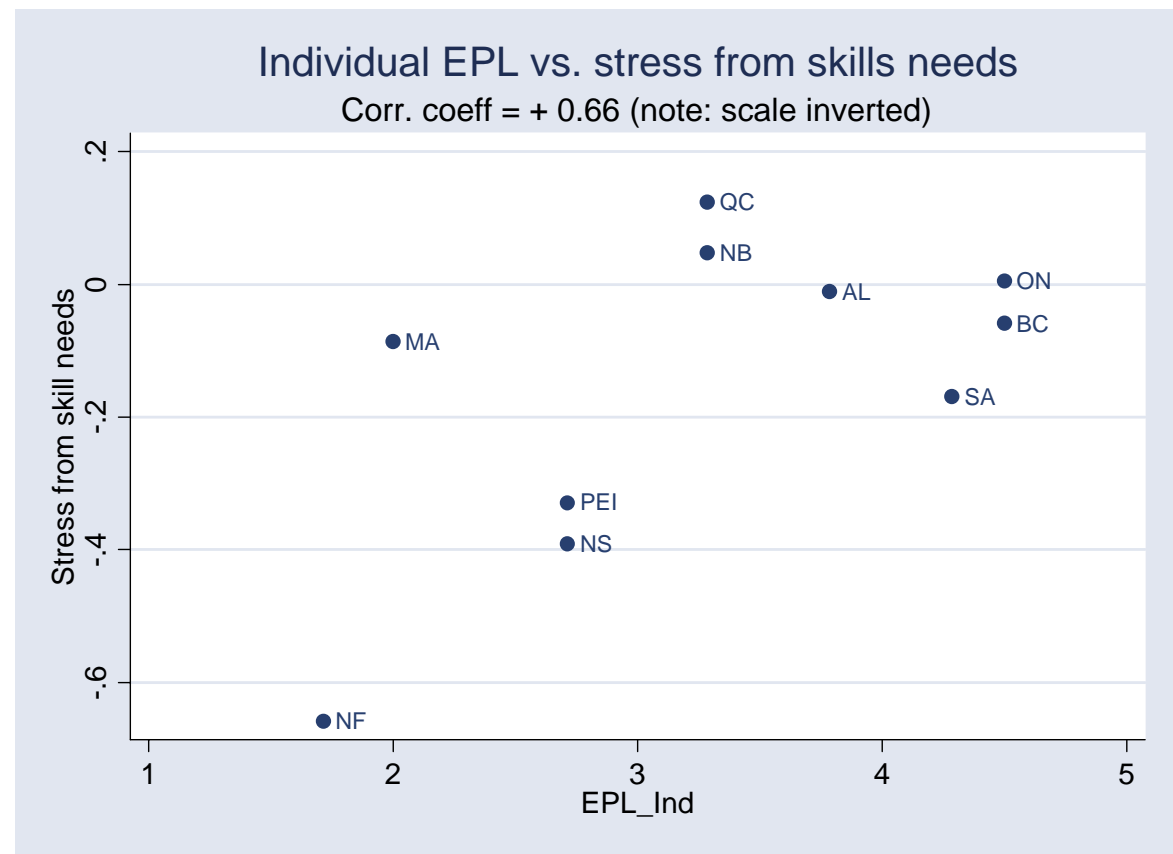

Individual EPL vs. Stress

Figure 5. Correlation between EPL_ind and Stress from Job Loss

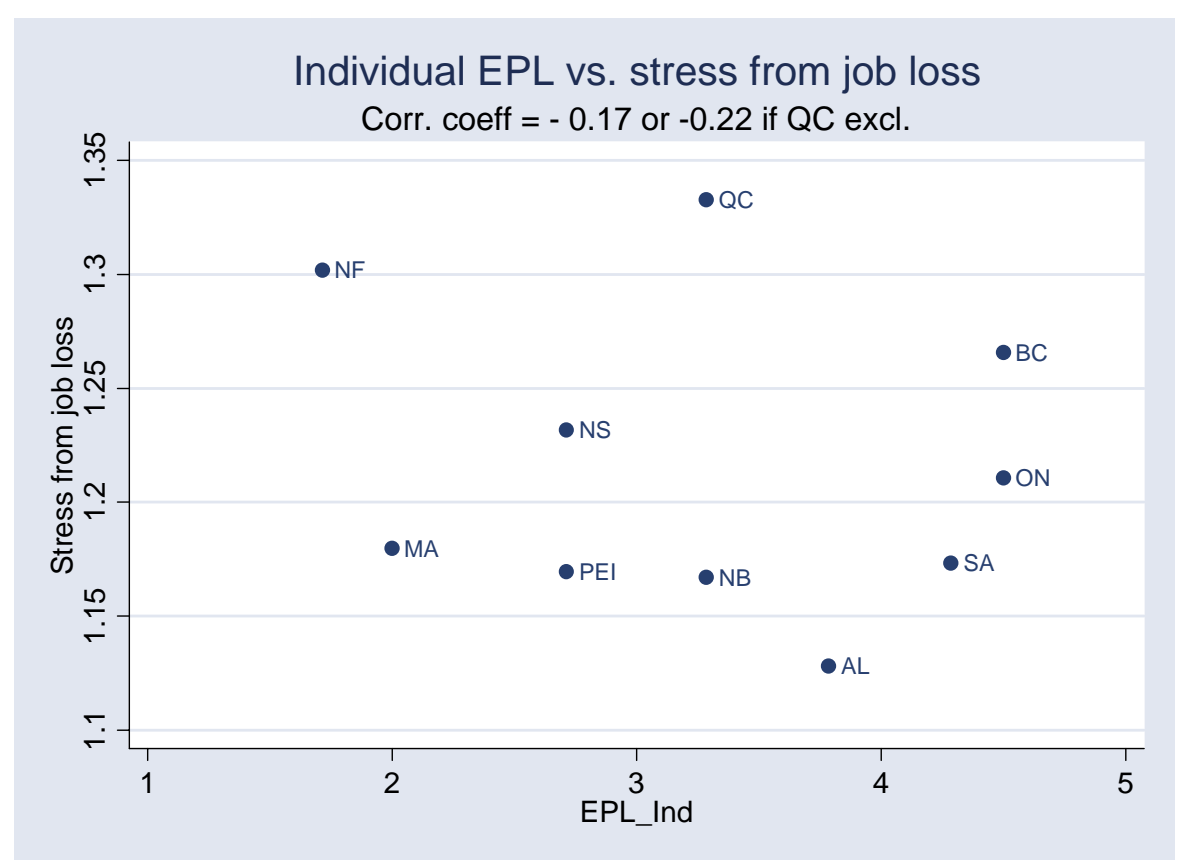

Individual EPL vs. Stress 


\section{Technical Appendix: construction and verification of regional EPL indices}

\section{C.1 Construction}

To create a single index for individual protection and another one for collective protection against dismissals, we created two grids, common to all provinces: one for seniority (12 categories) and one for firm size (8 categories). We then calculate from table B an average across all lines of the grid of the notice period. Table $\mathrm{C}$ provides the averages per province. We thus obtain two indicators of absolute individual and collective EPL. It is interesting to notice that the correlation across regions of the two indicators is not very strong: it is even negative $(-0.24)$. Alternatively, one can build relative indicators of individual and collective EPL, based on the position of each province in the distribution of EPL legislation. They appear to be very correlated with absolute measures, with a correlation coefficient of 0.92 , so hereafter we focus only on absolute indicators.

\section{C.2 Comparison}

We investigate the impact of these variables on EPL indicators. A crucial question is how to identify the EPL effects, both individual and collective. We can now show a number of correlation indicating that our indicators capture some important dimension of regional labor market conditions. A business report from the Fraser Institute provides indicators of provincial "labour market regulations", including EPL but also various other dimensions of labor relations. ${ }^{31}$ Provinces are scored from 0 to 10 on each indicator. A score of 10 indicates an optimal labour law in terms of providing labour-market flexibility. To ease the comparability with our EPL indices, we take a linear transformation of the Fraser Institute indicator, in applying $x \rightarrow 10-x$ : a positive correlation coefficient between our EPL index and the Fraser Institute index will thus indicate that two indices are coïncident. The report of Fraser institute in addition reports the ranking of regions ( 1 for the most flexible to 10 for the less flexible).

We display the correlation matrix between our EPL indices, where EPL_both is the sum of the two EPL indicators and LMR is the index of labor market regulation from Fraser Institute (rk stands for the ranking index and sc for the score). It appears that collective EPL is pretty well correlated with both indicators of the Fraser institute. Individual EPL is positively correlated too but to a lesser extent. Figure $\mathrm{C} 1$ confirms that the correlation with the sum of the two indicators is pretty good, especially if British Columbia is excluded from the calculation.

\begin{tabular}{lccccc}
\hline & EPL_both & EPL_ind & EPL_coll & LMR $_{(r k)}$ & LMR $_{(s c)}$ \\
\hline \hline EPL_both & 1 & & & & \\
EPL_ind & 0.1782 & 1 & & & \\
EPL_coll & 0.913 & -0.2387 & 1 & & \\
FI-LMR(rk) & 0.515 & 0.2716 & 0.3956 & 1 & \\
FI-LMR(sc) & 0.4285 & 0.1083 & 0.378 & 0.9257 & 1 \\
\hline
\end{tabular}

Note: correlation coefficients between various indicators of EPL

Another check is to correlate EPL indicators with the duration of unemployment spells. Indeed, most existing theory points out that employer will be more reluctant to create jobs and take risks when EPL is more important. We find that the correlation between collective EPL and unemployment duration is

\footnotetext{
31 "The Index of Labour Market Regulation assesses several indicators of the provincial labour-relations laws. Specifically, the following aspects of the relation laws are examined: (1) processes of certification and decertification; (2) arbitration process; (3) union security; (4) successor rights; (5) treatment of technology; (6) replacement workers; (7) third-party picketing; and (8) openness of the provincial Labour Relations Boards." Details in Clemens et al. (2003), a report of the Fraser Institute. The website of the institute is presented as follows: "Established in 1974, The Fraser Institute is an independent public policy organization with offices in Vancouver, Calgary, and Toronto."
} 
positive and relatively large, while the correlation between individual EPL and unemployment duration is pretty small and actually negative. The correlation with the sum of the two indicators (EPL_both) is however fairly positive, which is reinsuring. Finally, we can simply correlate EPL with union density. Again, there is a clear pattern of positive correlation between collective EPL and union density: the correlation is 0.46 and reaches 0.61 if one outlier is taken away. See also Figure C2.

\section{Technical Appendix:}

\section{D.1 Covariance matrix of error terms with individual and regional clustering}

Let first assume that the error term follows

$$
\varepsilon_{i t}=u_{i}+e_{i t}
$$

where $i$ is the individual and $t$ is time, where the $\varepsilon_{i t}$ is iid. We assume two time periods for simplicity of the exposition. The covariance matrix of residuals is then given by:

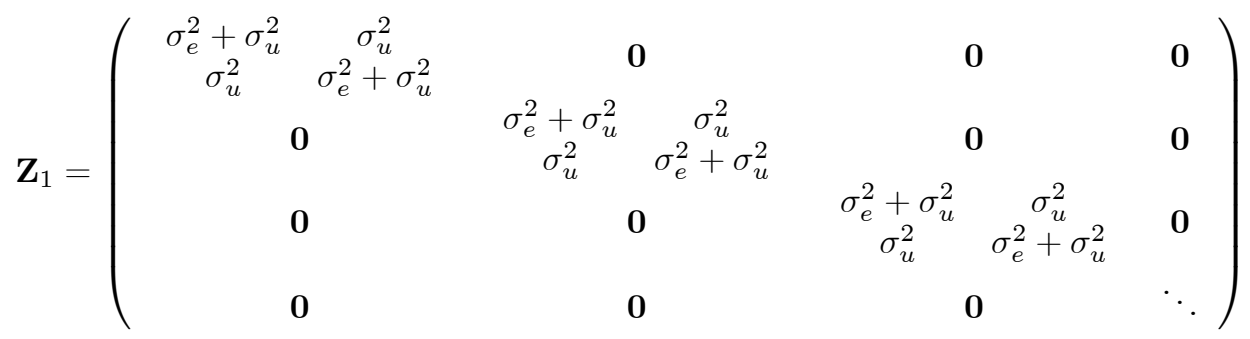

In this case, standard correction techniques available in all softwares apply. The problem becomes more severe with a three-level structure for residuals: we have 2 time observations, 2 regions and $n$ individuals, as follows:

$$
\varepsilon_{i r t}=v_{r}+u_{r i}+e_{\text {rit }}
$$

where $r=A, B$ is a region and $v_{r}$ is a regional effect, $u_{r i}$ is an individual effect. Assume for simplicity of the exposition that individuals 1,2 are in region $\mathrm{A}$ and individual 3 in region $\mathrm{B}$. In matricial notations, we have

$$
\varepsilon=\left(\begin{array}{c}
v_{A}+u_{A 1}+e_{A 11} \\
v_{A}+u_{A 1}+e_{A 12} \\
v_{A}+u_{A 2}+e_{A 21} \\
v_{A}+u_{A 2}+e_{A 22} \\
v_{B}+u_{B 3}+e_{B 31} \\
v_{B}+u_{B 3}+e_{A 32} \\
\cdots
\end{array}\right)
$$

The covariance matrix then becomes

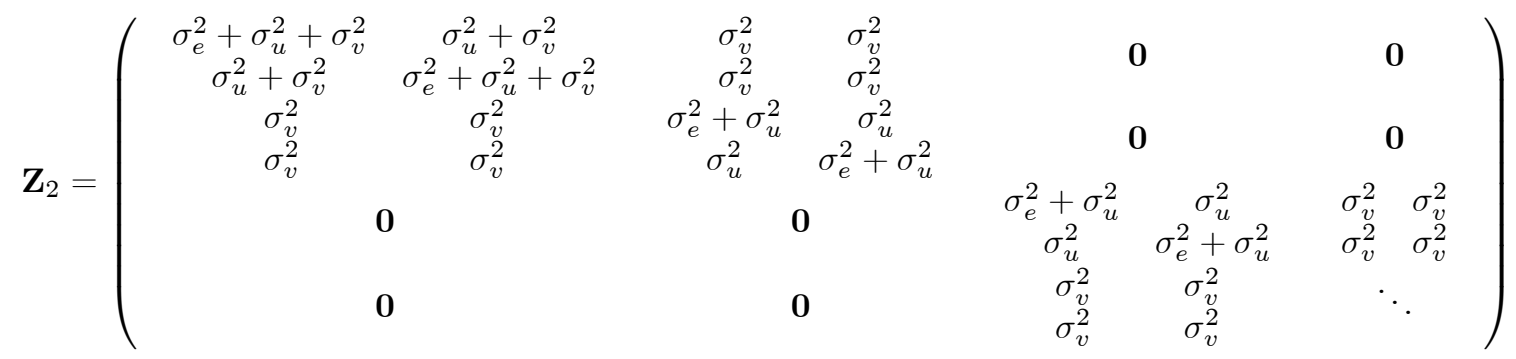

In that matrix, the dimension of the upper left block is $T$, the dimension of the $2 * 2$ block is $n_{A} * T$ that is the total number of observations in region $\mathrm{A}$ if $n_{A}$ is the number of individuals in region $A$, 
etc...One can notably see that

$$
\mathbf{Z}_{2}=\mathbf{Z}_{1}+\left(\begin{array}{ccc}
\sigma_{v}^{2} * \mathbf{J}\left(n_{A} * T\right) & \mathbf{0} & \mathbf{0} \\
\mathbf{0} & \sigma_{v}^{2} * J\left(n_{A} * T\right) & \mathbf{0} \\
\mathbf{0} & \mathbf{0} & \ddots
\end{array}\right)
$$

where $J(p)$ is a square matrix of 1 s of dimension $p$. This additivity may be used to estimate $\sigma_{v}$ in a first step, and then obtain corrected s.e. in the second stage. However, given that $\rho$ seem to be small and importantly, of opposite signs across the two waves, we will not investigate this issue further.

\section{D.2 Correction of s.e. of the generated (imputed) regressors}

We apply here Little and Rubin's (1987) correction (pp. 256-57): let $\widehat{\theta}_{l}, l=1, . ., M$ be the estimated coefficient of $E P L$ in the NPHS regression, when the regressor is obtained from the $l^{\text {th }}$ of $M$ bootstrap imputation from the EPA-LFS survey. Let $\widehat{W}_{l}$ be its estimated variance. The estimate of $\theta$ is simply

$$
\overline{\theta_{M}}=M^{-1} \sum_{l=1}^{M} \widehat{\theta}_{l}
$$

whereas the within-imputation variance is

$$
\bar{W}_{M}=M^{-1} \sum_{l=1}^{M} \widehat{W}_{l}
$$

The between-imputation component is

$$
\bar{B}_{M}=(M-1)^{-1} \sum_{l=1}^{M}\left(\widehat{\theta}_{l}-\overline{\theta_{M}}\right)^{2}
$$

and total variance is

$$
T_{M}=\bar{W}_{M}+\frac{M+1}{M} \bar{B}_{M}
$$

In our case, $M=20$. As we impute two variables (EPL_ind and EPL_coll) we adapt equation (D18) so has to transform the scalar $\left(\widehat{\theta}_{l}-\overline{\theta_{M}}\right)^{2}$ into the matrix $\left(\widehat{\theta}_{l}-\overline{\theta_{M}}\right)^{\prime}\left(\widehat{\theta}_{l}-\overline{\theta_{M}}\right)$.

In practice, we found that the ratio of the within to the between component is typically very large, that is, about 4500 for the imputation of EPL_ind and 370 for EPL_coll, so that the s.e. in practice differ little from the robust s.e. estimated from GLS: an approximation is

$$
\begin{aligned}
\text { s.e.bootsrap } & \simeq\left(\bar{W}_{M}\right)^{0.5}\left(1+\frac{\bar{B}_{M}}{\bar{W}_{M}} \frac{M+1}{2 M}\right) \\
& \simeq \text { s.e.robust }(1.000016) \text { for } E P L \_ \text {ind } \\
& \simeq \text { s.e.robust }(1.00041) \text { for } E P L \_ \text {coll }
\end{aligned}
$$


Figure C1. Ex-post check of the EPL variables. EPL_ind+EPL_coll vs. Employment Regulation Index

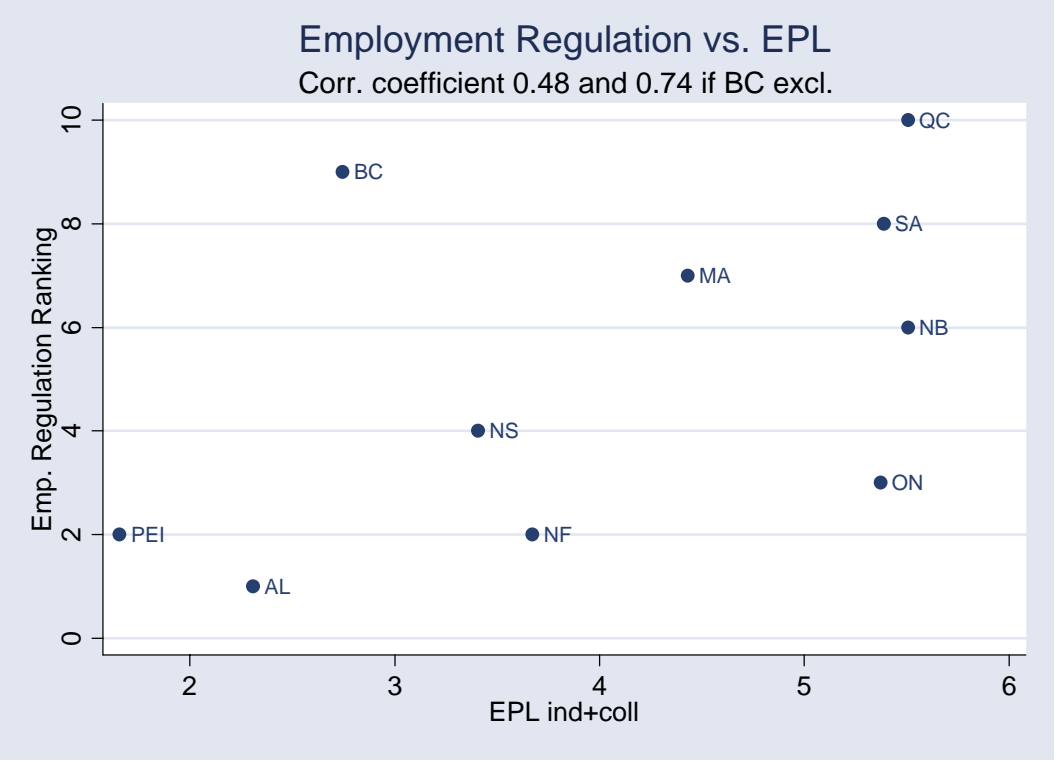

Figure C2. Ex-post check of the EPL variables. EPL_coll vs. union rate

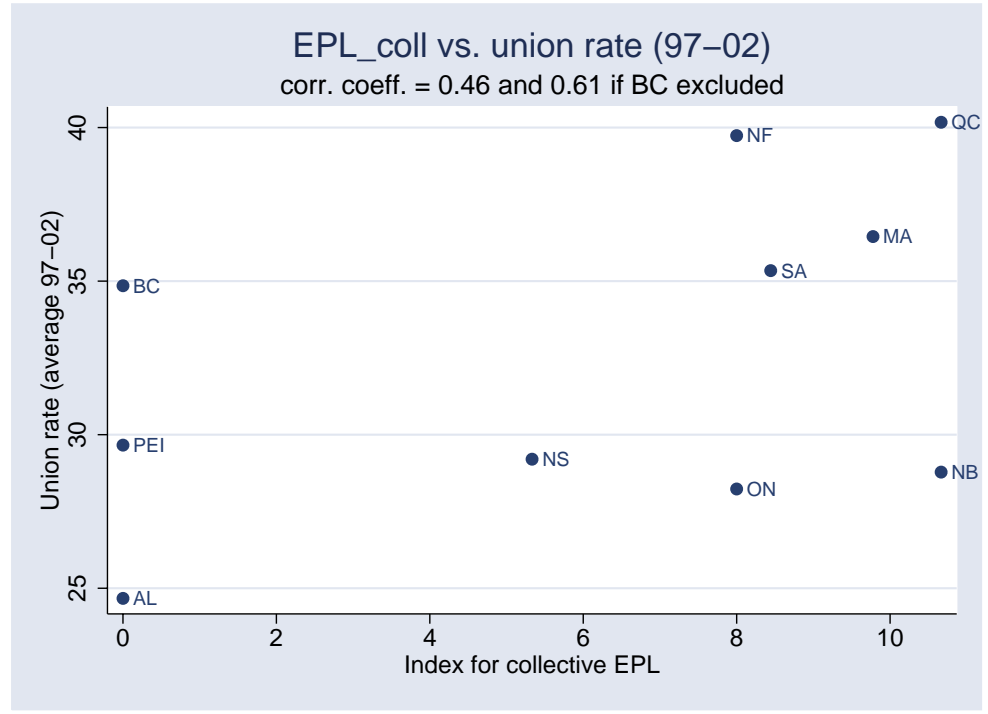

Collective EPL vs. Union density 
Table C. Construction of regional indices of EPL

\begin{tabular}{|c|c|c|c|c|c|c|c|c|c|c|c|c|c|c|}
\hline IND & 1995 & & & & & & & & & & & & mean & \\
\hline seniority & Alberta & BC & Man & NB & NF & NS & Ont & PEI & QC & Sask & NWT & Yuk & & \\
\hline 0,083333333 & 0 & 0 & 2 & 0 & 1 & 1 & 0 & 0 & 0 & 0 & 0 & 0 & 0,33 & 0,65134 \\
\hline 0,25 & 1 & 0 & 2 & 0 & 1 & 1 & 1 & 0 & 1 & 1 & 2 & 0 & 0,83 & 0,71774 \\
\hline 0,5 & 1 & 2 & 2 & 2 & 1 & 1 & 1 & 2 & 1 & 1 & 2 & 1 & 1,42 & 0,51493 \\
\hline 1 & 1 & 2 & 2 & 2 & 1 & 1 & 2 & 2 & 2 & 2 & 2 & 1 & 1,67 & 0,49237 \\
\hline 2 & 2 & 2 & 2 & 2 & 2 & 2 & 2 & 2 & 2 & 2 & 2 & 1 & 1,92 & 0,28868 \\
\hline 3 & 2 & 3 & 2 & 2 & 2 & 2 & 3 & 2 & 2 & 4 & 3 & 1 & 2,33 & 0,7785 \\
\hline 4 & 4 & 4 & 2 & 2 & 2 & 2 & 4 & 2 & 2 & 4 & 4 & 1 & 2,75 & 1,13818 \\
\hline 5 & 4 & 5 & 2 & 4 & 2 & 4 & 5 & 4 & 4 & 6 & 5 & 1 & 3,83 & 1,4668 \\
\hline 6 & 5 & 6 & 2 & 4 & 2 & 4 & 6 & 4 & 4 & 6 & 6 & 1 & 4,17 & 1,74946 \\
\hline 7 & 5 & 7 & 2 & 4 & 2 & 4 & 7 & 4 & 4 & 6 & 7 & 1 & 4,42 & 2,06522 \\
\hline 8 & 6 & 8 & 2 & 4 & 2 & 4 & 8 & 4 & 4 & 6 & 8 & 1 & 4,75 & 2,45412 \\
\hline 9 & 6 & 8 & 2 & 4 & 2 & 4 & 8 & 4 & 4 & 6 & 8 & 1 & 4,75 & 2,45412 \\
\hline 10 & 8 & 8 & 2 & 4 & 2 & 8 & 8 & 4 & 8 & 8 & 8 & 1 & 5,75 & 2,89592 \\
\hline 12 & 8 & 8 & 2 & 4 & 2 & 8 & 8 & 4 & 8 & 8 & 8 & 1 & 5,75 & 2,89592 \\
\hline mean & 3,79 & 4,50 & 2,00 & 2,71 & 1,71 & 3,29 & 4,50 & 2,71 & 3,29 & 4,29 & 4,64 & 0,86 & 3,19 & 1,22865 \\
\hline COLL & 1995 & & & & & & & & & & & & & \\
\hline size & Alberta & BC & Man & NB & NF & NS & Ont & PEI & QC & Sask & NWT & Yuk & & \\
\hline 0 & 0 & 0 & 0 & 0 & 0 & 0 & 0 & 0 & 0 & 0 & 0 & 0 & 0,00 & 0 \\
\hline 10 & 0 & 0 & 0 & 6 & 0 & 8 & 0 & 0 & 8 & 4 & 0 & 0 & 2,17 & 3,35297 \\
\hline 25 & 0 & 0 & 0 & 6 & 0 & 8 & 0 & 0 & 8 & 4 & 4 & 4 & 2,83 & 3,24271 \\
\hline 50 & 0 & 0 & 10 & 6 & 8 & 8 & 8 & 0 & 8 & 8 & 8 & 8 & 6,00 & 3,71728 \\
\hline 100 & 0 & 0 & 14 & 6 & 8 & 12 & 8 & 0 & 12 & 12 & 12 & 12 & 8,00 & 5,32575 \\
\hline 200 & 0 & 0 & 14 & 6 & 12 & 12 & 12 & 0 & 12 & 12 & 12 & 12 & 8,67 & 5,54868 \\
\hline 300 & 0 & 0 & 14 & 6 & 12 & 16 & 12 & 0 & 16 & 12 & 16 & 16 & 10,00 & 6,6606 \\
\hline 500 & 0 & 0 & 18 & 6 & 16 & 16 & 16 & 0 & 16 & 12 & 16 & 16 & 11,00 & 7,31126 \\
\hline 1000 & 0 & 0 & 18 & 6 & 16 & 16 & 16 & 0 & 16 & 12 & 16 & 16 & 11,00 & 7,31126 \\
\hline mean & 0,00 & 0,00 & 9,78 & 5,33 & 8,00 & 10,67 & 8,00 & 0,00 & 10,67 & 8,44 & 9,33 & 9,33 & 6,63 & 4,23955 \\
\hline COLL+IND & 3,79 & 4,50 & 11,78 & 8,05 & 9,71 & 13,95 & 12,50 & 2,71 & 13,95 & 12,73 & 13,98 & 10,19 & 9,82 & 4,14956 \\
\hline
\end{tabular}




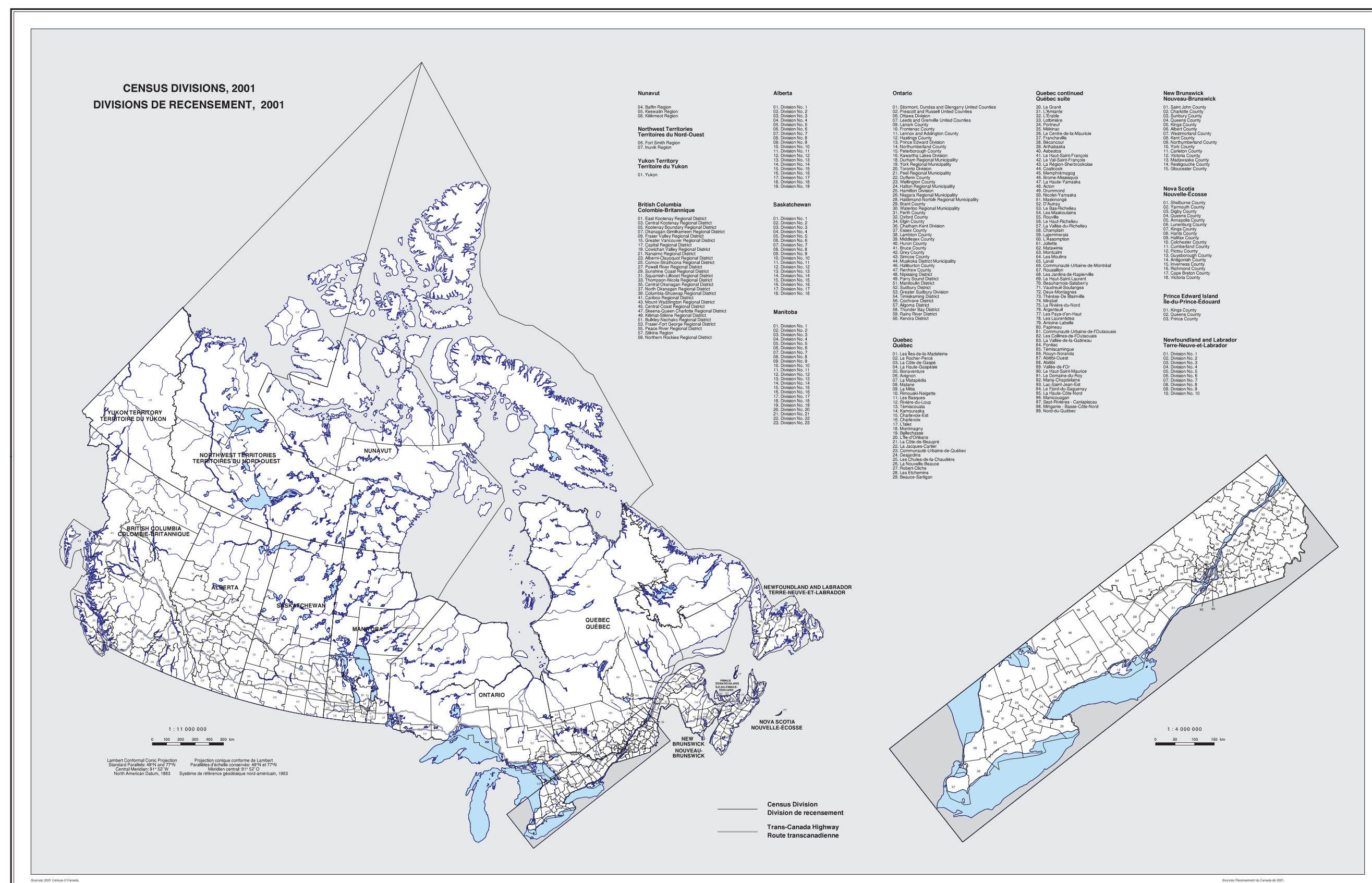

